José Fábio Guastelli Gastaldo

Análise fotoelástica das tensões ao redor dos implantes, na mandíbula, com aplicação de força em próteses tipo protocolo,

revestidas em resina acrílica

São Paulo

2013 
José Fábio Guastelli Gastaldo

Análise fotoelástica das tensões ao redor dos implantes, na mandíbula, com aplicação de força em próteses tipo protocolo,

revestidas em resina acrílica

Versão Corrigida

Tese apresentada à Faculdade de Odontologia da Universidade de São Paulo, para a obtenção do título de Doutor, pelo Programa de Pós-Graduação em Ciências Odontológicas.

Área de Concentração: Prótese Dentária

Orientadora: Profa. Dra. Dalva Cruz Laganá

São Paulo 
Autorizo a reprodução e divulgação total ou parcial deste trabalho, por qualquer meio convencional ou eletrônico, para fins de estudo e pesquisa, desde que citada a fonte.

Gastaldo, José Fábio Guastelli.

Análise fotoelástica das tensões ao redor dos implantes, na região de mandíbula, com aplicação de força em próteses tipo protocolo, revestidas em resina acrílica / José Fábio Guastelli Gastaldo ; orientador Dalva Cruz Laganá. -São Paulo, 2013.

111 p. : fig.; $30 \mathrm{~cm}$.

Tese (Doutorado) -- Programa de Pós-Graduação em Ciências Odontológicas. Área de Concentração: Prótese Dentária. -- Faculdade de Odontologia da Universidade de São Paulo.

Versão corrigida.

1. Prótese sobre implantes ósseointegrados. 2. Implantes dentários. 3. Oclusão dentária. 4. Força de mordida. I. Laganá, Dalva Cruz. II. Título. 
Gastaldo JFG. Análise fotoelástica das tensões ao redor dos implantes, na região de mandíbula, com aplicação de força em próteses tipo protocolo, revestidas em resina acrílica. Tese de Doutorado apresentada à Faculdade de Odontologia da Universidade de São Paulo para obtenção do título de Doutor em Ciências Odontológicas, área de concentração Prótese Dentária.

Aprovado em:

\section{Banca Examinadora}

$\operatorname{Prof}(\mathrm{a}) . \operatorname{Dr}(\mathrm{a})$. Instituição:

Julgamento: Assinatura:

Prof(a). Dr(a). Instituição:

Julgamento: Assinatura:

Prof(a). Dr(a). Instituição:

Julgamento: Assinatura:

Prof(a). Dr(a). Instituição:

Julgamento: Assinatura:

Prof(a). Dr(a). Instituição:

Julgamento: Assinatura: 


\section{Dedico}

Aos meus pais Cicero (in memoriam) e Marilena, por tudo.

À Paula e aos meus filhos, a quem amo, dedico a conclusão desta etapa de nossas vidas; vocês são estímulo para minha vida.

Sem vocês não teria conseguido! 
À minha orientadora,

Profa. Dra. Dalva Cruz Laganá, Profa. Titular do Departamento de Prótese da FOUSP, pela orientação, amizade, dedicação e determinação incansável e que muito colaborou para meu crescimento profissional e pessoal.

Muito obrigado! 
Ao Prof. Dr. Wilson Roberto Sendyk, pela amizade, incentivo e grande colaboração neste estudo. 


\section{AGRADECIMENTOS}

À Faculdade de Odontologia da Universidade de São Paulo, por me acolher nesta etapa importante da minha vida.

Ao Departamento de Prótese da FOUSP, na pessoa da Prof ${ }^{a}$. Dalva Cruz Laganá, Chefe do Departamento, pela condução do curso e pelo apoio.

Ao Prof. Dr. Roberto Chaib Stegun, pelo auxílio na elaboração deste trabalho.

A todos os docentes do Departamento de Prótese, em especial aos Professores: Prof. Dr. Atlas Edson Nakamae, Prof. Dr. Bruno Costa, Prof. Dr. Ivo Contim, Prof. Dr. Matsuyoshi Mori, Profa . Dra. Maria Luíza Moreira Arantes Frigeiro e ao Prof. Dr. Claudio Luis Sendyk.

Ao Laboratório de Prótese Projet, na pessoa dos técnicos em prótese dentária, Toshio Uehara, Geraldo Kayo e Carmen Kayo, pela confecção da peça protética.

À empresa Conexão Sistemas de Prótese Ltda., que possibilitou o desenvolvimento do trabalho pela doação de implantes e peças protéticas.

A todos os funcionários do Departamento de Prótese, pela colaboração em diversos momentos. Às secretárias Sandra Maria Gomes da Silva, Coraci Aparecida de Moraes e Marlete Benjamin dos Santos. À técnica Maria Cristina Falcão Curci Puraca pela sua atenção e dedicação durante a parte laboratorial.

Aos colegas e docentes de Pós-Graduação da Universidade de Santo Amaro, Angélica Pimentel, Cristiane Polo, Paulo Cosimato e Sergio Tricta Quaresma.

Aos colegas da Pós-Graduação e amigos Érico, Fábio, Piero, Patricia, Glaís, Isabele, Antonio, Tatiana, Wallace, Maria Helena, Natasha, José Augusto e Simone. 
Aos funcionários do Serviço de Documentação Odontológica da Biblioteca da FOUSP, pela ajuda na revisão deste trabalho.

À fotógrafa Laís Guadanhim, pelo profissionalismo e colaboração.

Aos meus irmãos Rosana e Luciano, pelo apoio e amizade.

Aos meus sogros, Hélio e Wanda, por sempre me incentivarem.

Às minhas funcionárias Vania e Lucília pela compreensão e atenção a mim dedicada.

A todas as pessoas que, de maneira direta ou indireta, colaboraram com o desenvolvimento deste trabalho.

À minha esposa, Paula e a meus filhos Lorenzo e Matheo, sempre ao meu lado, com muita dedicação, amor, carinho e compreensão pelos momentos ausentes.

Muito obrigado! 
O conhecimento torna a alma jovem e diminui a amargura da velhice. Colhe, pois, a sabedoria. Armazena suavidade para o amanhã. 


\section{RESUMO}

Gastaldo J. F. G. Análise fotoelástica das tensões ao redor dos implantes, na região de mandíbula, com aplicação de força em próteses tipo protocolo, revestidas em resina acrílica [tese]. São Paulo: Universidade de São Paulo, Faculdade de Odontologia; 2012. Versão Corrigida.

Introdução: O objetivo desta pesquisa é analisar, pelo método fotoelástico, o comportamento das tensões que ocorrem nas estruturas periimplantares, em suportes de prótese fixa, segundo o protocolo de Brånemark, parafusada sobre cinco implantes, de diferentes comprimentos $(10 \mathrm{~mm} ; 13 \mathrm{~mm}$ e $15 \mathrm{~mm})$, quando submetidas às cargas oclusais. Métodos: Foram construídos três modelos fotoelásticos de mandíbulas: MD10; MD13 e MD15, com cinco implantes cada um, de 3,75mm de diâmetro, hexágono interno e posicionados paralelamente na região interforaminal. Sobre os implantes, em cada modelo, foram instalados pilares do tipo micro unit com cinta de $1 \mathrm{~mm}$ e, sobre eles, uma única prótese, com uma infraestrutura metálica em cobalto/cromo, com cantilever de $15 \mathrm{~mm}$, revestida em resina acrílica. Foram aplicadas pressões de 1,0 e 3,0 bars e as imagens foram fotografadas e avaliadas. Resultados: Os resultados mostraram que as maiores tensões ocorreram nos implantes com 10mm de comprimento e o padrão de tensões se manteve nos vários comprimentos de implantes, mudando apenas a magnitude das tensões ao longo do corpo do implante. $O$ incremento do comprimento foi relevante quanto à diminuição dos níveis de tensão na região analisada no modelo. Conclusões: Conclui-se que: 1) Os implantes de maior comprimento distribuíram melhor as tensões ao longo do corpo do implante; 2) As tensões se localizaram mais apicalmente, tanto por mesial como distal, nos implantes de maior comprimento, 3) Os implantes que sofreram maiores tensões foram os mais próximos do cantilever e o implante central.

Palavras-chave: Próteses Implanto-suportadas. Forças oclusais. Implantes dentários. Tensão. 


\begin{abstract}
Gastaldo J.F.G. Photoelasticity stress analysis around implants in mandible region with application of strength to Branemark protocol prosthesis covered with acrylic resin [thesis]. São Paulo: Universidade de São Paulo, Faculdade de Odontologia; 2012. Corrigida Version.
\end{abstract}

The purpose of this study was to analyze, using the photoelasticity method, the behavior of stresses occurring in peri-implant structures and fixed prosthesis supports following Brånemark protocol that are screwed on five implants of different lengths, $10 \mathrm{~mm} ; 13 \mathrm{~mm}$ and $15 \mathrm{~mm}$, when submitted to occlusal loads. Three mandible photoelastic models were built: MD10; MD13 and MD15, with five implants each, $3.75 \mathrm{~mm}$ of internal diameter and located in parallel with each other in the interforaminal region. Microunit pillars were installed on each implant model with a $1 \mathrm{~mm}$-belt, and a single prosthesis was installed over them with a cobalt/chrome metallic infrastructure covered with thermoplastic acrylic resin. Loads of 1.0 and 3.0 bars were applied and images were photographed and evaluated. Results showed that highest tensions occurred in 10mm-length implants; the patterns of stresses was the same in implants of different lengths and only the magnitude of stresses changed along implant body. The greater the length the lower the stress in the analyzed region of the model. We concluded that: 1) The implants of greater length tension better distributed along the body of the implant. 2) Tensions were located more apically by both mesial and distal implants of greater length. 3) The implants have suffered greater tensions were the closest to the cantilever and implant center.

Keywords: Implant-supported prostheses. Oclusal force. Dental implants. Stress. 


\section{LISTA DE FIGURAS}

Figura 4.1 - a) Refletor de luz; b) Polarímetro; c) Recipiente de vidro; d) Aparelho para aplicação de força; e) Filtro polarizador; f) Câmera fotográfica; g) Suporte do filtro polarizador; h) Base rotatória; i) Controle de força aplicada

Figura 4.2 -Aparelho de aplicação de carga Crânio em polímero: a) e b) Bases horizontais; c) Plataforma de sustentação; d) Pistão que aplicará as forças; e) Crânio; f) e g) Parafusos de preensão do crânio; h) Manguitos condutores de ar comprimido; i) Haste vertical de sustentação do aparelho; e seta indicando direção de aplicação de

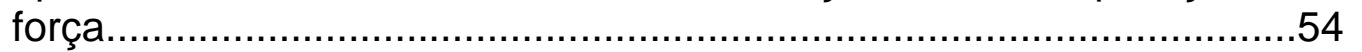

Figura 4.3 - Manivela (A) e Manômetro (B) responsáveis pela aplicação de força....54

Figura 4.4 - Câmara de vácuo 56

Figura 4.5 - Fresadora Microtec 56

Figura 4.6 - Crânio Fotoelástico 57

Figura 4.7 - Mandíbula Desdentada 58

Figura 4.8 - Transferência da maxila para o articulador 59

Figura 4.9 - Fixação do modelo da maxila no ramo superior do articulador semiajustável. 60

Figura 4.10 - Base de prova com plano de orientação 60

Figura 4.11 - Registro da dimensão vertical 61

Figura 4.12 -Transposição do registro de dimensão vertical para o plano de cera articulado com a maxila. 
Figura 4.13 - Montagem de dentes inferiores 62

Figura 4.14 - Interposição do carbono accufilm ${ }^{\circledast}$ entre a maxila e plano com montagem de dentes 63

Figura 4.15 - Guia cirúrgico transparente 64

Figura 4.16 - Marcação dos foramens mentuais 65

Figura 4.17- Terceira marcação (centro do implante). 65

Figura 4.18 - Perfurações sendo executadas. 66

Figura 4.19 -Modelo mestre com os análogos em posição 66

Figura 4.20 -Vista lingual dos análogos de implante em relação à montagem de dentes 67

Figura 4.21 -Corte e ajuste dos cilindros plásticos 68

Figura 4.22 -Vista palatina da infraestrutura encerada 68

Figura 4.23 -Infraestrutura encerada e com retenções 69

Figura 4.24 -Infraestrutura fixada à base do cadinho 69

Figura 4.25 -Preenchimento do anel com revestimento 70

Figura 4.26 -Infraestrutura fundida 71

Figura 4.27 -Infraestrutura seccionada, unida em resina Durallay ${ }^{\circledR}$ e indexada em gesso especial tipo IV 71

Figura 4.28 -Pré-soldagem elétrica com solda $\mathrm{Co} / \mathrm{Cr}$ 72 
Figura 4.29 -Infraestrutura soldada a maçarico e acoplada nos análogos de micro unit da mandíbula.

Figura 4.30 -Infraestrutura parafusada na mandíbula montada no articulador e unida à guia cirúrgica com resina

Figura 4.31 -Mandíbula reproduzida em resina com os análogos transferidos em posição

Figura 4.32 -Mensuração da extensão do cantilever 74

Figura 4.33a - Vista do cantilever do lado esquerdo 74

Figura 4.33b - Vista do cantilever do lado direito 74

Figura 4.34 -Infraestrutura revestida com opaco rosa 75

Figura 4.35 -Prótese tipo protocolo metalo plástica finalizada e articulada com modelo da maxila 76

Figura 4.36 -Mandíbula com a prótese parafusada no interior da forma que recebeu o silicone de reprodução 77

Figura 4.37 -Silicone de reprodução vertido sobre o conjunto, mandíbula e prótese ....78

Figura 4.38 -Conjunto pilar micro unit/implante 3,75 de diâmetro por $10 \mathrm{~mm}$ de comprimento do tipo hexágono interno acoplado e parafusado no cilindro da prótese 78

Figura 4.39 -Resina fotoelástica sendo vertida no interior do molde, dentro da câmara de vácuo 79

Figura 4.40 -Mandíbula fotoelástica com implantes de 10mm 80

Figura 4.41 -Mandíbula fotoelástica com implantes de 13mm 81 
Figura 4.42 - Mandíbula fotoelástica com implantes de 15mm

Figura 5.1 - Modelo 10 sem aplicação de carga, apresentando colorações fotoelásticas em algumas regiões delimitadas ...................................... 84

Figura 5.2 - Modelo 10 com aplicação de pressão de 1 bar ..................................... 85

Figura 5.3 - Modelo 10 com aplicação de pressão de 3 bars..................................... 86

Figura 5.4 - Vista lateral esquerda do Modelo 10 com aplicação de pressão de 3 bars.

Figura 5.5 - Vista lateral direita do Modelo 10 com aplicação de pressão de 3 bars

Figura 5.6 - Modelo 13 com ausência de pressão mostrando tensões em algumas áreas......

Figura 5.7 - Modelo 13 com aplicação de pressão de 1 bar 88

Figura 5.8 - Modelo 13 com aplicação de pressão de 3 bars. 89

Figura 5.9 - Vista lateral direita do Modelo 13 com aplicação de pressão de 3 bars 90

Figura 5.10 - Vista lateral esquerda do Modelo 13 com aplicação de pressão de 3 bars

Figura 5.11 -Modelo 15 com ausência de pressão, mostrando tensões em alguma áreas

Figura 5.12 - Modelo 15 com aplicação de pressão de1 bar 92

Figura 5.13 -Modelo 15 com aplicação de pressão de 3 bars 93

Figura 5.14 - Vista lateral direita do Modelo 15 com aplicação de pressão de 3 bar .... 93 
Figura 5.15 - Vista lateral esquerda do Modelo 15 com aplicação de pressão de 3 bars.......94

Figura 5.16 - Fotografia das vistas frontais de todos os comprimentos e todos os carregamentos. a) MD 10 - pressão 0, b) MD 10 - pressão 1, c) MD 10 - pressão 3, c) MD 13 - pressão 0, e) MD 13 - pressão 1, f) MD 13 pressão 3, g) MD 15 - pressão 0, h) MD 15 - pressão 1 e i) MD 15 pressão 3. 95

Figura 5.17 - Fotografias laterais de todos os comprimentos $e$ todos os carregamentos. a) MD 10 - lado direito, b) MD10 - lado esquerdo, c) MD 13 - lado direito, d) MD13 - lado esquerdo, e) MD 15 - lado direito e f) MD 15 - lado esquerdo.........................................................96 


\section{LISTA DE QUADROS}

Quadro 4.1 - Materiais empregados na pesquisa

Quadro 4.2 - Relação entre pressão e força para o aparelho utilizado 55 
SUMÁRIO

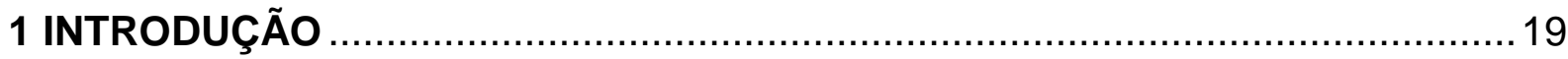

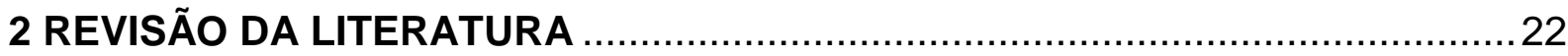

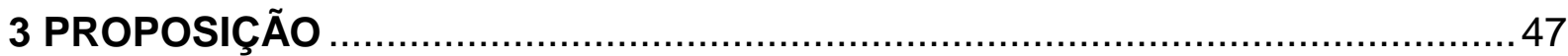

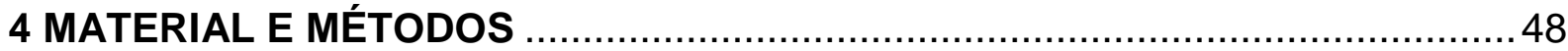

5 RESULTADOS

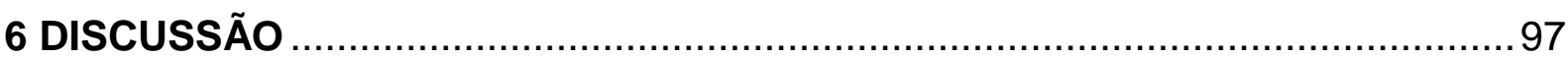

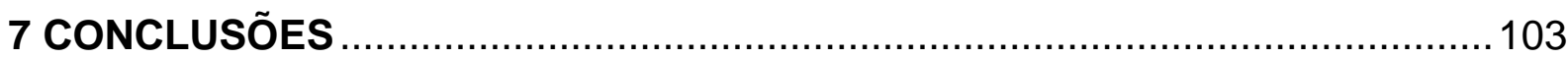

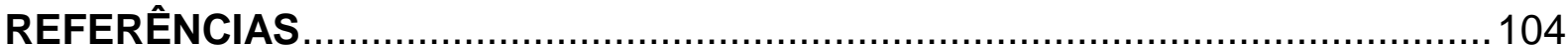




\section{INTRODUÇÃO}

Durante o século passado, a forma mais utilizada para reabilitar pacientes totalmente desdentados foi a prótese total suportada inteiramente pela mucosa que recobre o remanescente ósseo do rebordo alveolar. Os princípios de retenção e estabilidade dessas próteses, considerados os pontos mais críticos desse tipo protético de reabilitação, são influenciados por fatores como a qualidade e quantidade de saliva, ação da musculatura e oclusão. Além disso, nem sempre as condições ideais de retenção e estabilidade são obtidas em função de condições desfavoráveis como anatomia do rebordo residual e da mucosa, problemas de coordenação neuromuscular ou de intolerância ao uso de próteses, por parte do paciente.

Diante desse quadro, as alternativas de tratamento que se apresentam são as cirurgias para aumento de rebordo ou aprofundamento do sulco vestibular. Os resultados, porém, podem diferir dos esperados (Dyn, 2004).

Pacientes desdentados totais, muitas vezes, ficam debilitados tanto física como psicologicamente, devido a essa condição (Friedman; Landesman, 1987), sendo que alguns não são capazes de superar o trauma com reabilitações removíveis. Portanto, em tais situações, são recomendáveis, quando possíveis, reabilitações fixas.

O uso de implantes osseointegrados como ferramenta para soluções funcionais e estéticas tem proporcionado excelentes resultados, para os profissionais e para os pacientes.

A situação biomecânica para um implante é fundamentalmente diferente daquela de um dente natural, que é circundado por ligamento periodontal. Assim, a possibilidade de se transferir carga excessiva ao implante, e deste ao osso adjacente, pode acabar ultrapassando o limite fisiológico e provocar a perda da osseointegração (Kenny; Richards, 1998).

Muitas complicações podem ocorrer após a fase de reabilitação protética, na qual os implantes, até então inativos, são colocados em função na cavidade oral (Lindquist et al., 1988; Duyck et al., 2001). Entre as complicações relatadas, aparecem o afrouxamento do parafuso do pilar intermediário ou da prótese, a fratura 
do material de revestimento e outras, que podem até levar à perda da osseointegração (Schwarz, 2000).

Carter et al. (1981) já relatavam que o osso, comparado a outros materiais estudados, possuía baixa resistência à fadiga. Relataram, porém, que pequenos danos que ocorrem diariamente no osso poderiam funcionar como um estímulo constante para o processo de remodelação óssea. O dano acabaria por ser significativo quando a remodelação óssea não compensasse o estímulo danoso inicial.

Um dos maiores desafios na reabilitação de pacientes totalmente desdentados com implantes osseointegrados, sem dúvida, é o assentamento passivo dos componentes protéticos sobre os implantes. Também se deve considerar que os implantes recebem forças oclusais axiais e tangenciais, que irão se distribuir ao seu redor, de acordo com a geometria dos componentes protéticos (Moberg et al., 2001; Engquist et al., 2002; Bozkaya; Müflü, 2004; Cehreli et al., 2004).

De acordo com o protocolo clássico descrito por Brånemark em 1977, para mandíbulas totalmente edêntulas, dois estágios cirúrgicos são necessários. No primeiro, os implantes de titânio, em forma de parafuso, são colocados na parte anterior da mandíbula, entre os forâmens mentuais, em números variáveis, entre quatro a seis implantes, com diâmetros de $3,75 \mathrm{~mm}$. Sugere-se tempo de cicatrização de quatro a seis meses entre a primeira e a segunda etapa cirúrgica, que permitirá a instalação de prótese fixa total com a presença de infraestrutura metálica e cantilever entre 15 e $20 \mathrm{~mm}$ de comprimento, suportando dentes de estoque (Brånemark, 1983).

Embora esse tipo de prótese venha sendo aplicado há alguns anos e ofereça boa previsibilidade em seus resultados (Bernard et al., 1995; Becker et al., 1997, Bruyn; Collaert, 2002), a questão da indução de tensões é uma consideração que deve sempre se sobrepor nesses tipos de reabilitações.

As complicações parecem acontecer, com maior frequência, nas conexões entre hexágono externo do implante e pilar intermediário (Binon, 1996; Schwarz, 2000), sendo bem menos ocorrentes nas conexões tipo hexágono interno ou conemorse (Merz et al., 2000). Outros autores, no entanto, contradizem essas considerações e relatam existirem comportamentos similares para hexágono externo 
e interno, inclusive no que diz respeito à distribuição de forças aos implantes (Cehreli et al., 2004).

A questão é que o desenho mecânico do tipo de conexão, o diâmetro dos implantes, assim como o desenho e o comprimento destes, têm efeito significante na manutenção da interface osso/implante, seja no quesito biomecânico, como na indução de tensões, como no biológico, quando permite infiltração bacteriana na interface de conexão, influenciando diretamente no sucesso em longo prazo da reabilitação (Jansen et al., 1997; Cehreli et al., 2004; Bozkaya; Müflü, 2004).

Os diversos avanços ocorridos nos últimos anos, tanto na Odontologia como na Engenharia, permitiram uma aproximação entre essas duas áreas. Dessa forma, tornou-se possível a análise e soluções de problemas complexos associados às reabilitações implanto-suportadas. Tais recursos envolvem, entre outros, a análise fotoelástica.

Uma das primeiras formas de avaliar as tensões em estruturas mecânicas complexas foi a análise fotoelástica. Esse processo é muito adequado, pois permite observar a distribuição de tensões em toda a estrutura, possibilitando uma percepção geral sobre o comportamento das tensões.

A análise fotoelástica, técnica consagrada na Odontologia, é utilizada para transformar forças mecânicas produzidas em estruturas geométricas complexas, em padrões de luz visíveis que indicam a localização e intensidade de tensões, porém a informação principal é dada com relação à direção e distribuição dos padrões. Quando um feixe de luz polarizada passa através de um material de dupla refração, se transforma em vibrações perpendiculares que atravessam o material em diferentes velocidades e a diferença de fase entre esses componentes de luz, pode ser observada através de um filtro polarizador (Glickman et al., 1970).

Assim sendo, a análise fotoelástica pode fornecer informações importantes para a distribuição e concentração de cargas ao longo de implantes osseointegrados e, também, ajudar a dirimir dúvidas acerc de como o comprimento e a forma geométrica do implante poderiam influenciar a biomecânica desse tipo de reabilitação. 


\section{REVISÃO DE LITERATURA}

Osseointegração e biomecânica das próteses suportadas por implantes

Carter et al. (1981) realizaram testes de tração e compressão não axiais em amostras de osso cortical de fêmur humano. Observaram que nem só a magnitude dessas forças, mas também a frequência com a qual são aplicadas (velocidade do ciclo de aplicação) no tecido ósseo, é que influenciam no surgimento de microdanos ou fadiga no tecido ósseo. Além disso, verificou que essa fadiga se acumulou mais em regiões que receberam forças compressivas do que naquelas que receberam forças de tração.

Skalak (1983) considerando os aspectos biomecânicos em reabilitações protéticas sobre implantes osseointegrados, analisou a distribuição macroscópica de tensões e mecanismos de transferência de carga, nas proximidades da interface osso/implante, tendo como objetivo informar alguns aspectos que podem transferir tensões do implante para o osso. O autor relatou que implantes rosqueáveis transmitem maiores tensões para osso circunjacente, quando comparados a implantes lisos. O autor também considerou que, em uma reabilitação fixa extensa, os aspectos de rigidez da infraestrutura e dos implantes, geometria e disposição dos mesmos no arco, assim como submissão da peça a torções e trações ou desadaptação dessa sobre os implantes e a aplicação de revestimentos estéticos, principalmente na mandíbula, influenciam na direção e intensidade da transmissão de tensões à interface da osseointegração.

Lindquist et al. (1988), em estudo longitudinal in vivo, analisaram a reabsorção óssea ao redor de implantes osseointegrados em reabilitações fixas em mandíbulas. Foram selecionados dois grupos de pacientes desdentados mandibulares, compostos por 25 e 21 pessoas, que foram submetidos a tratamentos idênticos de reabilitação, empregando-se próteses fixas implanto-suportadas. 0 acompanhamento foi realizado por quatro a cinco anos, em média. Radiografias 
intra-orais foram realizadas durante o período de acompanhamento, sendo que as tomadas originais, realizadas logo após o término das reabilitações, foram utilizadas para que fossem avaliadas comparativamente e permitissem a inspeção de perda óssea e alterações na densidade e arquitetura do osso ao redor dos implantes. A altura da ancoragem óssea foi medida nas regiões mesial e distal de cada implante e a média dos valores foi obtida para cada um deles. Outras variáveis como força de mordida, eficiência mastigatória, índices clínicos de disfunções, atrição, uso oclusal e grau de reabsorção óssea também foram avaliados antes do tratamento, por meio de radiografias de perfil. $O$ índice de higiene oral foi controlado durante o período de avaliação. Os resultados mostraram que a perda óssea marginal ao redor dos implantes, durante os três primeiros anos, foi similar para ambos os grupos. A maior perda ocorreu durante o primeiro ano $(0,40$ a $0,45 \mathrm{~mm})$. As perdas adicionais anuais foram por volta de 0,07 a $0,08 \mathrm{~mm}$. Observaram, ainda, que os implantes mediais tinham uma maior perda óssea quando comparados aos mais posteriores e sugeriram mais estudos nesse contexto. Fatores como força de mordida, eficiência mastigatória, extensão de cantilever, assim como outros fatores avaliados neste estudo não mostraram grau de correlação com a perda óssea. No entanto, o grau de higiene oral influenciou o nível de perda óssea.

Davis et al. (1988) analisaram a tensão gerada em estrutura protética sobre implantes, variando a configuração em dois, três, quatro e cinco implantes. Utilizaram extensometria in vivo e modelo de elementos finitos. Os resultados mostraram que a maior mudança na deformação da estrutura ocorreu quando somente dois pilares foram usados para suportar a estrutura. A distribuição da tensão foi similar quando utilizados quatro ou cinco pilares, tanto para forças axiais quanto para momentos fletores. Concluíram que ambas as situações com quatro ou cinco implantes poderiam ter resposta clínica favorável. Recomendando a utilização de cinco implantes para suporte de prótese fixa por ser mais previsível, caso houvesse falha de algum dos componentes.

Lekholm (1988) relatou a necessidade de um mínimo de 4 implantes com $10 \mathrm{~mm}$ de comprimento para próteses fixas em região de maxila. $\mathrm{Na}$ mandíbula, o número correspondente é de 4 implantes com no mínimo $7 \mathrm{~mm}$ de comprimento, apesar de que, na maioria dos planejamentos, o uso de 5 implantes, e mais longos, 
é preferível. Sempre que possível, implantes de maior comprimento e em maior número devem ser colocados se as restaurações tiverem amplo espaço protético ou com pônticos em balanço (cantlever).

Chapman (1989) afirmou ser a oclusão fundamental para a longevidade das próteses sobre implantes, relatando ter tido 97,7\% de sucesso nos implantes após 2,5 anos. Qualquer carga oclusal tem que ser suportada pela interface e, caso isso não ocorra, o tratamento falhará. Usou um aparelho computadorizado, que utiliza um sensor, para quantificar os dados dos contatos oclusais em tempo e forças. Avaliou os contatos oclusais protegendo a prótese sobre implante contra interferências em relação central e máxima intercuspidação, com uma melhor distribuição de forças. Se a prótese antagonista for a convencional, o autor recomenda uma oclusão balanceada a fim de ajudar na estabilidade e equilíbrio.

Lundgren et al. (1989) mensuraram a força de mordida em pacientes com próteses fixas mandibulares, com cantilevers bilaterais ocluindo com prótese total superior. O estudo in vivo utilizou oito pacientes (duas mulheres e seis homens). Foram colocados oito miniextensômetros nas próteses totais dos pacientes, o que permitiu o registro simultâneo das forças localizadas sobre toda a prótese inferior. A força oclusal foi mensurada de forma padronizada em três diferentes arranjos: 1. Contatos oclusais simetricamente divididos; 2. Penúltimo dente do cantilever em infraoclusão (16mm de extensão do cantilever); 3. Último dente do cantilever em infraoclusão (8mm de extensão do cantilever). Os resultados evidenciaram que a maior força foi mensurada no primeiro arranjo e observaram que $74 \%$ das forças de fechamento se concentraram na região de cantilevers, isto é, no implante mais próximo à região de carregamento. No desenho dois, observaram redução de $15 \%$ na intensidade da força em relação ao primeiro arranjo e a configuração três não apresentou diferença significativa com relação à diminuição do braço suspenso, com o decréscimo do carregamento. Contudo, sugere que a redução de força ao longo de todo o comprimento do cantilever indica melhor conformação de carregamento para as próteses.

Rangert et al. (1989) enfatizaram considerações a respeito de biomecânica em reabilitações protéticas fixas sobre implantes, confeccionadas de acordo com o 
protocolo Brånemark, sugerindo algumas orientações para a prática clínica, a fim de controlar a distribuição de carga sobre os implantes e, destes ao osso. Os autores alertaram para o fato de que o número e a distribuição ântero-posterior dos implantes em protocolos Brånemark é de grande importância para compensar a carga gerada pela atuação das forças de mastigação devido ao cantilever presente nessas peças. Idealiza-se que os mesmos devam ter o mínimo de extensão. Os autores também citam a grande importância da obtenção de uma carga bem distribuída em toda a prótese, assim como de aceitável adaptação entre os componentes protéticos e a infraestrutura da prótese, de forma a favorecer a função dos parafusos de fixação da peça. A modificação da inclinação das cúspides dos dentes também pode controlar forças transversais geradas durante a função.

Jemt (1991) realizou um estudo clínico longitudinal no qual foram avaliadas 391 mandíbulas e maxilas desdentadas, reabilitadas com próteses fixas sobre implantes múltiplos. Após um ano de acompanhamento, o índice de sucesso encontrado foi de $99,5 \%$ para as próteses e $98,1 \%$ para os implantes, sendo que os implantes na maxila (1,5\%) apresentaram perda maior que os da mandíbula $(0,3 \%)$. O maior número de falhas protéticas foi observado na maxila, sendo que as mais comuns foram problemas fonéticos e fraturas da base de resina. Na mandíbula, a queixa encontrada foi mordedura de lábios e bochechas. Todos os problemas foram solucionados e poucos prejudicaram a estabilidade encontrada nesse tipo de restauração fixa.

Bidez e Misch (1992), baseados em suas pesquisas clínicas e laboratoriais, observaram que o desenvolvimento de uma interface pode ser fortemente influenciado pelo ambiente mecânico. A oclusão serve como um importante determinante em estabelecer a direção de carga. Forças compressivas devem ser dominantes nas próteses sobre implantes, pois são melhores acomodadas, porque o osso cortical é mais resistente à compressão. A pressão exercida sobre os implantes pode ser controlada se for levada em consideração a influência do desenho do implante, o tipo de cirurgia e a prótese. O desenho do implante tem uma influência na natureza da transferência de força na interface osso-implante. Quanto maior o comprimento do implante, maior quantidade de osso haverá, consequentemente melhor será a osseointegração. 
Rodriguez et al. (1993) avaliaram a relação entre extensão dos cantilevers com a perda óssea ao redor dos implantes, para próteses tipo protocolo, por aproximação da tensão gerada nos implantes que suportam a prótese e na superfície óssea, durante o carregamento dos cantilevers. Uma prótese tipo protocolo com seis implantes foi colocada em modelo simulando mandíbula humana feita de resina. Os implantes possuíam comprimento de $15 \mathrm{~mm}$ e diâmetro de $4 \mathrm{~mm}$. Quatorze diferentes arranjos foram testados, em carregamentos estáticos unilaterais, com distâncias de $7 \mathrm{~mm}, 14 \mathrm{~mm}$ e $20 \mathrm{~mm}$ na distal do pilar terminal. Extensômetros foram colocados imediatamente na distal dos pilares terminais, na região correspondente à região óssea simulada. A tensão gerada no osso adjacente ao pilar terminal aumentou de forma diretamente proporcional ao aumento do comprimento dos cantilevers. Quando o comprimento aumentou de $7 \mathrm{~mm}$ para $14 \mathrm{~mm}$ o incremento de tensão na região adjacente ao último implante foi de $30 \%$; de $14 \mathrm{~mm}$ para $20 \mathrm{~mm}$ o valor crescente foi de $55 \%$; de $7 \mathrm{~mm}$ para $20 \mathrm{~mm}, 101 \%$. Os autores concluem que próteses com braços suspensos superiores a $7 \mathrm{~mm}$, não devem ter número reduzido de implantes.

Meijer et al. (1994) usaram método de elementos finitos tridimensional para avaliar a distribuição de tensões no osso ao redor de dois e quatro implantes colocados na região de sínfise da mandíbula, com dois estágios de reabsorção. Não observaram a redução de tensão nas extremidades livres quando a carga foi distribuída por quatro implantes em relação à configuração com dois implantes. Entretanto, houve uma tendência para o aumento gradual de tensão com a diminuição da altura da mandíbula, isto é, o fator que influenciou no aumento das tensões transmitidas ao osso foi o grau de reabsorção das mandíbulas.

Brånemark et al. (1995) realizaram um estudo retrospectivo em 156 pacientes reabilitados, de dez anos, com próteses implanto-suportadas, nos quais avaliou-se, de maneira comparativa, o índice de sobrevivência dos implantes para casos onde foram utilizados em número de quatro ou seis. O protocolo de dois estágios cirúrgicos foi conduzido. Após o período de cicatrização (três a quatro meses para mandíbula e cinco a oito para maxila), foram instaladas próteses fixas em ouro e resina acrílica. Radiografias foram tomadas no momento da instalação da prótese e anualmente até completar dez anos de acompanhamento. Os resultados mostraram 
que o índice de sobrevivência na mandíbula foi de $88,4 \%$ e 93,2\% para tratamentos com quatro e seis implantes, respectivamente. Para a maxila, os mesmos índices foram de $80,3 \%$ e $78,3 \%$, respectivamente. Os autores concluíram que embora haja um risco de perder um ou mais implantes quando somente quatro, ao invés de seis, são instalados para suportar uma prótese fixa, a probabilidade de manutenção por dez anos mostrou-se semelhante para ambos os grupos. Portanto, reconstruções protéticas podem ser realizadas com quatro implantes com grande previsibilidade de manutenção. Ressaltaram, ainda, a importância de se observar qualidade e quantidade óssea, bem como o comprimento dos implantes.

Henry et al. (1995) apresentaram resultados clínicos de dez anos de acompanhamento de reabilitação com implantes osseointegrados em mandíbulas desdentadas, em quinze pacientes. Nenhum implante foi perdido nesse período. Ocorreram complicações mecânicas e biológicas associadas ao processo de integração, mas foi dentro da faixa de insucessos registrados em outros estudos. Somente um paciente apresentou desgaste nas superfícies de oclusão relacionada à parafunção. Concluíram que 0 tratamento com prótese sobre implantes osseointegrados é um método eficaz, dando resultados, a longo prazo, previsíveis.

Wang e Hobkirk (1996) avaliaram a distribuição da força sobre seis implantes dentais $(3,75 \mathrm{~mm} \times 10 \mathrm{~mm})$ montados em modelo experimental de mandíbula com o objetivo de investigar a distribuição de carga nos implantes que suportam protocolo inferior sob diferentes combinações de número de implantes e extensão do cantilever. Os implantes foram distribuídos de forma uniforme entre os forâmens mentonianos e carregados com infraestrutura simétrica, fundida em ouro tipo IV. A estrutura possuía $17 \mathrm{~mm}$ de cantilever distal, sendo avaliadas três diferentes extensões (15, 10 e 5mm), sem apresentar problemas correlacionados à adaptação. Os implantes foram numerados de um a seis, do lado mais distal até o lado oposto, com carregamento de $50 \mathrm{~N}$ no braço suspenso. A avaliação da tensão de tração e compressão nos pilares foi feita por meio de extensômetros. Observou-se que a magnitude das forças foi decaindo com aumento da distância do local de carregamento e o posicionamento do implante, onde a força distribuída no implante está diretamente relacionada ao comprimento do cantilever, sendo o implante mais próximo à carga o mais solicitado, independente da configuração testada. Essa 
investigação sugere que as fixações sejam posicionadas com espaço uniforme entre elas, tornando-se a configuração dos implantes no arco significante para a distribuição da tensão.

Tashkandi et al. (1996) estudaram o efeito do comprimento do cantilever no comportamento das tensões geradas no osso circundante aos implantes dentários. Foram utilizados três implantes com $13 \mathrm{~mm}$ de comprimento em osso bovino, no qual foram posicionados seis strain gauges. Os implantes eram distribuídos com espaçamento de $15 \mathrm{~mm}$ de centro a centro. Foi confeccionada infraestrutura protética com cantilever de $30 \mathrm{~mm}$ de comprimento, medido a partir do centro do último implante, o qual também serviu para demarcar as regiões de carregamento a 0,5 , 10, 15, 20 e 25mm de distância em direção posterior. Os resultados não mostraram diferença estatística significante no aumento de comprimento de 5 para $10 \mathrm{~mm}$ e de 10 para $20 \mathrm{~mm}$. O maior valor de tensão foi verificado no extensômetro localizado na região cervical do implante mais próximo ao lado de carregamento.

Schnitman et al. (1997) investigaram o desenvolvimento de método para aplicação de carga imediata por meio de provisórios, em apenas parte dos implantes fixados, até o momento da instalação da prótese final, quando eram utilizados todos os implantes anteriormente implantados. Foram utilizados nesse trabalho sessenta e três implantes de diâmetro regular, de comprimentos variados, fixados em mandíbulas de dez pacientes, acompanhados por período de dez anos. Destes, trinta e cinco implantes não foram colocados em função e mantidos submersos. Após período de três meses os implantes submersos foram expostos e a prótese final instalada. Todos os implantes colocados em função imediata suportaram o período de três meses até a instalação final da prótese, a taxa de sucesso de todos os implantes foi de $93,4 \%$, sendo de $84,7 \%$ dos implantes colocados em carga imediata e de $100 \%$ para os implantes com carga mediata. A falha dos implantes colocados de maneira imediata foi relevante quando comparada aos implantes submersos; contudo o comprimento dos implantes imediatos, principalmente os colocados nas extremidades das próteses, era inferior a $10 \mathrm{~mm}$, sendo que os de carga tardia apresentavam comprimento igual ou superior a $10 \mathrm{~mm}$. Os autores observaram que, com o uso de três implantes posicionados na região entre os foramens mentonianos, não houve ocorrência de perda de implantes mediais e que, 
apesar de haver pequeno número de implantes perdidos na região distal, o tratamento pode ser considerado favorável, realçando suas vantagens na redução da complexidade de confecção e do custo.

Glantz e Nilner (1988) apresentaram revisão de literatura a respeito dos aspectos biomecânicos para reconstruções protéticas sobre implantes, ressaltam que as propriedades mecânicas dos implantes dentários são frequentemente analisadas por estudos in vivo e in vitro, sendo estes últimos desenvolvidos, frequentemente, por meio de elementos finitos, fotoelasticidade e/ou extensometria. Em termos gerais, todos os métodos de análise experimental e matemática dos corpos mencionados anteriormente são cálculos teóricos amparados na virtual impossibilidade de quantificar e controlar a grande variação das forças (direção e magnitude) presentes nas análises in vivo e isso se apresenta como um grande motivo do questionamento dos modelos teóricos presentes para sistemas de implantes dentários os quais falham em termos de falta de padronização e pela metodologia muito complexa, necessitando de simplificação. Muitas aproximações possuem pouca aplicabilidade clínica. O autor relata que o número de implantessuporte é um dos fatores de maior importância correlacionado à biomecânica do sistema; em termos gerais, a resistência funcional melhora com o acréscimo de implantes. Outro fator de relevância mencionado seria o comprimento das fixações, para atenuar o momento fletor, contudo, em pacientes com maior reabsorção óssea, menores deverão ser os comprimentos dos implantes e maiores as infraestruturas, para compensar a alteração da dimensão vertical de oclusão, assim aumentando o momento fletor. Com relação ao posicionamento dos implantes, desenhos em arco na instalação de três ou mais implantes em áreas desdentadas criam situações relativamente mais resistentes e mais favoráveis que posicionamentos lineares.

Korioth et al. (1998) utilizaram modelo experimental em cinco implantes, simulando protocolo inferior tipo Brånemark, na tentativa de avaliar hipoteticamente sua maior efetividade sobre sistemas com menor número de implantes $(n=3)$. Cinco implantes foram fixados em modelo acrílico simulando mandíbula desdentada, conectados à infraestrutura metálica. As próteses eram montadas em oposição à prótese total removível, em articulador semiajustável. O implante mais distal foi eleito para colocação de quatro strain gauges. Forças excêntricas eram simuladas no lado 
de trabalho e balanceio, com carregamento de 50N. Quatro situações foram avaliadas: 1. Carregamento no lado de trabalho da infraestrutura sobre cinco implantes; 2. Carregamento no lado de trabalho da infraestrutura sobre três implantes; 3. Carregamento no lado de balanceio da infraestrutura sobre cinco implantes; Carregamento no lado de balanceio da infraestrutura sobre três implantes. Quando a carga foi aplicada no lado de trabalho momentos fletores se mostraram estatisticamente significantes sobre as próteses com três implantes, quando comparadas às próteses com cinco implantes $(1,469 \mathrm{~N} / \mathrm{cm}$ para cinco implantes e $2.151 \mathrm{~N} / \mathrm{cm}$ para três implantes). No lado de balanceio os resultados não apresentaram diferença estatística significante. Assim, os autores concluem que maior número de implantes resulta em valores menores de momentos fletores sobre os implantes mais posteriores, os quais afetam as próteses fixas mandibulares em períodos de mastigação unilateral.

Ivanoff et al. (1999) tiveram por objetivo analisar e comparar o comportamento de implantes de diâmetro regular $(3,75 \mathrm{~mm})$ e implantes de diâmetro largo (4 e 5mm), quanto à estabilidade da fixação e à perda marginal, por período de três a cinco anos. Assim foram selecionados sessenta e sete pacientes, providos de, no mínimo, um implante de largo diâmetro. O grupo consistia de trinta e sete mulheres e trinta homens, sendo a média de idade de cinquenta e nove anos. Foram fixados 229 implantes (Sistema Brånemark) em 47 maxilas (32 parciais / 15 edêntulos totais) e 20 mandíbulas (19 parciais / 1 edêntulos totais), com diâmetros e comprimentos variados. O resultado para implantes de $5 \mathrm{~mm}$ de diâmetro revelou índice de perda de 18\%. Contudo, 38\% das áreas de implantação apresentavam pobre qualidade óssea e 7\% já haviam abrigado implantes de diâmetro regular, sendo que $45 \%$ dos implantes de $5 \mathrm{~mm}$ de diâmetro haviam sido utilizados para resgate de outros implantes. Os implantes de curto comprimento demonstraram pior evolução, quando utilizados em comprimento satisfatório os valores de sucesso se equipararam aos implantes de diâmetro regular e $4 \mathrm{~mm}$. Não foram relacionados fortes indícios entre falhas de implantes e tipo ósseo.

Snauwaert et al. (2000) realizaram estudo longitudinal por 15 anos com total de 4971 implantes instalados em 1315 pacientes, contemplando casos totais e parciais. Implantes com $13 \mathrm{~mm}$ de comprimento apresentaram os maiores índices de 
sucesso, contraindicando implantes abaixo de $10 \mathrm{~mm}$ de comprimento de maiores índices de insucesso. A maxila apresentou maiores taxas de perda óssea e insucesso de implantes. $O$ trabalho foi inconclusivo a respeito do diâmetro dos implantes mediante o baixo número de implantes usados com $5 \mathrm{~mm}$. Os autores comentam que as taxas anuais de fratura de implantes foram menores que $0,2 \% \mathrm{e}$ que falhas mecânicas normalmente ocorrem com parafunções correlacionadas e não por sobrecargas ocasionais. Alguns fatores de risco são citados: 1 - Hábitos parafuncionais (bruxismo, apertamento); 2 - Inclinação dos implantes para fora do eixo de força; 3 - Proporção coroa/implante desfavorável; 4 - Comprimento de cantilevers.

Duyck (2000) avaliou a distribuição e a intensidade do carregamento oclusal em treze voluntários portadores de reabilitações totais fixas sobre implantes dentários. Realizou-se análise quantitativa e qualitativa das forças sobre os implantes, sendo registrada a magnitude e o tipo de carregamento nos pilares com a utilização de extensômetros, durante a aplicação de carregamento de $50 \mathrm{~N}$ em diferentes posições ao longo da superfície oclusal. O teste foi conduzido quando as próteses eram suportadas por cinco a seis implantes e repetido com a prótese suportada sobre quatro e três implantes. Os antagonistas, em oito pacientes, eram restaurações totais fixas suportadas por implantes, quatro pacientes usavam próteses totais e apenas em um paciente 0 antagonista era dente natural. $O$ carregamento nos braços suspensos causou efeito de flexão tipo dobradiça, o qual induziu consideráveis forças compressivas nos implantes próximos ao local de aplicação da carga e força de tração e baixa compressão nos demais implantes. Em média, as maiores forças foram observadas com a diminuição do número de implantes-suporte. A média das forças axiais foi significantemente menor com o arranjo de seis implantes e cinco implantes quando comparadas aos arranjos com quatro e três implantes. A diferença entre as forças axiais entre quatro e três implantes não foi significante. O momento fletor apresentou piores valores para a configuração com três implantes, sendo também observado que, à medida que a força se distanciava do ponto de carregamento, ela decrescia sobre as fixações.

McAlarney e Stavropoulos (2000) estudaram o efeito das variações clínicas para a indicação da extensão do cantilever em 55 pacientes portadores de prótese 
fixas totais sobre implantes, teoricamente, calculando o seu tamanho máximo pelo modelo de Skalak, assim evitando perda futura do parafuso ou falhas por fadiga. As variações da investigação incluem o número de 3, 4, 5, 6, 7 e 8 implantes, distribuição das fixações (distância ântero-posterior), região e condições clínicas satisfatórias para o cantilever. Os resultados mostraram que forças excessivas ocorrem no lado de trabalho onde se localiza o cantilever. Forças compressivas concentram-se no implante mais distal, com valores que podem alcançar de duas a três vezes o valor do carregamento oclusal. Os autores afirmam que o número de três implantes é insuficiente para suportar próteses fixas totais e nesse trabalho, três implantes foram utilizados em casos específicos de pacientes com grandes perdas ósseas. Contudo, não relatam perda dessas fixações, ao contrário do observado em casos com quatro, cinco e seis implantes. Os autores concluem que os comprimentos dos braços suspensos são menores quando colocados na equação linear de Skalak e que a distância ântero-posterior ideal seria de até 11,0mm.

Eliasson et al. (2000) utilizaram a região entre forâmens para a colocação de quatro implantes para suporte de próteses fixas totais e relatam em seu trabalho o acompanhamento longitudinal, por cinco anos, de 119 pacientes tratados. No total foram colocados 476 implantes (Sistema Brånemark) em pacientes com média de idade entre 61 e 90 anos, sendo que 21 pacientes abandonaram 0 acompanhamento ao longo do tratamento. Foram confeccionadas infraestruturas metálicas, (AuPd $n=103$; Ti $n=15 ; \operatorname{CoCr} n=01$ ), com comprimento dos cantilevers variando de 10 a 20mm, associadas a dentes de estoques, com padrão oclusal limitado ao primeiro molar. No primeiro ano apenas dois implantes foram perdidos e 30 removidos por compressão do nervo alveolar inferior. O índice de sucesso com cinco anos foi de $98,6 \%$, com favoráveis margens de níveis ósseos. Os pacientes foram divididos conforme o tipo do antagonista, houve diferença significativa entre os resultados de pacientes com próteses totais e pacientes com próteses fixas implanto-retidas, sendo observado $9 \%$ de fraturas de dentes artificiais para pacientes portadores de prótese total (antagonista) contra 45\% para pacientes com próteses retidas por implantes. Dos pacientes com implantes perdidos, dois continuaram usando três implantes como suporte para as próteses, sem danos posteriores para a prótese e para o paciente. 
Moberg et al. (2001) compararam dois sistemas de implantes, Brånemark (dois estágios cirúrgicos) e ITI (estágio cirúrgico único), por três anos. Quarenta pacientes desdentados mandibulares foram divididos em dois grupos de vinte e tratados com os diferentes sistemas. Todos receberam próteses fixas aparafusadas de arco completo, em resina acrílica e dentes artificiais, variando o número de implantes instalados de quatro a seis. Parâmetros protéticos e biológicos, complicações, índice de sobrevivência, eficácia clínica e satisfação dos pacientes foram avaliados. Nenhuma diferença foi encontrada em relação ao acúmulo de placa, índice de sangramento e complicações durante o período de proservação. O sistema Brånemark mostrou sulco peri-implantar mais profundo, menor faixa de gengiva inserida e maiores valores para o Periotest. Nenhuma complicação protética foi relatada para os dois sistemas de implantes. Após três anos, o índice de sucesso cumulativo não apresentou diferença estatística significante entre os diferentes sistemas. Houve satisfação do paciente de uma maneira geral, a não ser o fato de metade dos pacientes que receberam implantes Brånemark reclamarem das etapas cirúrgicas. O tempo de tratamento foi similar para os dois sistemas, podendo os autores concluir que ambos possuem requisitos atuais para o tratamento com implantes de mandíbulas desdentadas.

Iplikçioglu e Akça (2002) realizaram estudo com o propósito de comparar o efeito do diâmetro, comprimento e número de implantes sobre a distribuição de tensão no osso para uma prótese fixa de três elementos, na região desdentada posterior da mandíbula. Para tanto, foi construído um modelo de elemento finito tridimensional (3-D FEM) de mandíbula classe II de Kennedy, usando seis diferentes configurações, variando o número de dois e três implantes, diâmetros de 3,75 e $4,1 \mathrm{~mm}$ e comprimento entre 8 e $10 \mathrm{~mm}$. Os resultados demonstraram que o comprimento dos implantes não apresentou influência significativa na distribuição de tensão, sendo o fator mais relevante para diminuição da tensão gerada na cortical óssea o aumento do número de implantes na região posterior. A diferença de diâmetro de 3,75 e 4,1 mm não foi significativa.

Sahin et al. (2002) avaliaram relatos de evidências publicados a respeito da influência das forças de carregamento sobre as próteses suportadas por implantes. Foram analisados artigos de pesquisas originais usando o MEDLINE ${ }^{\circledR}$, os quais 
relatavam o controle de carga sobre implantes dentários, força de oclusão, influência da qualidade óssea, tipo de prótese, material das próteses, número de suporte dos implantes e a técnica de engenharia usada para avaliar a sobrevivência mecânica e biológica dos implantes analisados. Os autores relatam que os mecanismos responsáveis pela falha dos implantes ainda não estão totalmente compreendidos e os fatores considerados preocupantes pela literatura, relacionados a severos fatores mecânicos, são inconclusivos. Por envolver muitas variáveis, é difícil avaliar a resultante biomecânica sobre os implantes e muitos resultados de trabalhos são falhos ou incompletos, já que a real caracterização do problema é complexa e engloba o acompanhamento dos parâmetros e o correto isolamento das forças envolvidas nos experimentos. Contudo, é consenso que fatores de sobrecarga afetam a qualidade e a quantidade dos componentes osso/implante/prótese. Segundo os dados encontrados, o número, diâmetro, comprimento e posicionamento dos implantes têm influência na transferência de força e sequencialmente na geração de tensão e tração ao redor dos implantes. 0 incremento do número, diâmetro e comprimento, gera melhoras na sobrevida dos implantes, principalmente daqueles submetidos a momentos fletores. Maiores forças foram observadas quando da diminuição do número de implantes, maior momento fletor foi correlacionado ao uso de três implantes. Os autores concluem que existem poucos estudos a respeito de grandes trabalhos clínicos coletados nestas três últimas décadas. Sob a luz do pensamento vigente, para melhores resultados das reabilitações deve-se ter critério quanto às forças oclusais excessivas, que haja incremento no número e o diâmetro dos implantes e que o posicionamento destes reduza o momento fletor quando forem sustentar próteses fixas.

Assenza et al. (2003) avaliaram ao redor dos implantes submetidos à carga ou em repouso a presença e a quantidade de osteoclastos a fim de determinar se a carga nos implantes contribuiria ou não para perda óssea. Na mandíbula de 4 cães foram inseridos quarenta e oito implantes. Aguardado o tempo de cicatrização de três meses, próteses foram instaladas sobre vinte e quatro implantes (grupo-teste), enquanto que nos outros implantes apenas os cicatrizadores foram posicionados (grupo-controle). Após seis meses, doze implantes dos grupos controle e teste foram removidos e, após doze meses, os restantes. Todos os implantes estavam osseointegrados, e o número de osteoclastos encontrados na crista óssea e a três 
milímetros de distância da interface implante-osso foi determinado. Não foi observada diferença significativa entre os grupos. Concluiu-se que a carga sobre os implantes pareceu não ser relevante na ativação dos osteoclastos no tecido ósseo peri-implantar. Os autores acreditam que o real motivo da perda óssea marginal seja devido à presença de microrganismos na interface pilar-implante e que futuros estudos deveriam ser realizados para melhor se entender o processo de perda óssea marginal ao redor dos implantes dentais.

Himmlová et al. (2004) avaliaram a distribuição da tensão ao redor dos implantes, variando o comprimento e o diâmetro das fixações, por meio de simulação matemática. Foram criados modelos computacionais 3-D na posição vertical, simulando implantes com diâmetros de 3,6mm e comprimento de 8, 10, 12 , 14, 16, 17 e 18mm para observação da influência do comprimento dos implantes. Com objetivo de analisar o diâmetro, foram criados modelos com $12 \mathrm{~mm}$ de comprimento e diâmetros de 2,9/ 3,6/4,2/ 5,0/ 6,0 e 6,5mm, na região de molares inferiores. Para simplificação do modelo, ele foi desenhado sem roscas e o osso foi confeccionado na forma de prisma com a base quadrangular e paredes simulando octógono irregular. O carregamento foi realizado utilizando média de força mastigatória no sentido natural, oblíquo ao plano oclusal. As maiores forças foram observadas na região da crista cervical, para todas as variações testadas, apresentando sempre o mesmo padrão contudo, com grandezas diferentes. Foi observada variação significante na diminuição da tensão, quando do aumento do diâmetro nos desenhos dos implantes. Quando o diâmetro dos pilares variou de $4,2 \mathrm{~mm}$ para $5 \mathrm{~mm}$, foi computada redução de $16,4 \%$ da tensão na crista óssea. Para o aumento do comprimento dos implantes, não se observaram mudanças significativas, como as verificadas no aumento do diâmetro das fixações. Assim os resultados dessa simulação apontam que a variação no diâmetro dos implantes foi mais significativa que o comprimento, para otimizar a distribuição da tensão ao redor dos implantes.

Hermann et al. (2005) realizaram revisão de literatura sobre estudos clínicos, buscando avaliar o paciente, implante e características do tratamento, tentando identificar possíveis fatores que pudessem facilitar prognóstico para falhas nos implantes. Foram estudados 487 pacientes (1738 implantes) reabilitados com 
diferentes protocolos cirúrgicos, apenas do Sistema Brånemark, com acompanhamento de cinco anos. Os resultados mostraram fortes indícios para alguns fatores de risco: qualidade óssea, maxila $x$ mandíbula, formato ósseo, comprimento dos implantes (apenas para diâmetro de 3,75mm), 7 a 10mm, protocolo cirúrgico e protético. Não foi correlacionada influência quanto ao número de implantes-suporte para uma reabilitação e seu sucesso clínico. Os autores discutem que a interação de fatores de risco aumenta a taxa de insucesso do tratamento e concluem que a seleção do paciente para estudos é fator importante para os índices de sucesso.

Kim et al. (2005) revisaram em estudo a importância da oclusão na longevidade e sucesso da terapia com implantes. Sobrecarga e outros fatores, como extensos cantilevers, parafunção, desenho oclusal impróprio e contatos prematuros, podem influenciar de maneira negativa no prognóstico de planejamentos com implantes. Esses fatores serão determinantes das causas potenciais de periimplantite, perda óssea e falência do implante e da prótese sobre implante. Não havia até então um conceito específico de oclusão em implante, sendo assim seriam necessários futuros estudos nessa área para tentar mostrar a relação entre oclusão e o sucesso da terapia com implantes.

Aparício et al. (2006) realizaram revisão de literatura na busca por trabalhos com evidências científicas para validação e padronização de testes que identificam clinicamente a qualidade da interface osso/implante, para posterior correlação entre estabilidade da implantação com fatores biomecânicos. Foram utilizados como fatores de inclusão dois testes e equipamentos de uso frequente para a determinação da estabilidade dos implantes (RFA, Resonance Frequence Analysis e Periotest). O RFA usa valores relacionados a um Quociente de Estabilidade de Implante (ISQ) que possui índices de 1 a 100 e o Periotest, avalia valores qualitativos para micromovimentação dos implantes. Os resultados encontrados demonstravam na época poucos relatos na literatura de correlação de comportamento biomecânico e estabilidade das fixações, pelas dificuldades de padronização de testes efetivos. Contudo, os dados coletados apontam que fatores como densidade óssea, tanto em maxila como em mandíbula, comprimento dos pilares, comprimento das fixações, visivelmente influenciaram os testes. Os autores 
concluem que os testes avaliados possuem pouca significância clínica e que maiores estudos com os mesmos devem ser validados com mais avaliações prospectivas.

Renouard e Nisand (2006) realizaram revisão de literatura com o objetivo de avaliar o índice de sucesso e comportamento referentes ao comprimento e diâmetro de implantes dentários. Ficou caracterizado que implantes com comprimentos menores que $8 \mathrm{~mm}$ seriam considerados curtos e diâmetros maiores que $4,5 \mathrm{~mm}$, de largo diâmetro, em comparação aos diâmetros de $3,75 \mathrm{~mm}$. A busca no PubMed, resultou em 182 artigos sobre comprimento e 103 artigos sobre diâmetro de implantes dentários, dos quais foram aproveitados 53 estudos em seres humanos, fator utilizado como critério de inclusão. Para o comprimento dos implantes foi observada, na maior parte dos artigos, correlação entre implantes curtos e baixa taxa de sobrevida, observando-se a manutenção do diâmetro das fixações em $3,75 \mathrm{~mm}$ e grupo-controle com $13 \mathrm{~mm}$ de comprimento, variando a média de sobrevida de $91,5 \%$ a 97,4\%. Implantes de largo diâmetro apresentaram taxa média de sobrevida de $95,6 \%$ nos trabalhos analisados, demonstrando-se melhores resultados para a mandíbula; contudo, não foi observada padronização de comprimento e, em grande parte, os implantes perdidos eram curtos. A perda de osso ao redor do implante pode ser comparada aos implantes regulares. Estudos mais recentes apresentam taxa de sobrevida maior para implantes de largo diâmetro, fato que pode estar relacionado, segundo os autores, ao emprego de novas técnicas cirúrgicas, de novos desenhos e superfícies, seleção mais apropriada dos casos, o que aproxima as taxas de sobrevida aos implantes regulares e de largo diâmetro.

Degidi et al. (2007) estudaram o uso de implantes de largo diâmetro por meio de acompanhamento longitudinal, foram analisados 304 implantes sendo: diâmetros 5 ( $n=42) ; 5,5$ ( $n=248) ; 6,5$ ( $n=14)$, divididos em dois grupos: $\mathrm{Gl}<13 \mathrm{~mm}$ comprimento e Gll > 13mm de comprimento, num total de 205 pacientes (103 homens e 102 mulheres), com os critérios de seleção bastante rigorosos quanto aos hábitos dos pacientes e fatores sistêmicos. Após as cirurgias, eram realizados exames radiográficos periapicais e tomografia computadorizada da área, servindo de registro para comparação posterior da qualidade óssea. Nesse estudo, dos 304 implantes colocados, apenas cinco falharam posteriormente à colocação em função. Foi feito 
acompanhamento de 30 meses, sendo a taxa de sobrevida de 98,4\%; dos cinco implantes que falharam, apenas um apresentava comprimento abaixo de $10 \mathrm{~mm}$. Os autores relatam a influência entre procedimentos clínicos e comprimento dos implantes com as falhas apresentadas. Os implantes com maiores diâmetros $(5,5 / 6,5)$ e comprimento podem reduzir a perda óssea.

Van de Velde et al. (2007) realizaram estudos clínicos com dez pacientes reabilitados de forma imediata com o número de quatro a seis implantes, aproveitando a própria prótese total do paciente para uso de provisório imediato, após a fixação dos implantes na região anterior da mandíbula, entre os forâmens. Posteriormente, em um intervalo de tempo entre seis e doze meses, era realizada a reabilitação definitiva. Os resultados de sobrevida dos implantes, encontrados em acompanhamento longitudinal por três anos, mostraram índices de sucesso de $94,5 \%$, de acordo com os critérios propostos por Albrektsson.

Rilo et al. (2008) relataram que em médio ou longo prazo a falha de implantes dentários, depois do período de osseointegração concretizado, está associada, na maioria dos casos, com a carga oclusal. A sobrecarga depende do número e da localização dos contatos oclusais, os quais deveriam estar sob controle do cirurgiãodentista. Os pacientes poderiam ainda ser divididos em dois grupos. No primeiro, estariam os pacientes com muitos dentes e poucos implantes, e a carga oclusal seria direcionada totalmente aos dentes naturais, minimizando a carga sobre os implantes e tentando ao máximo direcioná-las axialmente. O segundo grupo seria composto por pacientes com muitos implantes em conjunto a poucos dentes ou ainda desdentados totais, fazendo com que as cargas oclusais sejam direcionadas integralmente aos implantes. Salientam ainda que muitos dos conhecimentos oclusais aplicados atualmente na implantodontia têm como referência conceitos baseados na oclusão de dentes naturais e concluem que o clínico deve se preocupar ao máximo para o arranjo oclusal em prótese sobre implantes, objetivando proporcionar excelente distribuição das forças oclusais.

Naconecy et al. (2010) realizaram estudo empregando análise extensiométrica para avaliar as causas da variação do número de implantes na biomecânica de planejamentos de próteses implanto-suportadas, com implantes 
paralelos e angulados. As próteses foram confeccionadas e suportadas por três, quatro ou cinco implantes. Um modelo foi composto por implantes verticais e paralelos, enquanto que o outro modelo possuía implantes distais angulados. Uma carga estática de $50 \mathrm{~N}$ foi aplicada na superfície livre posterior do cantilever $(15 \mathrm{~mm})$, e os extensiômetros foram posicionados nos pilares de cada modelo para medirem a deformação produzida. Os autores concluíram, através dos resultados obtidos, que, independente do número de implantes, a força axial no primeiro pilar, posicionado adjacente ao cantlever, foi maior nos implantes verticais que nos angulados. $O$ momento total de força foi maior quando três pilares estavam presentes, quando comparado com a presença de quatro ou cinco pilares apoiando a prótese.

Wiebke et al. (2010) realizaram estudo retrospectivo sobre a possibilidade de relacionamento entre a extensão do cantilver e a quantidade de perda óssea marginal ao redor de implantes mais distais. Foi realizado um protocolo de acompanhamento radiográfico em um período de 4 anos, para avaliar o nível ósseo nos implantes distais e nos mesiais, em total de 48 pacientes edêntulos com 313 implantes e 66 próteses conectadas, com cantilever distal de $12 \mathrm{~mm}$ em 30 maxilas e 36 mandíbulas. Após 4 anos, a média de perda ao redor dos implantes mesiais foi de 2,20 \pm 0,91 $\mathrm{mm}$ e a média de perda ao redor dos implantes distais foi de 2,31 \pm $1,05 \mathrm{~mm}$. Concluíram que o número de implantes e o comprimento do implante não se correlacionaram com a perda óssea. O comprimento do cantilever não influenciou a perda óssea marginal. Os resultados indicaram que as restaurações com extensões de cantilever até $12 \mathrm{~mm}$ são uma opção de tratamento adequada para pacientes desdentados.

De Kok et al. (2011) realizaram um estudo prospectivo comparando os resultados protéticos, satisfação do paciente e as taxas de sobrevivência de implantes, entre próteses tipo overdenture implanto-suportada retida por dois implantes e próteses fixas totais retidas por três implantes. Foram selecionados 20 pacientes e divididos igualmente em dois grupos. As sobredentaduras eram retidas por encaixe tipo bola e as próteses fixas com infraestrutura de titânio e recobrimento de resina e ambos os planejamentos proporcionaram alto grau de satisfação e qualidade de vida. Radiografias panorâmicas em período de 6 a 12 meses demostraram, em conjunto com acompanhamento, uma taxa de sobrevivência de 
$100 \%$, concluindo-se que ambos os tratamentos demonstraram sucesso, proporcionando saúde oral para os pacientes. No entanto, um período maior de observação faz-se necessário.

Minoretti et al. (2012) relataram os resultados clínicos, observados durante um período de 5 anos, de implantes não convencionais, colocados como apoio distal em próteses fixas tipo protocolo em mandíbula. Foram selecionados quatro pacientes desdentados totais inferiores que receberam 22 implantes, destes 18 foram Straumann e 4 Nobel Replace. A média de comprimento dos implantes foi de $14,5 \mathrm{~mm}$ (altura de 10 a $16 \mathrm{~mm}$ ). Os pacientes receberam implantes extraorais tanto do lado esquerdo como do lado direito, na região dos segundo molares. Implantes de diâmetro de 3,3mm, com um comprimento médio de 3,2mm. Os pacientes foram reabilitados após um período de cicatrização de 4,3 meses em média, com próteses fixas totais, com infraestrutura em ouro, recobrimento de porcelana e conexões não rígidas nos implantes distais. A média de comprimento dos cantilevers foi de $29,8 \mathrm{~mm}$, variando de 18,6 a $39,3 \mathrm{~mm}$. Durante o acompanhamento clínico e radiográfico num período de 5 anos, não houve evidência de perda óssea ao redor dos implantes anteriores e ao redor dos implantes distais. Conclui-se que o uso de implantes não convencionais na distal das próteses tipo protocolo em regiões com pouca altura óssea de mandíbula pode ser uma alternativa boa para se obter o sucesso do tratamento.

Análise Fotoelástica

A técnica da fotoelasticidade apresenta-se como técnica experimental de análise de tensões e deformações particularmente útil para peças e estruturas que apresentam infraestruturas complexas. Nesses casos, a utilização de métodos experimentais para pesquisa são mais adequados, já que métodos analíticos, mostram-se mais trabalhosos e, em algumas situações, inviáveis. $\mathrm{Na}$ fotoelasticidade de transmissão, como regra geral, deve-se construir modelo da estrutura a ser analisada em material fotoelástico, cuidando para que o limite da elasticidade não seja ultrapassado por pequenas deformações. A direção e 
magnitude das forças aplicadas no modelo devem ser simuladas o mais próximo da estrutural real. A birrefrigerância de certos materiais transparentes e oticamente isotrópicos, quando submetidos a tensões, torna-os oticamente anisotrópicos.

Essa característica permite que um raio de luz incidente sobre o corpo em tensão seja resolvido em dois raios ao longo dos planos principais do material. Os dois raios emergem com atraso, um em relação ao outro. A magnitude do atraso é proporcional à diferença entre tensões principais. O polariscópio foi usado para medir o retardamento e avaliar a variação das tensões (Mahler; Peyton, 1955).

Modelos teóricos matemáticos como os elementos finitos e modelos experimentais, tais como análise fotoelástica, têm sido amplamente utilizados para descrição de incidência de forças em prótese fixa sobre implantes (Porter et al., 2002).

A análise fotoelástica de tensões foi introduzida na Odontologia por Noonan em 1949, que a utilizou para analisar bidimensionalmente as restaurações de amálgama quanto ao tipo de preparo cavitário, o que permitiu uma análise qualitativa das tensões no interior de estruturas homogêneas.

Campos Jr et al. em 1986, explicaram que a técnica consiste na produção, sob passagem de luz polarizada, de faixas coloridas no interior de materiais transparentes submetidos às forças externas; essas faixas correspondem às regiões de concentração de tensões.

Caputo e Standlle em 1987 e Campos et al. em 1986 afirmaram que as técnicas de análise fotoelástica incluem três métodos: o bidimensional, o tridimensional e o quasi-tridimensional. A técnica bidimensional utiliza um modelo que mantém fidelidade geométrica em um plano. Consequentemente, forças aplicadas ao modelo devem estar no mesmo plano deste. A técnica bidimensional possui três vantagens: 1) os modelos são de confecção relativamente fácil; 2) uma larga variedade de condições de carga pode ser aplicada ao modelo; e 3) diferentes aplicações de carga podem ser ensaiadas no mesmo modelo. A maior desvantagem dessa técnica é a imperfeita reprodução da geometria tridimensional.

A técnica tridimensional faz uso da propriedade especial de certos materiais plásticos destinados à confecção de modelos. Explica-se: se esses materiais forem submetidos a cargas específicas, em condições de temperatura elevada e, se, em 
seguida, as mesmas cargas forem mantidas, mas o calor sofrer uma redução lenta e gradual até atingir a temperatura ambiente, as tensões neles formadas permanecerão após o completo cessamento das cargas. Esse processo é denominado de congelamento das tensões. Na técnica tridimensonal, há total fidelidade geométrica, mas a um alto custo. Assim, permite facilidade para extrair os dados sobre as tensões, porém essa técnica exige que o modelo seja finamente fatiado e que cada fatia seja analisada como um modelo bidimensional. A análise de todas as secções é que permite a construção da figura das tensões tridimensionais em sua totalidade. Dessa forma, a cada mudança de carga, um novo modelo deve ser confeccionado, o que pode onerar a pesquisa. Inclusive, a construção de modelos totalmente tridimensionais é considerada difícil.

A terceira técnica, denominada quasi-tridimensional, será a utilizada neste projeto. Foi desenvolvida por Caputo e Standlle em 1987, com o intuito de associar algumas vantagens das técnicas bi e tridimensional. A técnica quasi-tridimensional utiliza modelos com fidelidade geométrica, não restringindo a distribuição das tensões em um único plano como na bidimensional. Além disso, o modelo não precisa ser destruído para a obtenção dos dados fotoelásticos, como na técnica tridimensional. A principal desvantagem dessa técnica está na incapacidade de se obter a verdadeira distribuição de tensões em três dimensões no interior do modelo fotoelástico.

Laganá, em 1992, relatou que na técnica de fotoelasticidade é preciso estar atento à quantidade máxima de esforços externos a serem aplicados, de forma a não ultrapassar o limite de resistência do material fotoelástico, uma vez que se trata de uma técnica indireta, a qual exige modelos com reprodução extremamente fiel ao original.

White et al. (1994) avaliaram o efeito da extensão do cantilever na transmissão de carga para a mandíbula, por meio de técnica da fotoelasticidade. Os autores tinham por objetivo analisar formas de minimizar forças excessivas ofertadas pelos braços suspensos, aumentado a longevidade das fixações. Para confecção do modelo fotoelástico foi utilizada como referência, mandíbula moderadamente reabsorvida, com cinco implantes regulares de $3,75 \mathrm{~mm}$ de diâmetro e $13 \mathrm{~mm}$ de comprimento, sistema Brånemark, fixados na região de sínfise mentoniana. As 
infraestruturas foram devidamente conectadas sobre os implantes com torque de $10 \mathrm{~N} / \mathrm{cm}^{2}$, e sobre as mesmas foram colocados gabaritos de resina acrílica perfurados de $5 \mathrm{~mm}$ em $5 \mathrm{~mm}$, controlando as diferentes distâncias para simulação do carregamento. Os autores observaram o mesmo comportamento da distribuição da tensão para diferentes comprimentos do cantilever, contudo, com magnitudes diferentes. Foi observada concentração de tensões na região dos implantes mais distais, sobretudo na região cervical, sendo diretamente proporcional o aumento das distâncias ao aumento da tensão e com intensidade menor e mesmo padrão nos implantes opostos ao carregamento. Os autores completam o trabalho discutindo a validação de experimentos in vitro, sendo a sua aproximação válida para a maior compreensão do comportamento das tensões sobre os corpos e para 0 aprimoramento de novas técnicas e procedimentos.

Waskewicz et al. (1994) realizaram um estudo onde compararam o padrão de tensões produzidas ao redor de implantes entre infraestruturas de adaptação passiva e não passiva, utilizadas na confecção de próteses fixas tipo Protocolo Brånemark, através da análise fotoelástica. Os autores confeccionaram um modelo obtido através de um bloco de material fotoelástico CP5-4290 (Hysol, Olean, NY). A superfície do modelo recebeu cinco implantes com dimensões de $3.75 \times 10 \mathrm{~mm}$ (Brånemark System, Nobelpharma, Chicago, IL), dispostos de forma equidistantes, fixados ao modelo através de resina epóxi (Duro, Loctite). Pilares protéticos de $4,0 \mathrm{~mm}$ de altura foram adaptados sobre os implantes com um torque de $20 \mathrm{~N} / \mathrm{cm}^{2}$. Cilindros de ouro pré-fabricados foram utilizados para o enceramento de uma infraestrutura, posteriormente incluída e fundida em liga de Au-Pd (Allabond 60, Heraeus). A estrutura foi avaliada em relação à passividade de adaptação através da técnica do parafuso único, onde foi verificada a não existência de boa adaptação entre a mesma e os pilares, sendo tal estrutura considerada não passiva. Essa estrutura foi analisada através do método fotoelástico em um polariscópio circular por meio de sua fixação aos pilares do modelo com torque de $10 \mathrm{~N} / \mathrm{cm}^{2}$, através de três sequências de aperto de parafuso, determinadas pela posição dos implantes (1$2-3-4-5 ; 5-4-3-2-1 ; 3-2-4-1-5)$. Cada sequência de aperto testada foi repetida por cinco vezes, a fim de comparação, e fotografada apenas na última repetição. $O$ padrão de tensões induzidas pela estrutura não passiva foi analisado de acordo com o número e a concentração de franjas formadas ao redor dos implantes. Após essa 
análise, a mesma estrutura foi seccionada em pontos intermediários entre cada pilar, sendo as partes relacionadas e unidas através de resina acrílica Duralay ${ }^{\circledR}$. Foram, então, realizados os pontos de solda e feita nova avaliação da interface estrutura/pilar. A estrutura foi novamente fixada ao modelo com torque de $10 \mathrm{~N} / \mathrm{cm}^{2}$, nas mesmas sequências testadas anteriormente, onde foi submetida à nova análise fotoelástica. Os resultados mostraram que o aperto da estrutura não passiva sobre os pilares, nas três sequências de aperto testadas, gerou uma concentração de tensões ao redor dos implantes. Em relação à sequência de aperto dos parafusos, todos os implantes mostraram tensões, concentradas principalmente nos seus terços médios. No entanto, os implantes de extremidade (1 e 5) foram os que mostraram maior quantidade de tensões. Em contraste, os autores notaram que, quando a estrutura foi seccionada e soldada, um relacionamento passivo em relação aos pilares foi obtido sem indução de tensões aos implantes.

Assif et al. (1996) avaliaram a transferência de carga e a distribuição de tensões de uma prótese fixa implanto-retida através de análise fotoelástica. Para tanto, a estrutura foi submetida a uma carga vertical de $7,5 \mathrm{~kg}$ em sete pontos. A eliminação das tensões entre uma análise e outra foi feita por meio da colocação do modelo num forno a $140^{\circ} \mathrm{C}$, durante 120 minutos. Houve tensões criadas nas estruturas de suporte ao redor dos implantes. A quantidade de tensões foi diretamente proporcional à distância dos componentes do ponto de carga. Quando o cantilever foi submetido à carga, a maior parte das tensões foi distribuída na união com o implante distal. No estudo, as tensões foram distribuídas em dois ou, no máximo, três implantes mais próximos do implante mais distal.

Rubo e Souza (2001) discorreram sobre os diversos recursos existentes para análise e solução de problemas complexos encontrados no tratamento de pacientes com dentições comprometidas. Dentre esses recursos os autores citaram, além de outros, a análise fotoelástica, o método de elementos finitos e a extensiometria. Foram relatadas as aplicações desses procedimentos na resolução de carregamento de próteses sobre implantes. No entanto, os autores concluíram que existem vantagens e desvantagens inerentes a cada procedimento e observaram que nenhuma das formas de análise possui total preponderância sobre a outra, 
resultando em um consenso entre pesquisadores de que as mesmas se complementam, no intuito de uma validar a outra.

Barbosa (2006) estudou a correlação entre desajuste vertical/horizontal e tensões geradas na região cervical dos implantes, após a instalação de doze infraestruturas tipo Protocolo Brånemark sobre cinco implantes, antes e após a soldagem laser, por meio da técnica da fotoelasticidade plana. Para possibilitar a análise quantitativa da tensão cisalhante na interface cervical osso/implante, foi construído em gesso modelo plano com três paredes interligadas, conferindo ao modelo aspecto final curvo e referência à região anterior da mandíbula. A constante ótica $(\mathrm{K})$ para espessura constante da resina acrílica flexível (Polipox ${ }^{\circledR}$ ), utilizada nesse estudo, foi de 0,25N/mm. Após a etapa de soldagem, o desajuste horizontal apresentou-se semelhante entre os grupos e não houve diferença com relação à tensão gerada no modelo para diferentes ligas utilizadas, fato observado nos modelos anteriormente à soldagem. Foi observado que a passividade melhorou após a soldagem, porém as infraestruturas ainda geravam tensão após a soldagem; assim o autor conclui que as tensões geradas entre os implantes na região cervical estão mais relacionadas ao desajuste horizontal que ao desajuste vertical; mesmo com a utilização da soldagem a laser, não foi possível a obtenção de infraestrutura totalmente livre de tensões.

Bernardes et al (2006) relataram que implantes osseointegrados vêm apresentando limitações desde sua concepção. Uma delas seria a perda óssea marginal crônica. Tal fenômeno seria justificado por cargas mastigatórias que levariam a concentrações de tensões junto à crista óssea. Ao longo dos anos, os autores relatam que foram sugeridas modificações buscando minimizar tal perda, por exemplo, o desenvolvimento de novas junções pilar/implante e até mesmo implantes com pilares em peça única. Dentre as várias vantagens citadas das junções internas sobre o tradicional hexágono externo, estaria a capacidade das primeiras em distribuir melhor as tensões, de maneira que impedissem concentrações excessivas na crista óssea. $O$ trabalho dos autores objetivou analisar qualitativamente e quantitativamente as tensões geradas em modelos fotoelásticos decorrentes de cargas aplicadas em peças simulando implantes com a mesma forma externa, diferindo apenas no tipo das junções: hexagonal externa $(\mathrm{HE})$, 
hexagonal interna $(\mathrm{HI})$, cônica interna $(\mathrm{Cl})$ e um implante sem junção (peça única, PU). Essas peças foram inseridas em blocos fotoelásticos e submetidas a dois tipos de cargas compressivas, uma axial (carga I) e outra 6,5mm fora do longo eixo (carga II). Foram analisados diversos pontos de tensão ao longo de quatro corpos de cada espécie (46 para carga I e 61 para carga II), nos quais se determinou a tensão cisalhante máxima. Os pontos analisados geraram gráficos que a partir dos quais foram determinadas áreas individuais para cada uma das duas situações de carga em todo o corpo do implante e apenas para a região de pescoço do mesmo. Depois de aplicados os testes de Kruskal-Wallis, $U$ de Mann-Whitney, t de Student e ANOVA, de acordo com a necessidade de cada análise, não foi encontrada diferença significante $(p<0,05)$ em nenhuma das duas situações propostas para carga I. Entretanto, para carga II, quando avaliando todo o corpo do implante, os de hexágono interno apresentaram diferenças significantes $(p<0,05)$, com os menores valores, em relação aos outros grupos (hexágono externo, cônico interno e peça única). Da mesma forma, para a análise da região de pescoço sob a carga II, 0 grupo de implantes $\mathrm{HI}$ mostrou ser estatisticamente diferente $(p<0,05)$ dos grupos $\mathrm{HE}$ e PU, porém $\mathrm{HI}$ e $\mathrm{Cl}$ não apresentaram diferenças, bem como $\mathrm{HE}, \mathrm{PU} \mathrm{E} \mathrm{Cl}$. Quando tirando conclusões baseadas nos valores encontrados, em porcentagem, observou-se que, para a carga I, o grupo $\mathrm{Cl}$ apresentou os menores valores de tensão cisalhante máxima para todo o corpo, seguido pelo grupo PU, 0,45\% maior e após estes os grupos $\mathrm{HI}$ com 2,02\% e HE com 3,33\% maiores que o primeiro. Nessa situação de carga, quando analisando a área de pescoço da peça, foram encontrados menores valores para o grupo PU, seguido pelo $\mathrm{HI}$ com 1,69\% maior, $\mathrm{Cl}, 3,15 \%$ e HE, 3,82\% maiores que o primeiro. Quando para carga II, o grupo $\mathrm{HI}$ apresentou os menores valores para todo o corpo da peça, seguido pelo $\mathrm{Cl}$ com 10,9\%, PU e HE com o mesmo valor de 12,93\%. Na situação de carga II, para a região de pescoço do implante, a ordem encontrada foi a seguinte: com menor valor o grupo $\mathrm{HI}$, seguido pelo $\mathrm{Cl}$ com 9,45\%, PU com 15,20\% e HE com 17,36\%. 


\section{PROPOSIÇÃO}

O objetivo desta pesquisa é analisar, por meio da técnica de fotoelasticidade, - comportamento e a distribuição das tensões que ocorrem nas estruturas periimplantares, suportes de prótese fixa, segundo o protocolo de Brånemark. Para atingir tal objetivo, cargas axiais de carregamento serão aplicadas a próteses metalo-plásticas, parafusadas sobre 5 implantes de hexágono interno, com comprimentos de 10,13 e $15 \mathrm{~mm}$. 


\section{MATERIAL E MÉTODOS}

\subsection{Material}

Os materiais que foram empregados na execução e confecção dos corpos de prova estão relacionados no Quadro 4.1.

\begin{tabular}{|c|c|c|}
\hline PRODUTO & MARCA & FABRICANTE/DISTRIBUIDOR \\
\hline $\begin{array}{c}\text { Resina fotoelástica GY279 BR E } \\
\text { HY2963BR }\end{array}$ & Araldite $^{\circledR}$ & Araltec Prod Quim - Guarulhos- SP \\
\hline Broca multilaminada & Edenta & Edenta AG - Switzerland \\
\hline $\begin{array}{l}\text { Broca perfuração implante n. 2, } 3 \\
\text { piloto }\end{array}$ & Conexão $^{\circledR}$ & $\begin{array}{c}\text { Conexão Sistemas de Implantes, Arujá, } \\
\text { SP }\end{array}$ \\
\hline $\begin{array}{c}\text { Resina autopolimerizável Incolor - } \\
\text { RAAQ }\end{array}$ & Clássico & Art. Odontol Clássico, São Paulo, SP \\
\hline Isolante para resina acrílica & Cel-Lac & $\begin{array}{l}\text { SS White Artigos Dentários Ltda Rio de } \\
\text { Janeiro, RJ }\end{array}$ \\
\hline Gesso Tipo IV & Fujirock $^{\circledR}$ & GC Europe - Bélgica \\
\hline $\begin{array}{l}5 \text { Parafusos Corticais de Titânio } \\
\text { Master Cone AR } 3,75 \times 10,0\end{array}$ & Conexão $^{\circledR}$ & $\begin{array}{c}\text { Conexão Sistemas de Implantes, Arujá, } \\
\text { SP }\end{array}$ \\
\hline $\begin{array}{l}5 \text { Parafusos Corticais de Titânio } \\
\text { Master Cone AR } 3,75 \times 13,0\end{array}$ & Conexão $^{\circledR}$ & $\begin{array}{l}\text { Conexão Sistemas de Implantes, Arujá, } \\
\text { SP }\end{array}$ \\
\hline $\begin{array}{l}5 \text { Parafusos Corticais de Titânio } \\
\text { Master Cone AR 3,75 x 15,0 }\end{array}$ & Conexão $^{\circledR}$ & $\begin{array}{l}\text { Conexão Sistemas de Implantes, Arujá, } \\
\text { SP }\end{array}$ \\
\hline $\begin{array}{c}5 \text { componentes protéticos tipo micro } \\
\text { unit }\end{array}$ & Conexão $^{\Theta}$ & $\begin{array}{l}\text { Conexão Sistemas de Implantes, Arujá, } \\
\text { SP }\end{array}$ \\
\hline $\begin{array}{c}5 \text { coifas protéticas para pilar tipo } \\
\text { micro unit }\end{array}$ & Conexão $^{\circledR}$ & $\begin{array}{l}\text { Conexão Sistemas de Implantes, Arujá, } \\
\text { SP }\end{array}$ \\
\hline $\begin{array}{c}5 \text { transferentes de moldagem com } \\
\text { parafusos }\end{array}$ & Conexão $^{\circledR}$ & $\begin{array}{l}\text { Conexão Sistemas de Implantes, Arujá, } \\
\text { SP }\end{array}$ \\
\hline 5 parafusos de fixação das coifas & Conexão $^{\circledast}$ & $\begin{array}{l}\text { Conexão Sistemas de Implantes, Arujá, } \\
\text { SP }\end{array}$ \\
\hline $\begin{array}{c}5 \text { análogos de implantes hexágono } \\
\text { interno }\end{array}$ & Conexão $^{\circledR}$ & $\begin{array}{c}\text { Conexão Sistemas de Implantes, Arujá, } \\
\text { SP }\end{array}$ \\
\hline 5 análogos de micro unit & Conexão $^{\circledR}$ & $\begin{array}{l}\text { Conexão Sistemas de Implantes, Arujá, } \\
\text { SP }\end{array}$ \\
\hline $\begin{array}{c}\text { Silicone de condensação } \\
\text { laboratorial }\end{array}$ & Zetalabor & Zermack - Itália \\
\hline Maxicut números 205 e 197 & Tri-Hawk & $\begin{array}{l}\text { Tri-Hawk do Brasil Imp e Exp de Produtos } \\
\text { Médicos, São Paulo, SP }\end{array}$ \\
\hline
\end{tabular}




\begin{tabular}{|c|c|c|}
\hline Cera $n^{0} 7$ & Clássico & $\begin{array}{c}\text { Artigo Odontológico Clássico Ltda, São } \\
\text { Paulo, Brasil }\end{array}$ \\
\hline Papel Carbono para articulação & Accufilm ${ }^{\circledR}$ & Parkell - NY - EUA \\
\hline Lixa d'água n. 500, 1500 e 2000 & T- 223 & Norton, Worcester, Massachussets, EUA \\
\hline Óleo Mineral branco & Campestre & $\begin{array}{c}\text { Campestre Ind E Com de Óleos } \\
\text { Vegetais Ltda - São Bernardo do Campo } \\
- \text { SP }\end{array}$ \\
\hline Resina para Prototipagem & Novox $^{\circledR}$ & Avant Supplies,Chigago, EUA \\
\hline Cera para escultura dental & $\begin{array}{l}\text { Schuler } \\
\text { Azul }\end{array}$ & Schuler Dental Ulm - Alemanha \\
\hline Cera em fio meia cana & & Ind e Com Babinete, São Paulo, SP \\
\hline Sprues de Cera 3,0mm & Kota $^{\circledR}$ & Kota $^{\circledR}$ Ind. e Com.Ltda, São Paulo, SP \\
\hline Revestimento Gilvest HS & BK & BK Giulinp - Alemanha \\
\hline Antibolha & Kota $^{\circledR}$ & Kota $^{\circledR}$ Ind e Com Ltda, São Paulo, SP \\
\hline Liga Dental de CoCr & StarLoy $\mathrm{C}^{\Theta}$ & Dentsply ${ }^{\circledR}$ Degudent, Hanau, Alemanha \\
\hline Resina Autopolimerizável & Duralay $^{\circledR}$ & $\begin{array}{c}\text { Duralay }{ }^{\circledR} \text { Resiliance-MFG Co, Chigago, } \\
\text { EUA }\end{array}$ \\
\hline Adesivo à base de cianocrilato & $\begin{array}{c}\text { Super } \\
\text { bonder }^{\circledR}\end{array}$ & Henkel Co, Dusseldorf, Alemanha \\
\hline Dentes Artificiais U 36 e U 85 & Artplus $^{\circledR}$ & Dentsply ${ }^{\Theta}$ Ind Com Ltda, São Paulo, SP \\
\hline Optosil Xantropen & $\begin{array}{l}\text { Heraus } \\
\text { Kulzer }^{\circledR}\end{array}$ & $\begin{array}{l}\text { Heraus Kulzer }{ }^{\circledR} \text { Gmbh, Hanau, } \\
\text { Alemanha. }\end{array}$ \\
\hline Moldeiras Zanetti Jon & Jon & $\begin{array}{l}\text { Jon Com de Produtos Odontológicos } \\
\text { Ltda, São Carlos, Brasil }\end{array}$ \\
\hline Compasso de Willis Jon & Jon & $\begin{array}{l}\text { Jon Com. de Produtos Odontológicos } \\
\text { Ltda, São Carlos, Brasil }\end{array}$ \\
\hline Opaco Vipi-Tone & Vipi & $\begin{array}{l}\text { Vipi Ind Com e Exp e Imp de Prod } \\
\text { Odontológicos Ltda, Pirassununga, SP }\end{array}$ \\
\hline Resina Vipi-Cril STG & Vipi & $\begin{array}{l}\text { Vipi Ind Com e Exp e Imp de Prod } \\
\text { Odontológicos Ltda, Pirassununga, SP }\end{array}$ \\
\hline Borracha Líquida Dow Corning $^{\Theta}$ & D'Altomare & D’Altomare Química, São Paulo, SP \\
\hline
\end{tabular}

Quadro 4.1 - Materiais empregados na pesquisa 


\subsubsection{Resina Fotoelástica}

Para a confecção dos corpos de prova, foi empregada a resina fotoelástica Araldite-Araltec Prod Quim - Guarulhos - SP.

A resina Araldite é formada por dois componentes líquidos: a GY279 BR, modificada, com diluente reativo, de baixa até média viscosidade, formulada à base de bisfenol A e um endurecedor HY2964, à base de amina cicloalifática, modificado, de baixa viscosidade, que permite melhor aplicação e manuseio. A cura ocorre à temperatura ambiente por meio de um sistema endurecedor após 72 horas, o que possibilita a confecção de modelos de plástico fotoelástico, transparente, de alto brilho e sem exsudação. Ambos devem ser armazenados a uma temperatura entre $18-25^{\circ} \mathrm{C}$, sendo que o GY279 BR pode ser armazenado por um ano e por dois anos o HY2964.

A quantidade de plástico necessária deve ser previamente calculada de acordo com o tamanho da peça a ser modelada e a proporção da mistura recomendada é de 100 partes de GY279 para 48 partes de HY2964.

As características dessa resina serão descritas a seguir:

Propriedades da Araldite GY270 BR:

- Baixa tendência à cristalização;

- Viscosidade a $25^{\circ} \mathrm{C}(500-700 \mathrm{mPa})$;

- $\quad$ Equivalente epóxi $192-213 \mathrm{Eq} / \mathrm{Kg}$;

- $\quad$ Cor (gardner) $\leq 3$;

- Peso específico $1,10 \mathrm{~g} / \mathrm{cm}^{33}$ 
Propriedades do endurecedor HY2964:

- Viscosidade a $25^{\circ} \mathrm{C}(40-70 \mathrm{cP})$;

- Cor (gardner) - 2;

- $\quad$ Ponto de fusão $229^{\circ} \mathrm{F}$.

Após a mistura de 100:48 partes de peso, resultam as seguintes características:

- Viscosidade a $25^{\circ} \mathrm{C}(200 \mathrm{mPa})$;

- Tempo de gel- $46 \mathrm{~min} / 100 \mathrm{ml}-20^{\circ} \mathrm{C} 65 \% \mathrm{UR}$;

- Tempo de cura -72 horas.

\subsubsection{Aparelhos}

Polariscópio

A técnica fotoelástica fornece uma exibição visual das tensões em um determinado modelo. Essas tensões são reveladas com o auxílio de um dispositivo denominado Polariscópio.

Há dois tipos de polariscópio: o plano, que proporciona campo de visão escuro através dos polarizadores de eixos cruzados e o claro, através dos polarizadores de eixos paralelos. Portanto, dois tipos de franjas são visualizados em um polariscópio plano: os padrões coloridos (claros) que são as franjas isocromáticas que mostram a intensidade das tensões e as linhas escuras, chamadas isoclínicas, sobrepostas às franjas coloridas e relacionadas com a direção da tensão. Para aplicação dental, as principais informações requeridas são a localização e a intensidade das concentrações de tensões.

Para melhor visualização dos padrões isocromáticos (franjas coloridas), devese eliminar as isoclínicas (franjas escuras), e isso pode ser feito com o uso de filtros. Esses filtros, chamados placas quarter-wave, irão cancelar rotações das ondas de luz, o que anula as franjas isoclínicas (escuras). Esse arranjo é chamado de Polariscópio Circular. 
Neste experimento, foi utilizado um polariscópio do tipo circular. Para melhor nitidez das imagens, os modelos foram mergulhados juntamente com o aparelho para aplicação das cargas, em um tanque contendo óleo mineral puro, o que possibilita ainda melhor visualização das franjas isocromáticas (coloridas). Para isso, também foi adaptado ao polariscópio, um refletor fotográfico para a fonte de luz e um difusor de luz. A esse conjunto denominou-se fotoelasticímetro (Figura 4.1).

Na sua parte óptica, esse aparelho possui uma fonte de luz branca (lâmpada Photoflood - G\&E - 250W), um filtro polarizador, um difusor e um filtro analisador.

Na sua parte mecânica interposta entre os conjuntos polarizador e analisador, o aparelho apresenta um instrumento que possibilita posicionar o modelo a ser analisado no centro geométrico dos filtros.

Como equipamento auxiliar do fotoelasticímetro foi acoplada uma câmera fotográfica digital, modelo Canon 5D Marc 2, lente 24/70mm, F/2.8 (Sony, Japão), com lente objetiva macro que permite visualizar as franjas e registrar as imagens em fotografias digitais.

O fotoelasticímetro necessita ser ajustado de maneira padrão até o final dos ensaios, como se segue:

a) fonte de luz branca Photoflood com refletor; b) difusor de luz; c) filtro polarizador;

d) filtro analisador - ângulo paralelo ao eixo do polarizador. 


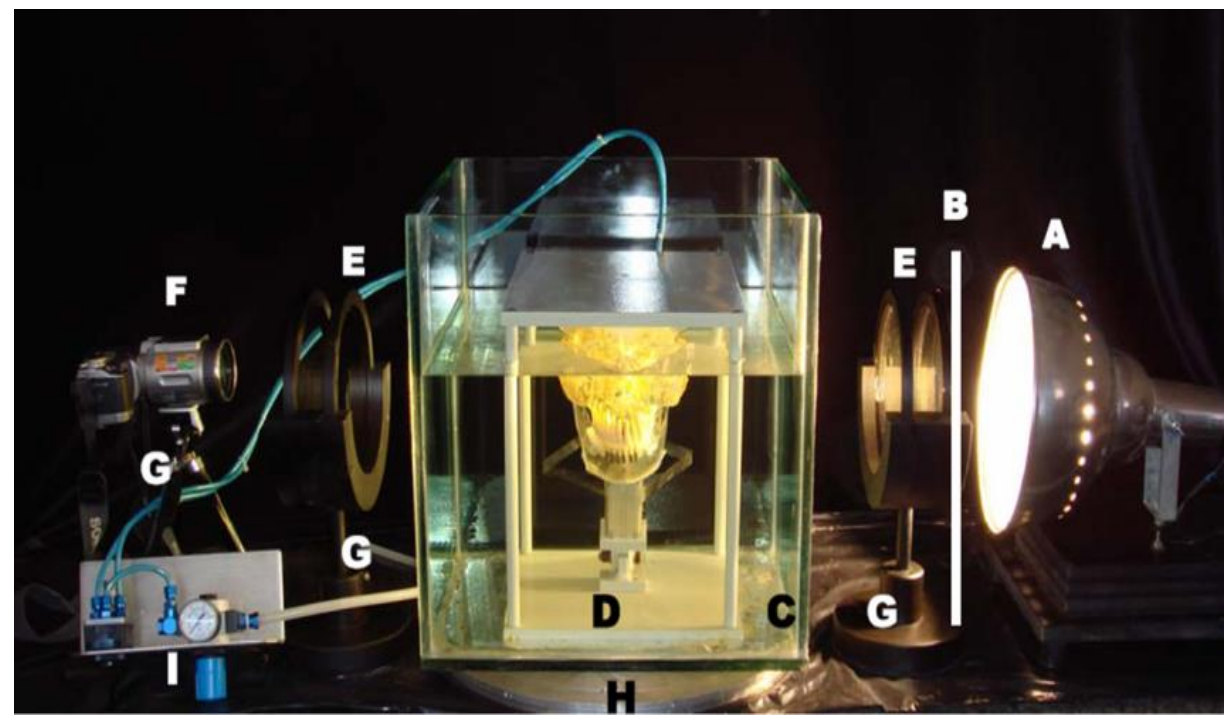

Figura 4.1 - a) Refletor de luz; b) Polarímetro; c) Recipiente de vidro; d) Aparelho para aplicação de força; e) Filtro polarizador; f) Câmera fotográfica; g) Suporte do filtro polarizador; h) Base rotatória; i) Controle de força aplicada

Aparelho de Aplicação de Força

O aparelho de aplicação de cargas foi o empregado por Cruz (2004), com capacidade de imprimir força no modelo fotoelástico, impulsionado por ar comprimido de um compressor que foi acoplado ao aparelho, incidindo pressões de tal forma que fossem direcionadas da mandíbula em direção à maxila, na ordem de 1,0 e 3,0 bars, sucessivamente. A pressão é transmitida através de um pistão de área calculada de $4,42 \mathrm{~cm}^{2}$ (Figura 4.2 item D).

Foram aplicadas as respectivas pressões por serem próximas à força oclusal exercida por um indivíduo reabilitado com próteses implanto-suportadas (Federick; Caputo, 1996; Sadowsky; Caputo, 2000).

O aparelho consiste em duas bases paralelas, sendo uma superior e outra inferior, quadradas, medindo $15 \times 15 \mathrm{~cm}$ e com quatro pilares de apoio.

A plataforma que transmite a carga para a base da mandíbula é de acrílico transparente, para permitir uma melhor passagem de luz e, consequentemente, melhor visualização das franjas. 
Para manter a mandíbula em posição foram utilizados elásticos fixados em um dispositivo na região da apófise coronóide, passando pelo arco zigomático.

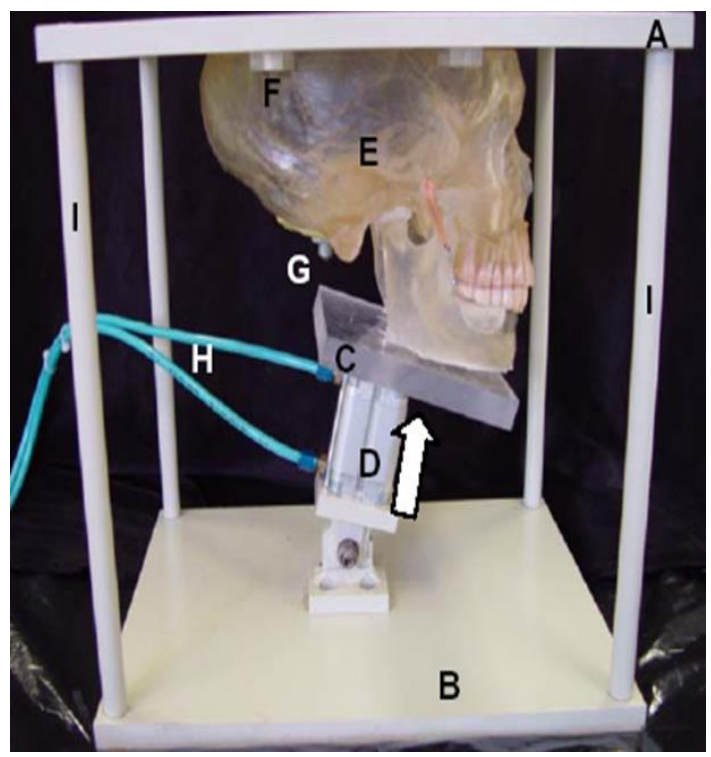

Figura 4.2 - Aparelho de aplicação de carga Crânio em polímero: a) e b) Bases horizontais; c) Plataforma de sustentação; d) Pistão que aplicará as forças; e) Crânio; f) e g) Parafusos de preensão do crânio; h) Manguitos condutores de ar comprimido; i) Haste vertical de sustentação do aparelho e seta indicando direção de aplicação de carga

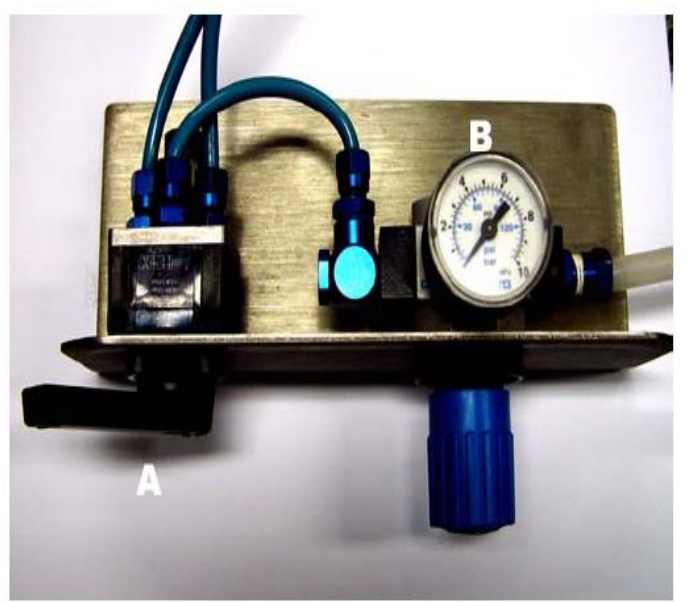

Figura 4.3 - Manivela (A) e Manômetro (B) responsáveis pela aplicação de cargas 
A relação entre pressão e força incidente, levando-se em consideração a área de $4,42 \mathrm{~cm}^{2}$ do pistão é apresentada no Quadro 4.2 que segue:

\begin{tabular}{|c|c|c|}
\hline Pressão/Bar & Força/Newton & Resultante/Quilograma \\
\hline $\mathbf{1 , 0}$ & 44,2 & 4,5 \\
\hline $\mathbf{3 , 0}$ & 130,0 & 13,5 \\
\hline
\end{tabular}

Quadro 4.2 - Relação entre pressão e força para o aparelho utilizado

Câmara de vácuo JB Fast Vac T.M. (JB Industries Inc.)

A câmara de vácuo é um aparelho que permite obter um modelo fotoelástico sem a presença de bolhas. Ela é composta por uma câmara acrílica hermeticamente fechada e uma bomba de vácuo, a fim de que as bolhas de ar da resina fotoelástica em fase de manipulação sejam eliminadas (Figura 4.4).

Os componentes da resina fotoelástica foram misturados e manipulados em um recipiente de Becker com um bastão de vidro e colocados no interior da câmara de vácuo, duas vezes, por pelo menos 20 minutos continuamente, sob pressão atmosférica que inicia em zero e se eleva gradualmente até $750,0 \mathrm{mmHg}$ ou 29,5 pol. $\mathrm{Hg}$, antes de ser vertida no molde. 


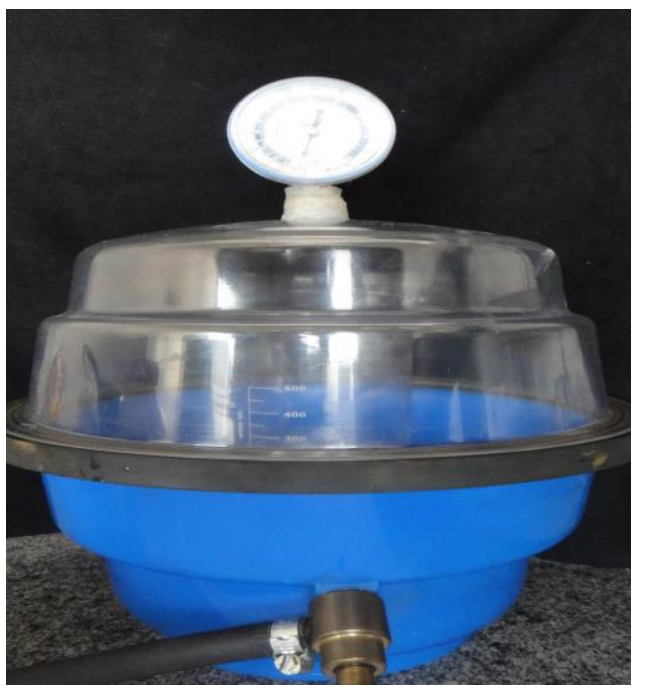

Figura 4.4 - Câmara de vácuo

Máquina Digital Fotográfica Canon 5D Marc 2, lente 24/70mm, F/2.8 (Canon, Japão) Articulador Semiajustável Dentflex (Dentflex Ind e Com Ltda Ribeirão Preto, São Paulo)

Balança Digital modelo 5500 Marte (Marte balanças e aparelhos de precisão Ltda) Espatulador elétrico (VRC Ind e Com Ltda)

Fresadora Microtech (Microtech SNC, Appignano, Itália) (Figura 4.5)

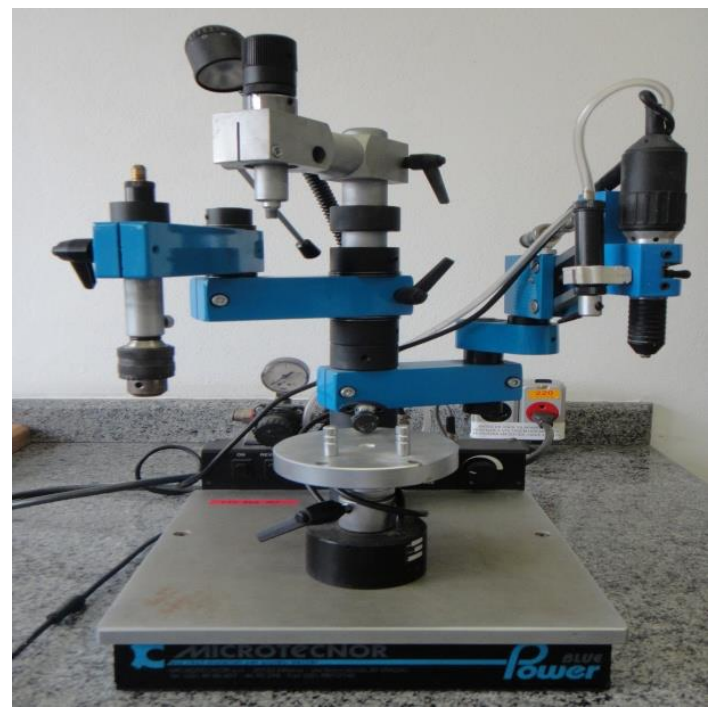

Figura 4.5 - Fresadora Microtech 


\subsection{Método}

Este trabalho experimental e laboratorial utilizou modelos fotoelásticos para análise do gradiente de tensões. Três modelos fotoelásticos, com cinco implantes cada e uma infraestrutura metálica em cobalto/cromo, simulando uma prótese fixa, revestida em resina acrílica termoplástica, constituíram os corpos de prova, cuja confecção será descrita a seguir.

Confecções dos modelos

Crânio fotoelástico

Para a realização desta pesquisa, utilizou-se o crânio fotoelástico feito por Cruz (2004), (Figura 4.6), a partir da qual foi reproduzida a mandíbula, para a confecção dos corpos de prova e posterior realização dos ensaios fotoelásticos.

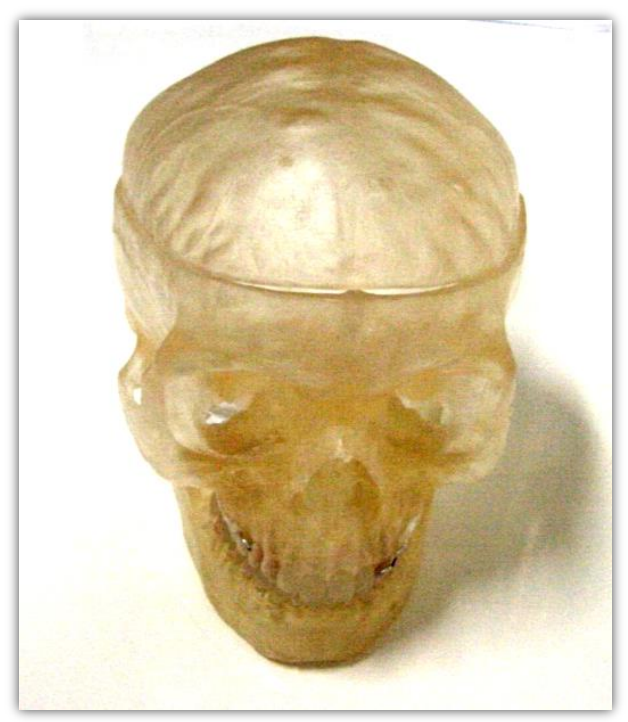

Figura 4.6 - Crânio Fotoelástico 
Mandíbula desdentada

Para a obtenção dos modelos, foi utilizada como referência a disposição dos implantes do sistema para Protocolo Brånemark. As matrizes contiveram cinco implantes, com hexágono interno de diâmetro regular $(3,75 \mathrm{~mm})$ com comprimentos de: $10 \mathrm{~mm}, 13 \mathrm{~mm}$ e $15 \mathrm{~mm}$.

O modelo com cinco implantes respeitou os limites entre os forâmens mentuais.

Os dentes da mandíbula do crânio foram retirados dos alvéolos e estes foram preenchidos com resina epóxi, para se obter uma mandíbula com característica anatômica desdentada (Figura 4.7).

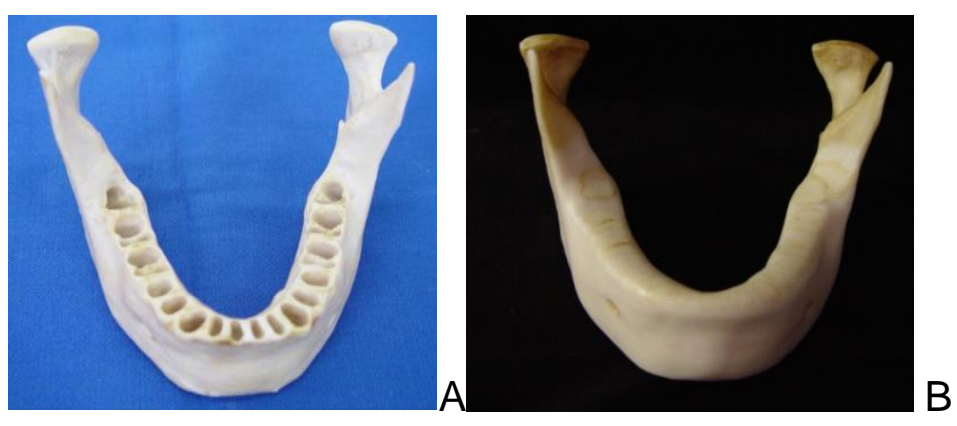

Figura 4.7 - a) Mandíbula desdentada com alvéolos; b) Mandíbula preparada com característica anatômica desdentada

O modelo da mandíbula desdentada em resina epóxi foi colocado dentro de um recipiente e vertido ao seu redor silicone industrial, manipulado de acordo com as recomendações do fabricante (Plastofibras Comercial Ltda). Após 48 horas, o modelo foi retirado do molde.

A partir desse molde a reprodução da mandíbula foi obtida pelo vertimento de resina Novox ${ }^{\circledR}$ (Novox ${ }^{\circledR}$ Base - Polímero alcoólico, Novox ${ }^{\circledR}$ Activador - Mistura de componentes orgânicos), utilizada em prototipagem.

Foi aguardado o tempo de polimerização da resina recomendado pelo fabricante (45 minutos) e a mandíbula retirada do molde. 
Reprodução da maxila do crânio

A maxila do crânio fotoelástico foi reproduzida utilizando-se técnica de transferência direta, com moldeira metálica em alumínio Zanetti ${ }^{{ }^{*}}$, para otimizar a montagem do modelo superior no articulador (Figura 4.8).

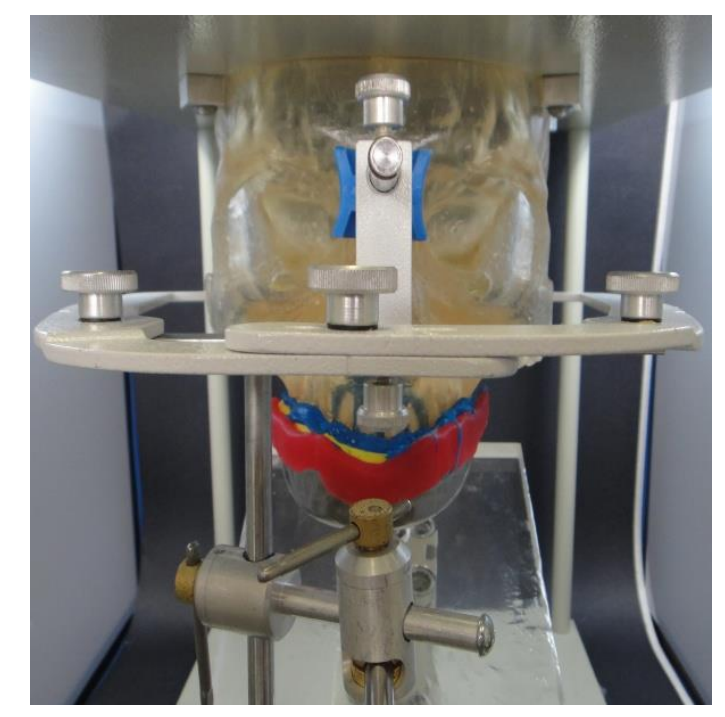

Figura 4.8 - Transferência da maxila para o articulador

Foi selecionado o tamanho da moldeira e esta, individualizada com cera utilidade. Em seguida foi realizada a moldagem com silicone de condensação.

A primeira moldagem foi feita com silicone pesado Optosil ${ }^{\circledR}$ (Heraus Kulzer $^{\circledR}$ Gmbh, Hanau, Alemanha), que foi aliviado internamente e feita a segunda moldagem com silicone leve Xantropen ${ }^{\circledR}$ (Heraus Kulzer ${ }^{\circledR}$ Gmbh, Hanau, Alemanha).

A transferência do modelo superior foi feita pelo arco facial simples, utilizando-se a técnica de transferência direta.

O modelo superior foi fixado no ramo superior do articulador semiajustável previamente ajustado com ângulo de Bennett em 15ำ ângulo de guia condilar em $30^{\circ}$, plataforma incisal em $0^{\circ}$ e a distância intercondilar pequena.

* Kit Zanetti ${ }^{\circledR}$ 
Foi realizado então vertimento do gesso especial tipo IV dentro do molde, com a quantidade suficiente para fixação na plataforma superior.

Utilizou-se o Kit Ribas ${ }^{* *}$, para maior precisão de montagem, que consiste de um anteparo anterior e um apoio abaixo da moldeira (Figura 4.9).

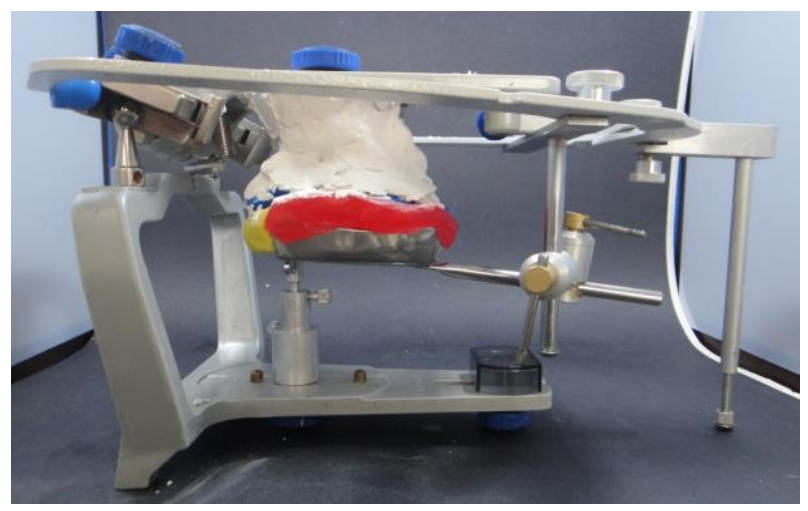

Figura 4.9 - Fixação do modelo da maxila no ramo superior do articulador semi ajustável

Confecção da base de prova com plano de orientação na mandíbula.

Na mandíbula de resina duplicada foi confeccionada base de prova com plano de orientação de cera para que a mandíbula fosse fixada em relação à maxila.

A área basal foi delimitada, de acordo com os princípios estabelecidos por Tamaki (1983) para a confecção da base de prova em resina acrílica ativada quimicamente (Figura 4.10).

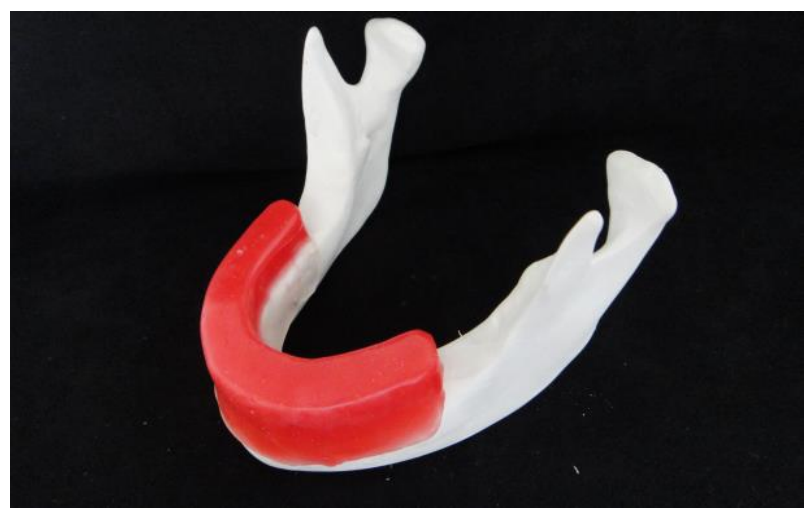

Figura 4.10 - Base de prova com plano de orientação 
Construiu-se sobre a base de prova o plano de orientação em cera 7 , orientada pela posição dos dentes superiores do Crânio Fotoelástico.

Registro da dimensão vertical de oclusão e fixação do modelo inferior

A dimensão vertical de oclusão foi obtida pela mensuração da distância vertical maxilo-mandibular, utilizando-se 0 modelo da mandíbula dentada reproduzida em resina, obtida da mandíbula original do crânio (Figura 4.11).

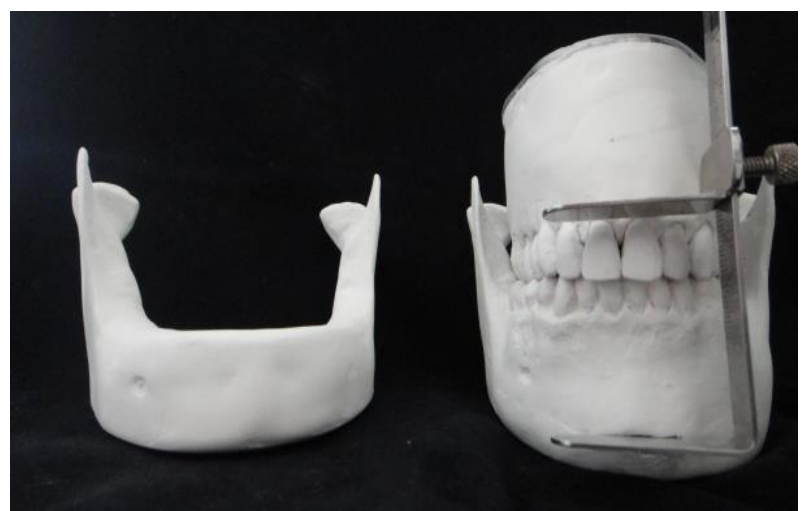

Figura 4.11 - Registro da dimensão vertical

Para essa etapa foi utilizado um compasso de Willis, estabelecendo dois pontos: um na maxila e outro na mandíbula. As duas hastes paralelas com marcação milimetrada na haste principal permitiram a obtenção da distância vertical maxilo-mandibular.

Esses pontos foram transpostos para o registro de dimensão vertical no plano de cera articulado com a maxila (Figura 4.12). 


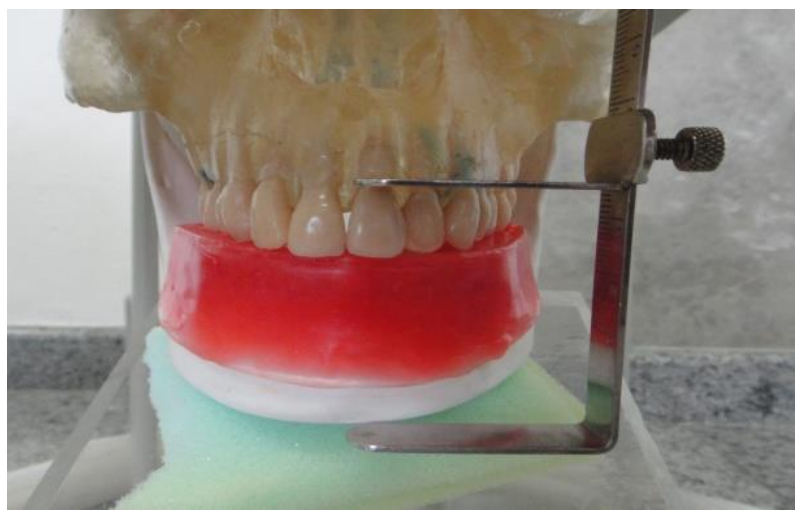

Figura 4.12 -Transposição do registro de dimensão vertical para o plano de cera articulado com a maxila

Obtido o registro maxilo-mandibular, entre o arco superior e a mandíbula reproduzida em gesso, com o plano de orientação, fixou-se a mandíbula no ramo inferior do articulador.

A etapa seguinte consistiu na montagem dos dentes artificiais em acrílico préfabricados da marca Artplus A3 - U36 e U85, obedecendo à posição dos dentes superiores e à Dimensão Vertical previamente estabelecida (Figura 4.13).

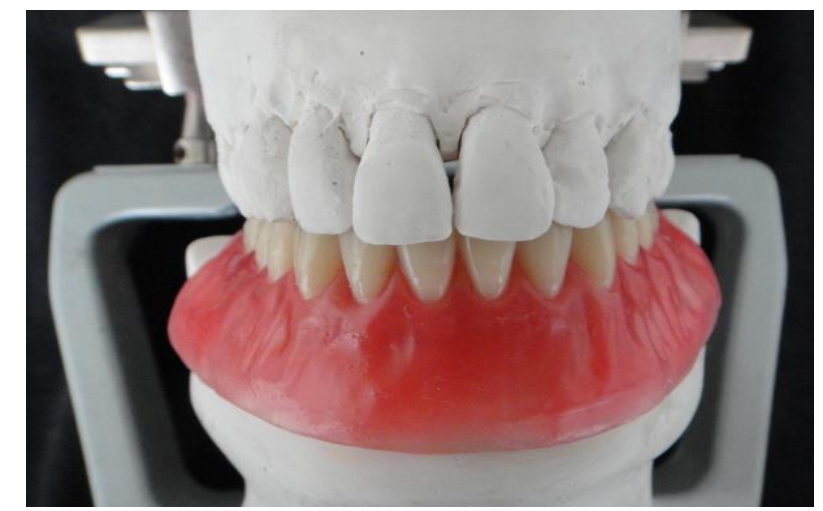

Figura 4.13 - Montagem de dentes inferiores em resina acrílica

A base de prova foi instalada na mandíbula e articulada com a maxila do crânio, sendo feito o ajuste oclusal com carbono tipo acculfilm ${ }^{\circledR}$, interposto entre a maxila e a montagem de dentes no plano de orientação de cera (Figura 4.14), a fim 
de que fosse obtido maior número de contatos simultâneos e bilaterais. Os desgastes foram realizados com brocas de acabamento para resina.

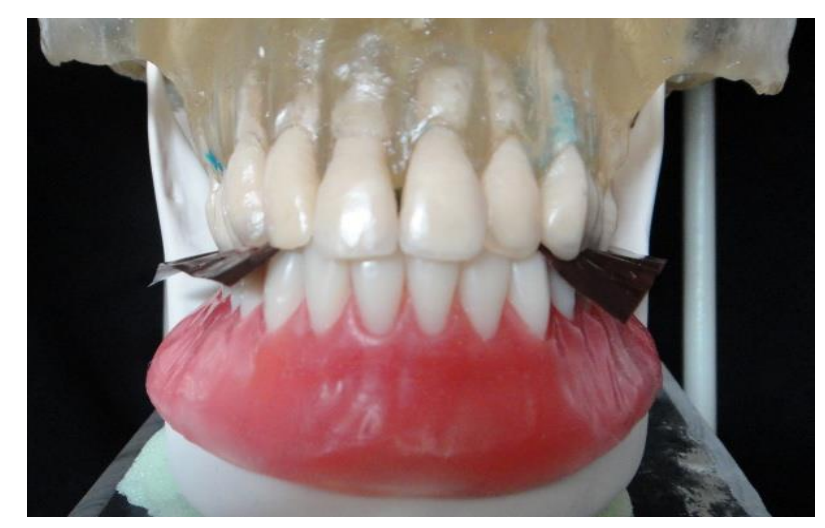

Figura 4.14 - Interposição do carbono accufilm ${ }^{\circledR}$ entre a maxila e plano com montagem de dentes

Confecção da guia cirúrgica

A partir da montagem de dentes, realizou-se a reprodução da montagem com o silicone ZetaLabor (Zermack - Itália) e a obtenção da guia cirúrgica em resina acrílica transparente (Figura 4.15).

$\mathrm{Na}$ guia cirúrgica foram marcados os pontos de eleição para colocação dos implantes, utilizando-se como referência a disposição dos implantes do sistema para protocolo Brånemark.

Por meio da guia cirúrgica foi possível visualizar os limites da área basal e o posicionamento dos dentes em relação aos locais dos implantes, a fim de que fossem respeitados esses limites para futura confecção da infraestrutura metálica. 


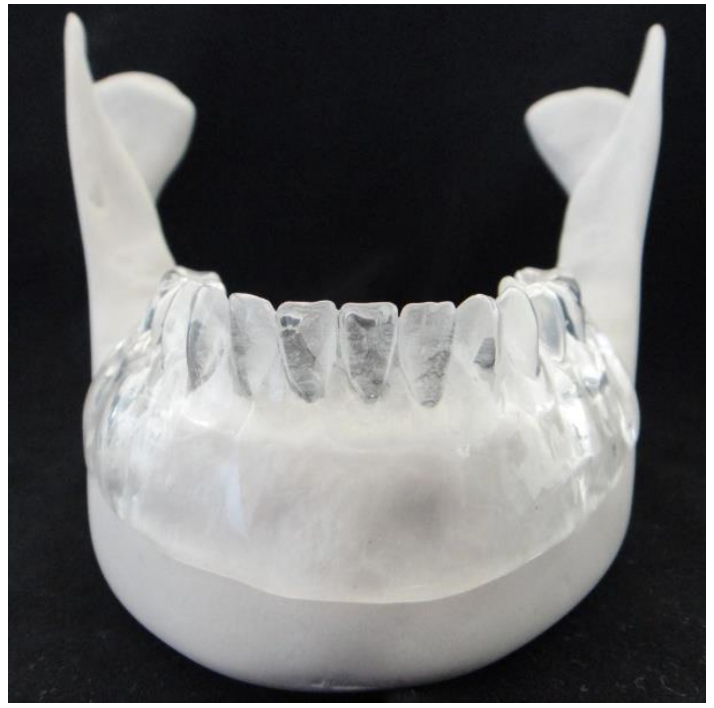

Figura 4.15 - Guia cirúrgica transparente

Perfuração e fixação dos análogos de pilares micro units nos modelos

As perfurações na mandíbula de resina Novox ${ }^{\circledR}$ com a Guia Cirúrgica em posição, foram realizadas com uma fresadora marca Microtech (Microtech SNC, Appignano, Itália) e broca cirúrgica (Conexão Sistemas de Implantes).

A mandíbula foi posicionada na plataforma da fresadora e foram realizadas as marcações dos forâmens mentuais com caneta Pilot ${ }^{\circledR}$ ponta fina de 1,0mm (Figura 4.16). A partir dos forâmens mentuais realizou-se a segunda marcação numa distância de 3,0mm, que corresponde à área distal do implante posterior.

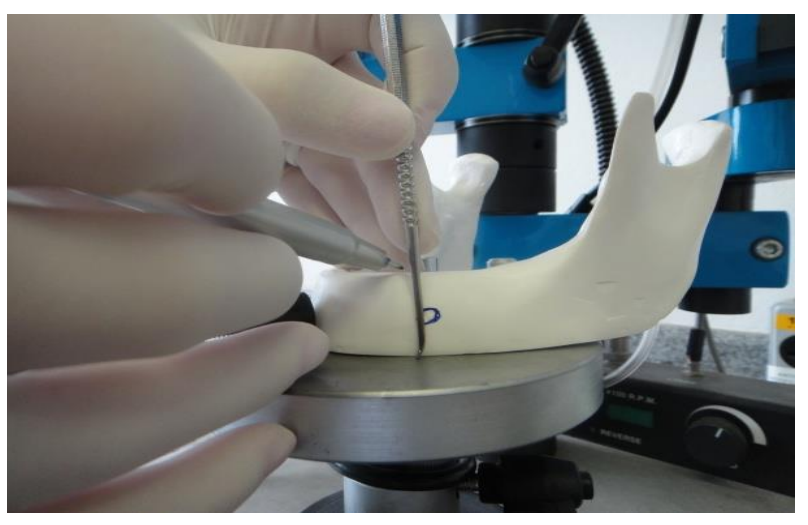

Figura 4.16 - Marcação dos foramens mentuais 
Como o análogo de micro unit possui um diâmetro de 4,6mm, realizou-se a terceira marcação em 2,3mm, a partir da segunda marcação, que corresponderá ao centro do primeiro implante (Figura 4.17).

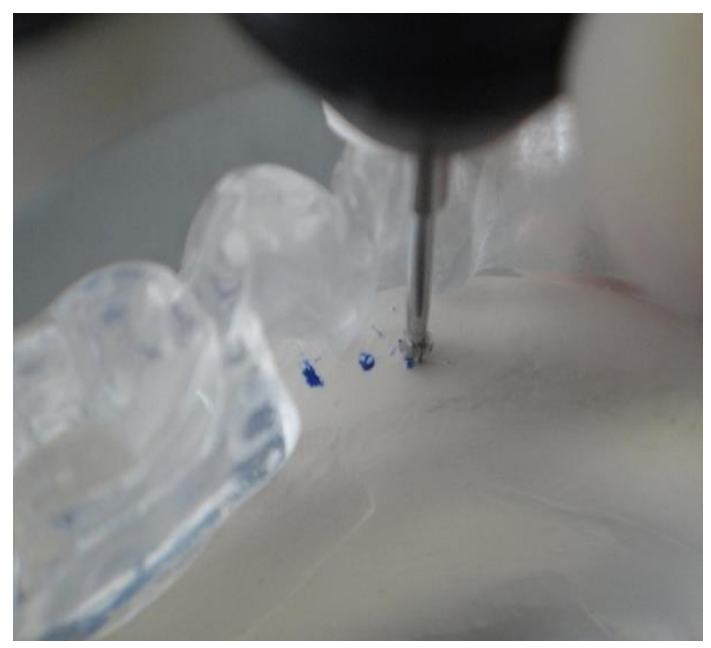

Figura 4.17 - Terceira marcação (centro do implante)

A plataforma onde a mandíbula estava fixada foi movimentada até que fosse estabelecido um correto eixo de inserção dos análogos em relação à mandíbula e o posicionamento dos dentes obtido pela guia cirúrgica. A partir dessa etapa foram efetuadas as perfurações (Figura 4.18).

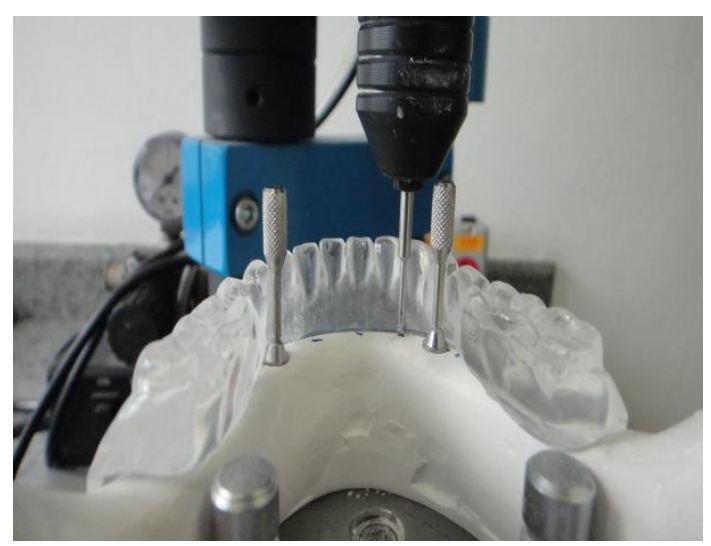

Figura 4.18 - Perfurações sendo executadas 
Em um primeiro momento foi usada uma broca esférica para pontuar o local; em seguida, uma broca número 2 (broca piloto), broca número 3 e broca número 5 . As perfurações foram feitas de tal maneira que ficaram equidistantes. Com auxílio de um paralelômetro, as réplicas de pilares micro units foram posicionadas de forma paralela no sentido mésio-distal e no sentido vestíbulo-lingual, sendo fixados às perfurações com cola à base de cianoacrilato (Super Bonder ${ }^{\circledR}$, Loctite, São Paulo).

Dessa forma, o modelo mestre simulou uma mandíbula desdentada, com cinco análogos de micro unit interforâmens (Figura 4.19).

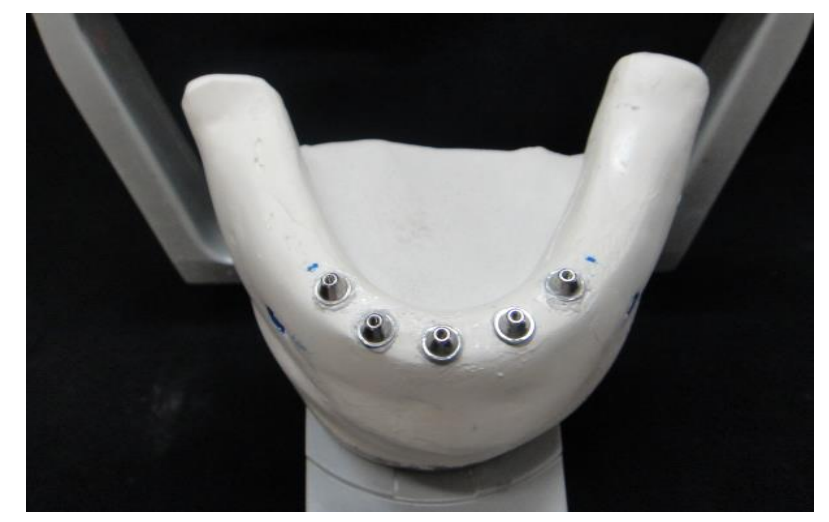

Figura 4.19 - Modelo mestre com os análogos em posição

Confecção da infraestrutura protética

Enceramento da infraestrutura

A mandíbula desdentada em resina com os análogos em posição foi recortada na porção posterior dos côndilos. O plano de orientação com a montagem de dentes foi recolocado e remontado em relação ao arco superior que já estava fixo no ramo superior do articulador. Dessa forma, fixou-se a mandíbula no ramo inferior do articulador, restabelecendo-se, assim, a posição maxilo-mandibular previamente estabelecida. 
Foi feita a remoção da cera e do acrílico na lingual da montagem de diagnóstico para visualização do local e do espaço que recebeu a infraestrutura (Figura 4.20).

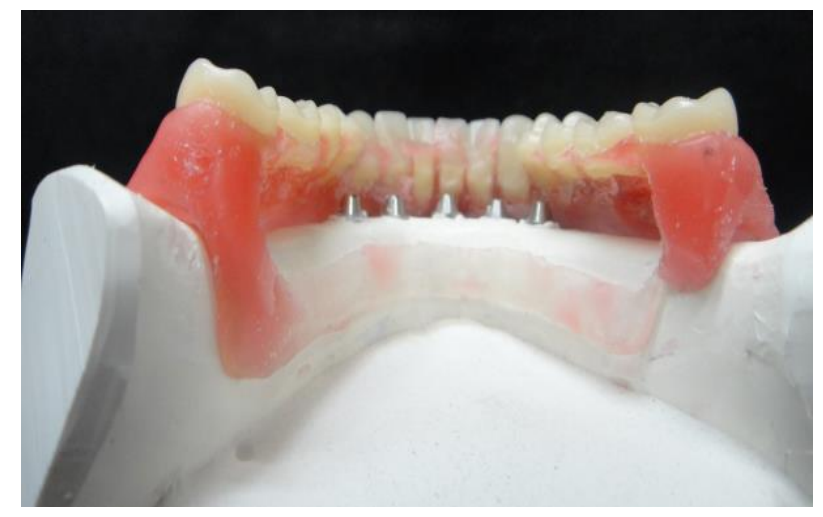

Figura 4.20 - Vista lingual dos análogos de implante em relação à montagem de dentes

Para enceramento da infraestrutura foram utilizados cinco cilindros de plástico pré-fabricados, para pilares micro unit (Conexão Sistema de Prótese - São Paulo Brasil).

Os cilindros foram parafusados aos análogos de micro unit que estavam fixados na mandíbula; os excessos oclusais foram recortados com disco, considerando-se a altura ocluso-gengival dos dentes obtidos na montagem inicial (Figura 4.21).

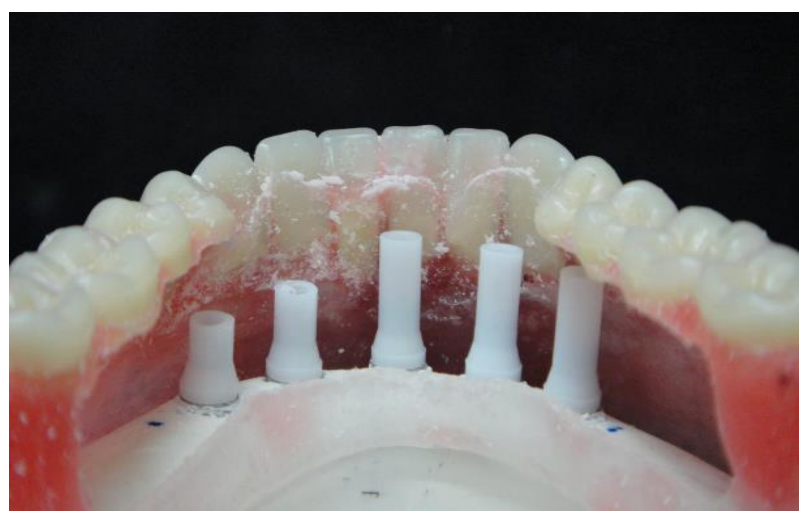

Figura 4.21 - Corte e ajuste dos cilindros plásticos 
Realizou-se o enceramento da infraestrutura, respeitando-se os limites vestíbulo-lingual e ocluso-gengival com uma extensão distal ou cantilever de $15 \mathrm{~mm}$, a partir dos implantes posteriores, de tal forma que o comprimento foi suficiente para apoio oclusal até região dos primeiros molares da maxila (Figura 4.22).

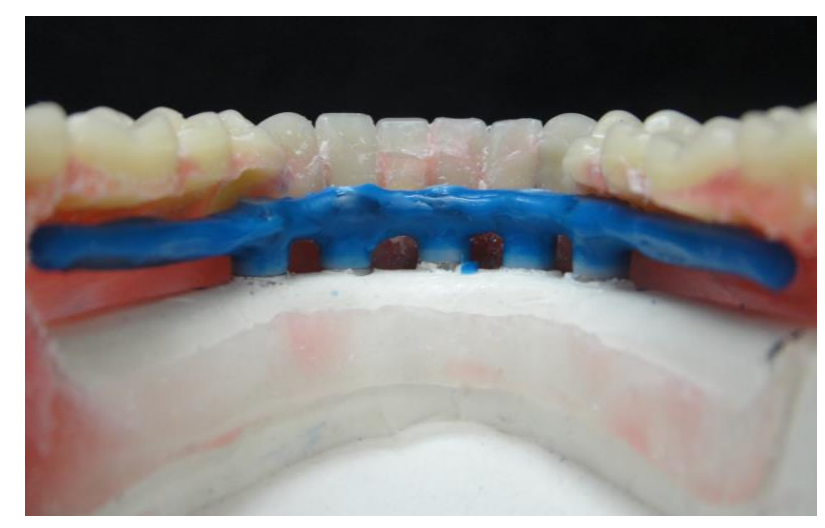

Figura 4.22 - Vista lingual da infraestrutura encerada

Para o enceramento foi utilizada cera azul em esferas Schuler (Shuler Dental Ulm - Alemanha) e cera em fio com secção meia cana (Ind e Com de ceras Babinete). As retenções foram feitas em escama de peixe e posteriormente a peça foi seccionada (Figura 4.23).

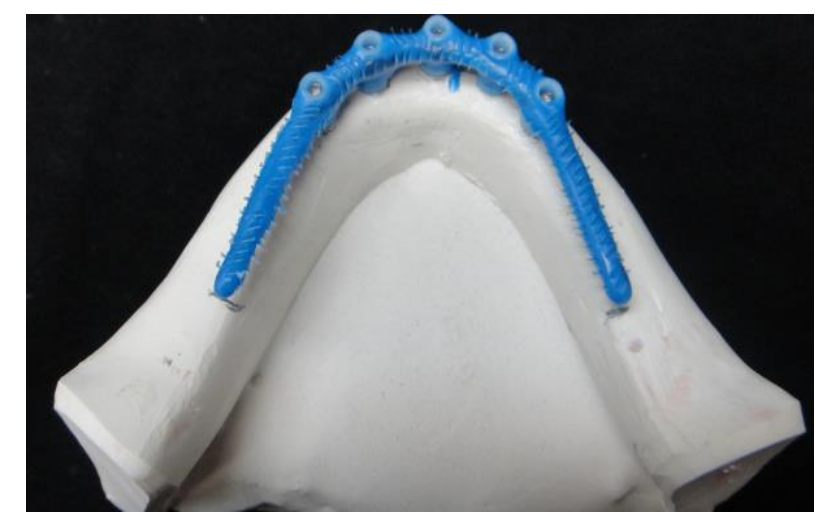

Figura 4.23 - Infraestrutura encerada e com retenções 
Inclusão e fundição

Canais de alimentação pré-fabricados de cera com diâmetro de 3,0mm (Kota Ind e Com Ltda), foram posicionados sobre a superfície dos enceramentos, angulados em 45․ Os padrões de cera foram fixados com cera 7 às bases formadoras de cadinho, pulverizados com spray redutor de tensão de superfície (Kota Ind e Com Ltda) e deixados secando em temperatura ambiente. A infraestrutura encerada foi fixada à base formadora de cadinho (Figura 4.24).

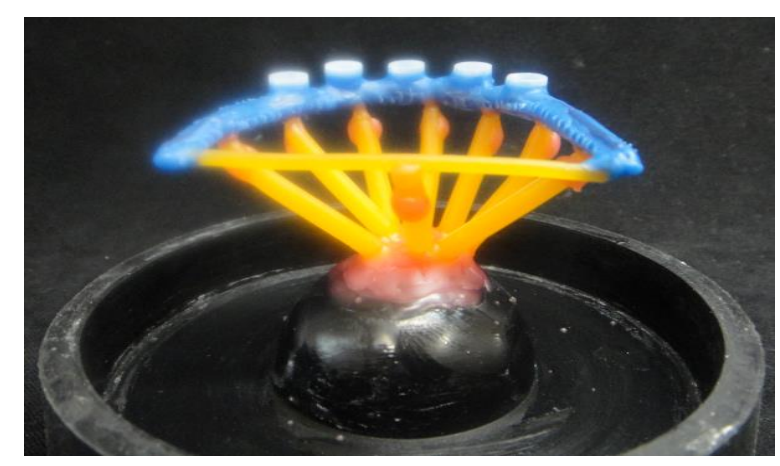

Figura 4.24 - Infraestrutura fixada à base do cadinho

A inclusão foi realizada em uma etapa e a proporção pó/líquido seguiu as normas do fabricante. O revestimento fosfatado usado foi o Gilvest HS (BK Giulinp/ Alemanha), proporcionado com 300 gramas de pó x $85 \mathrm{ml}$ de líquido, espatulado mecanicamente a vácuo por 60 segundos em espatulador elétrico (VRC Ind. e Com Ltda) e o anel foi preenchido sob vibração para evitar formação de bolhas (Figura 4.25). 


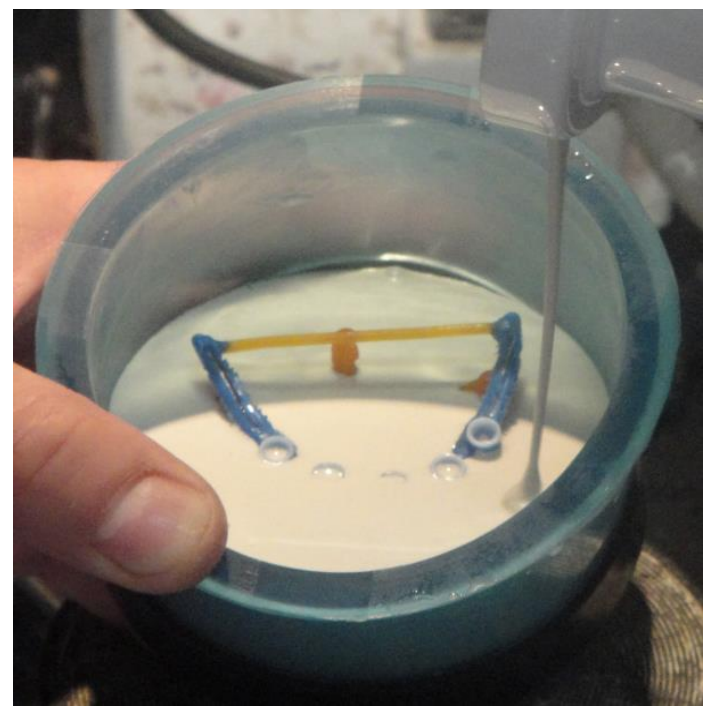

Figura 4.25 - Preenchimento do anel com revestimento

Foi aguardado o início da reação de cristalização do revestimento e, após 60 minutos, eles foram levados ao forno elétrico para expansão do revestimento por 10 minutos. A seguir, o anel foi levado ao forno à temperatura de $200^{\circ} \mathrm{C}$, onde esta foi elevada a $700^{\circ} \mathrm{C}$. Aguardou-se 10 minutos; foi elevada novamente à temperatura de $850^{\circ} \mathrm{C}$; aguardou-se 10 minutos e, finalmente, a temperatura chegou a $950^{\circ} \mathrm{C}$, aguardando-se, nesse momento, 15 minutos para o processo de fundição.

As peças foram fundidas em Cobalto/Cromo - StarloyC (Degudent Dentsply/Germany), compatível com os cilindros pré-fabricados e, conforme recomendação do fabricante, foram utilizadas 4 pastilhas.

Após a fundição, aguardou-se o resfriamento do revestimento por cerca de 1 hora. A infraestrutura (Figura 4.26) foi desincluída e jateada com óxido de alumínio 80 a 110 micras, sob pressão de 90 lib/pol ${ }^{2}$. Os condutos de alimentação foram seccionados com discos de carburundum. 


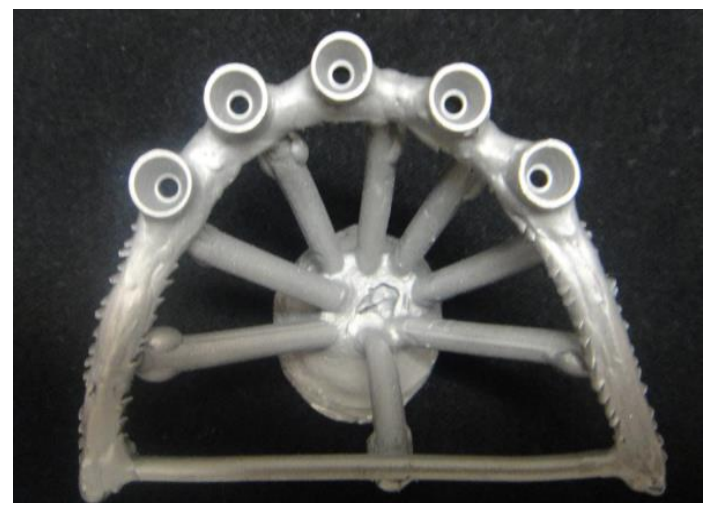

Figura 4.26 - Infraestrutura fundida

Seccionamento e soldagem da infraestrutura

A infraestrutura foi seccionada, parafusada no modelo de resina e unida em resina Durallay ${ }^{\circledR}$ (Duralay Resiliance-MFG Co, Chigago, EUA). Aguardou-se o tempo de presa, a peça foi removida, foi feito acoplamento dos análogos de micro unit e inclusão do conjunto em um recipiente com gesso especial tipo IV (Figura 4.27).

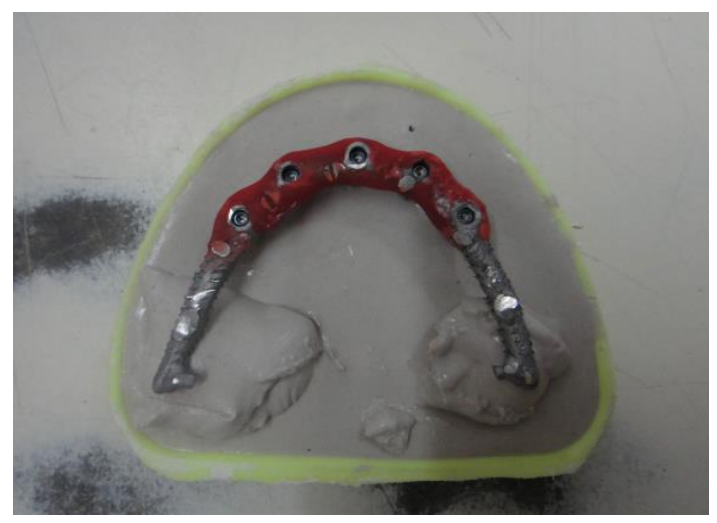

Figura 4.27 - Infraestrutura seccionada, unida em resina Durallay ${ }^{\circledR}$ e indexada em gesso especial tipo IV

Foi aguardado o tempo de presa do gesso e a resina que unia os copings foi removida, para que se efetuasse a soldagem.

Primeiro foi feita uma pré-soldagem com solda elétrica de fio ortodôntico Remanium de $\mathrm{Co} / \mathrm{Cr}$ (Dentorium/ Germany) em três pontos (Figura 4.28), e, em 
seguida, efetuada a soldagem final com solda a maçarico também em Co/Cr (Dentorium/Germany) e com intervalo de fusão entre $1200^{\circ} \mathrm{C}$ e $1315^{\circ} \mathrm{C}$ (Figura 4.29 ).

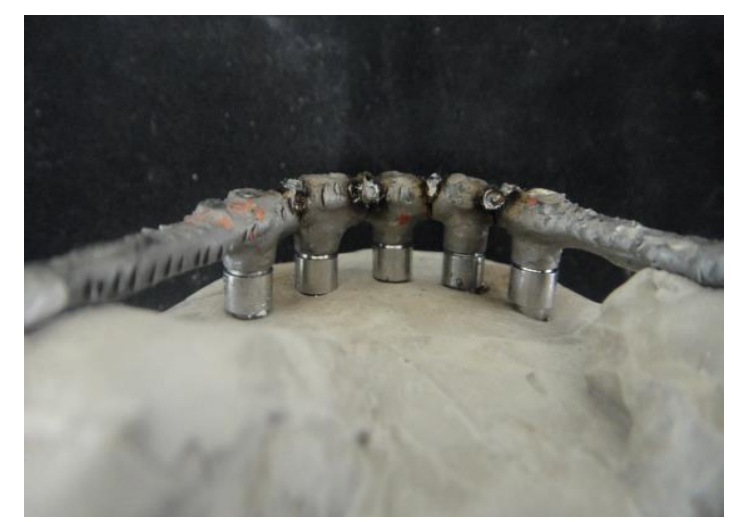

Figura 4.28 - Pré-soldagem elétrica com solda $\mathrm{Co} / \mathrm{Cr}$

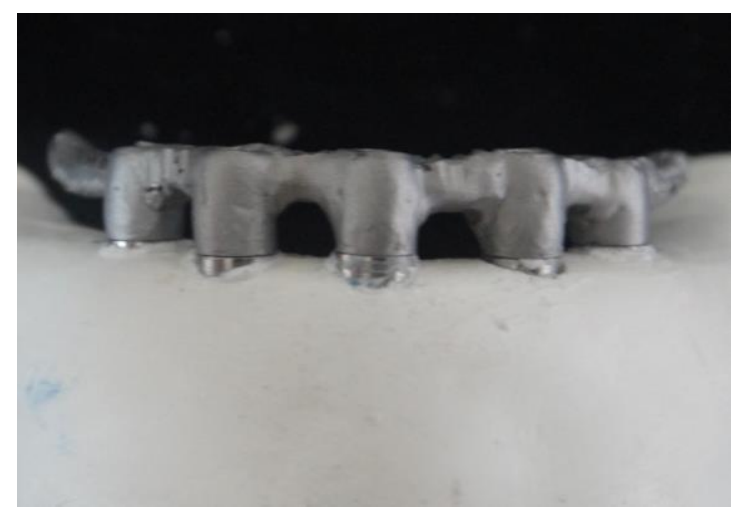

Figura 4.29 - Infraestrutura soldada a maçarico e acoplada nos análogos de micro unit da mandíbula

Transferência da infraestrutura para a mandíbula reproduzida em resina fotoelástica

Uma vez feita a união de solda, a infraestrutura foi novamente parafusada na mandíbula, que estava montada no articulador e unida com resina Durallay ${ }^{\circledR}$ à guia cirúrgica (Figura 4.30). Feita a união de estrutura na guia cirúrgica, transferiu-se a posição dos implantes para a mandíbula reproduzida em resina fotoelástica (Figura 4.31). 


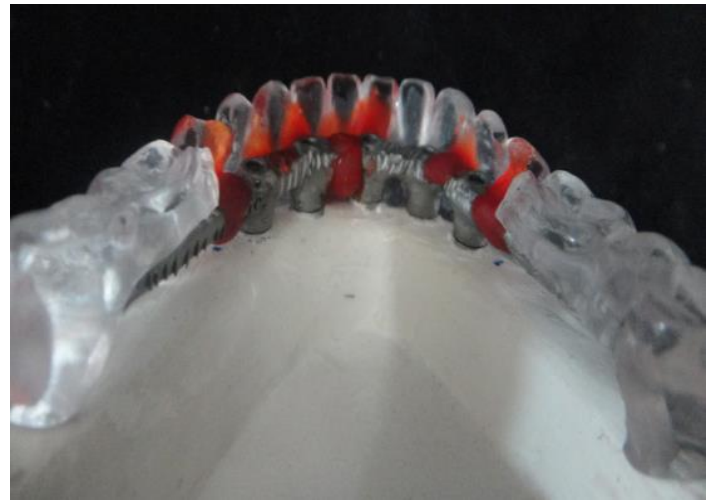

Figura 4.30 - Infraestrutura parafusada na mandíbula montada no articulador e unida à guia cirúrgica com resina

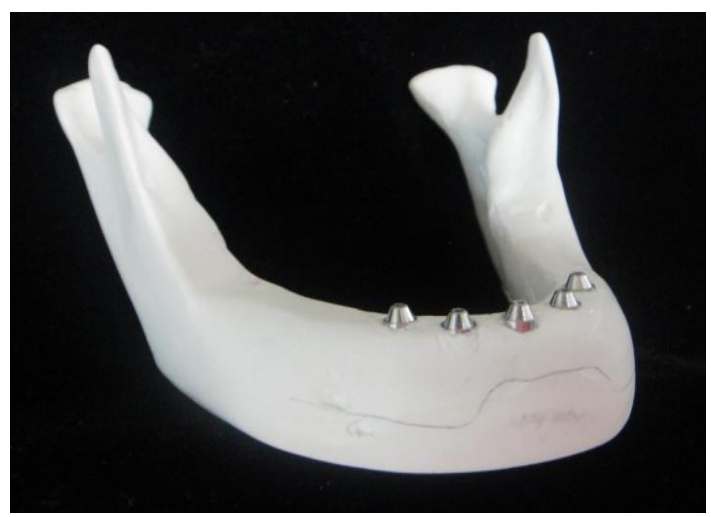

Figura 4.31 - Mandíbula reproduzida em resina com os análogos transferidos em posição

Corte da infraestrutura nas extremidades livres (cantilevers)

Após a transferência para a mandíbula do crânio, foi efetuada a mensuração das extremidades livres da infraestrutura, com o auxílio de um paquímetro (Figura 4.32) e cortada com disco de carburundum, o ajuste dos braços para o comprimento de $15 \mathrm{~mm}$ (Figura 4.33). 


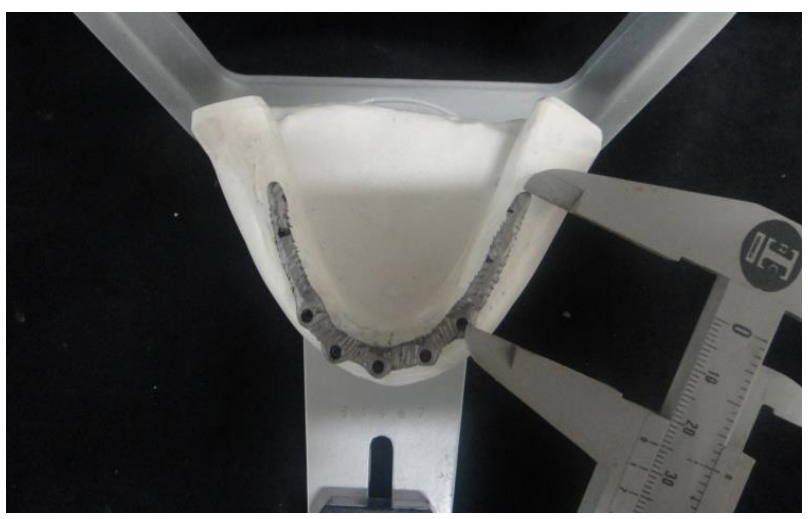

Figura 4.32 - Mensuração da extensão do cantilever em 15mm

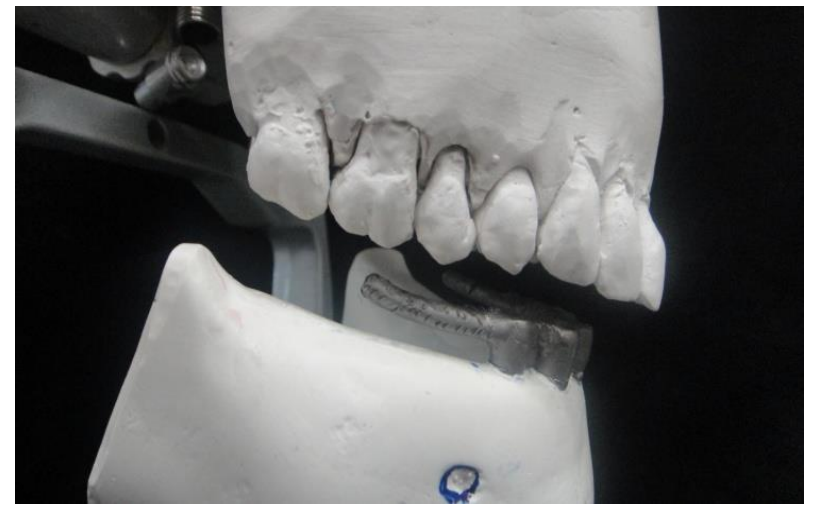

Figura 4.33 - a) Vista do cantilever do lado direito

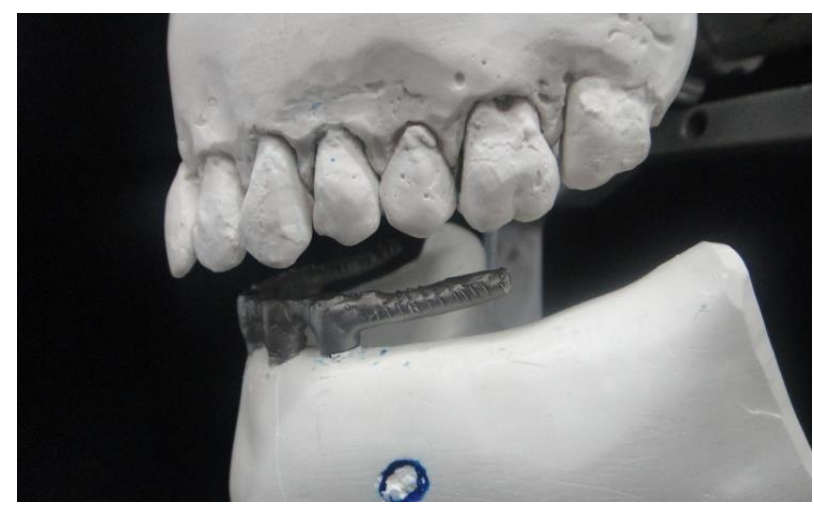

Figura 4.33 - b) Vista do cantilever do lado esquerdo

Aplicação do revestimento estético com resina acrílica sobre a infraestrutura

A peça foi jateada com óxido de alumínio a 110 $\mu$ m e limpa em banho de água destilada dentro de um aparelho de ultrassom durante dois minutos para remover a 
oleosidade. Após a limpeza, a peça não foi mais manipulada com a mão. Foi realizada a secagem da peça com jato de ar.

Nesse momento a infraestrutura já está pronta para receber uma camada de opacificador rosa-claro Vipi-Tone (Vipi Indústria, Comércio, Exportação e Importação de Produtos Odontológicos Ltda, Pirassununga, São Paulo ) (Figura 4.34).

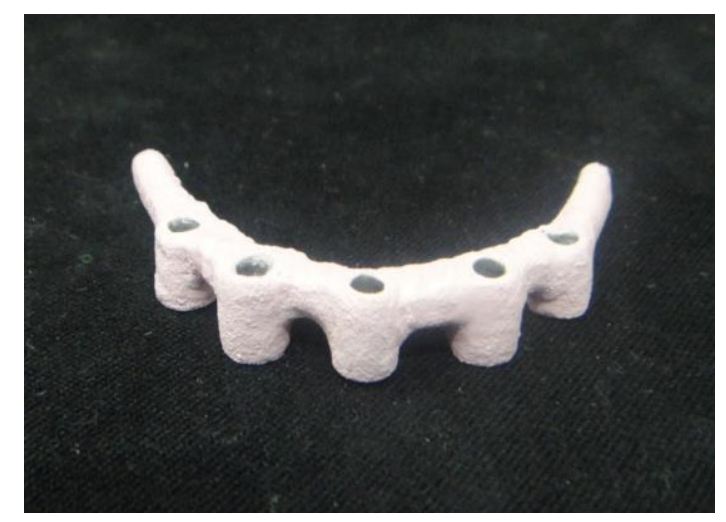

Figura 4.34 - Infraestrutura revestida com opaco rosa

Opacificada a infraestrutura, foi fixada a montagem de dentes sobre ela e feita a acrilização.

A peça protética foi desparafusada do modelo, incluída na mufla com gesso pedra e aguardados 40 minutos de espera. A mufla foi colocada em recipiente com água fervendo durante 5 minutos para que a cera no interior da mufla fosse eliminada.

A mufla foi aberta e colocou-se novamente na água por 1 minuto, para total remoção da cera.

Com a mufla fria foi espatulada a resina Vipi-Cril STG (Vipi Indústria, Comércio, Exportação e Importação de Produtos Odontológicos Ltda, Pirassununga, São Paulo), cor rosa-médio, roxa e vermelha; foi vertida durante a fase "teia de aranha". A mufla foi fechada e levada para prensagem com 0,5 quilograma por 30 minutos e elevada a força para 1,250 quilogramas, onde foi estabilizada nessa força e mantida por 12 horas. Para a cocção a mufla foi levada para um recipiente com água com 4 centímetros acima da mufla, a uma temperatura de $70^{\circ} \mathrm{C}$; em seguida 0 fogo foi desligado e a mufla foi deixada imersa durante 30 minutos. 
Foi elevada a temperatura no recipiente até a fervura da água, deixada por 1 hora e resfriada naturalmente.

Após essa etapa foi realizada a desinclusão, quando a mufla foi aberta e a prótese foi articulada com o modelo superior, feito o ajuste oclusal e em seguida a etapa final de acabamento e polimento.

Para o acabamento foram utilizadas brocas de resina maxicut e minicut, borrachas de acabamento e lixas d'água. Para o polimento foi utilizada pedra pomes com escova número 10 e, posteriormente, roda de algodão seca (Figura 4.35).

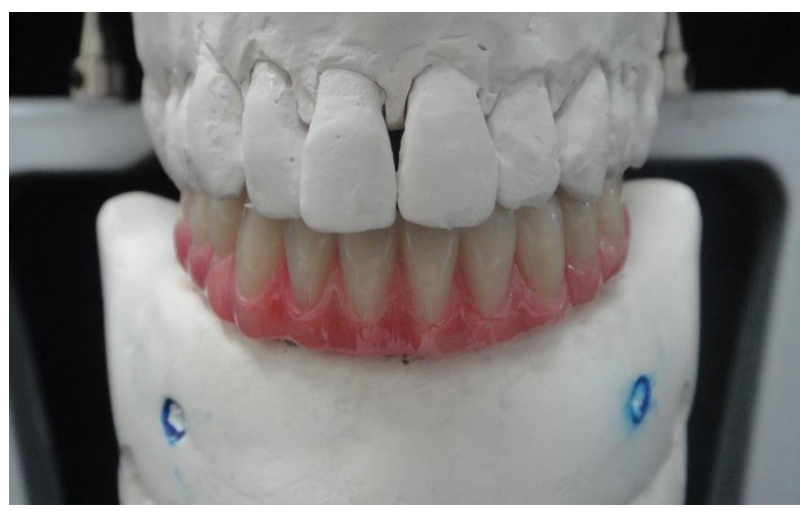

Figura 4.35 - Prótese tipo protocolo metalo-plástica finalizada e articulada com o modelo da maxila

\section{Ajuste oclusal}

A infraestrutura revestida foi acoplada na mandíbula duplicada em resina e feito o ajuste oclusal da prótese parafusada na mandíbula com carbono tipo accufilm $^{\circledR}$ (Parkell- NY-USA), brocas diamantadas de desgaste de resina, buscando o maior número de contatos, simultâneos e bilaterais com a maxila do crânio fotoelástico. 
Obtenção do modelo fotoelástico

Obtenção do molde de silicone

A moldagem de transferência foi realizada sobre o modelo de resina com os análogos de micro units e a infraestrutura revestida com dentes e resina acrílica, parafusada com parafusos longos de $15 \mathrm{~mm}$ de laboratório (Conexão). Os parafusos foram protegidos com bastões de cera a fim de que o espaço ocupado pela cera fosse o suficiente para 0 acesso posterior da chave para retirar os parafusos. $O$ conjunto, mandíbula de resina, análogos de micro unit e infraestrutura revestida, foi colocado dentro de uma forma de cartolina, que contorna a mandíbula com o conjunto e fixado à base, com auxílio de cola à base de cianoacrilato (Figura 4.36).

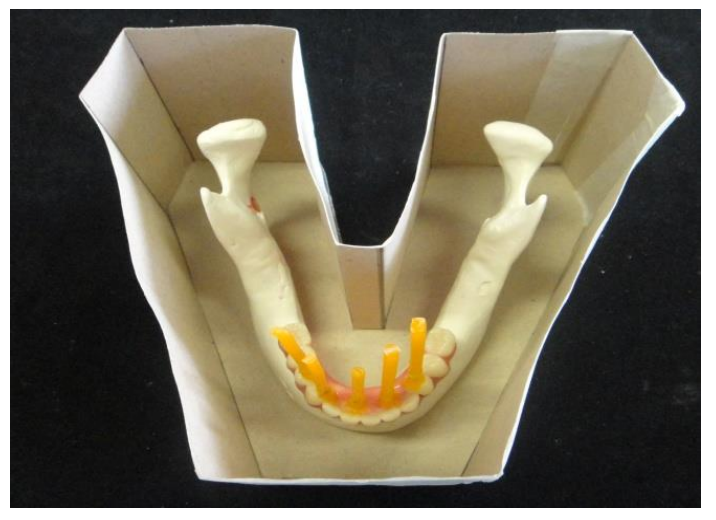

Figura 4.36 - Mandíbula com a prótese parafusada no interior do recipiente que recebeu o silicone de reprodução

Foi realizada a duplicação com o silicone de reprodução Dow Corning ${ }^{\oplus}$ (D’Altomare química - São Paulo). O material foi manipulado de acordo com as recomendações do fabricante, inserido no interior da forma e vertido ao redor da prótese (Figura 4.37). 


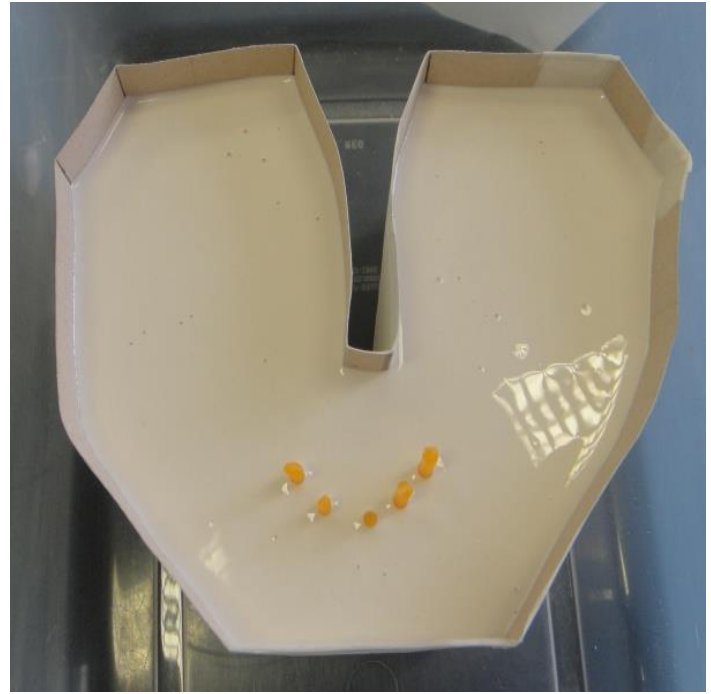

Figura 4.37 - Silicone de reprodução vertido sobre o conjunto, mandíbula e prótese

Após a polimerização, os parafusos foram desparafusados pela parte superior, permanecendo a prótese fixa no molde. Assim, cinco pilares micro unit com cinta de $1 \mathrm{~mm}$ foram parafusados sobre 5 implantes tipo hexágono interno com plataforma de $3,75 \times 10 \mathrm{~mm}$ de comprimento (Conect $A R^{\circledR}$, Conexão Sistemas de Prótese - São Paulo - Brasil) e torqueados com auxílio de um torquímetro de 20N (Conexão Sistemas de Prótese - São Paulo - Brasil). Em seguida, os conjuntos implantes/pilares foram posicionados nos cilindros da prótese e fixados com os parafusos de fixação (Figura 4.38).

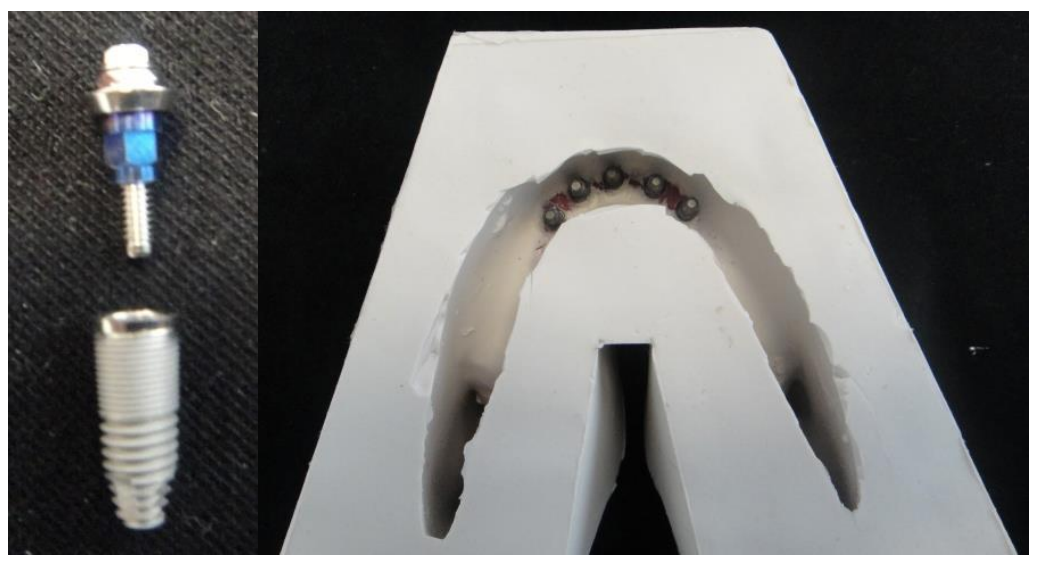

Figura 4.38 - Conjunto pilar micro unit/implante 3,75 de diâmetro por $10 \mathrm{~mm}$ de comprimento do tipo hexágono interno acoplados e parafusados no cilindro da prótese 
Para confecção do modelo fotoelástico utilizou-se resina fotoelástica Araldite ${ }^{\circledR}$ GY279BR (Araltec Produtos Químicos Ltda. - Hunstman - Guarulhos - São Paulo) modificada com diluído reativo, de baixa a média viscosidade, formulada à base de bisfenol A e o endurecedor Aradur HY2963BR (Araltec Produtos Químicos Ltda. Hunstman - Guarulhos - São Paulo) modificado, à base de amina ciclolifática, de baixa viscosidade. A cura dessa mistura ocorre à temperatura ambiente, e deverá ser armazenada de 18 a $25^{\circ} \mathrm{C}$.

A resina foi acondicionada num recipiente de Becker e manipulada de forma manual com auxílio de um bastão de vidro. O recipiente Becker foi levado ao interior de uma câmara acrílica hermeticamente fechada, acoplada à bomba de vácuo e um manômetro, para a eliminação de bolhas de ar incorporadas durante a mistura e manipulação dos componentes da resina fotoelástica.

A resina fotoelástica foi colocada lentamente no interior do molde, levado novamente à câmara de vácuo (Figura 4.39), a fim de eliminar as possíveis bolhas que pudessem ter sido incluídas. O molde foi recoberto com filme de PVC para proteção de sua superfície contra a deposição de impurezas durante a polimerização da resina.

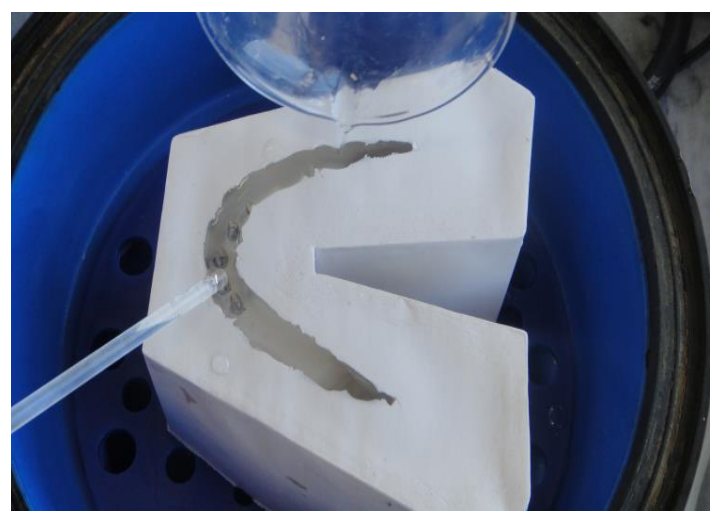

Figura 4.39 - Resina fotoelástica sendo vertida lentamente no interior do molde, dentro da câmara de vácuo

Após a completa polimerização da resina, que correspondeu a 72 horas, tempo recomendado pelo fabricante, foi feita a separação dos modelos. Os parafusos fixadores da prótese foram soltos e o modelo foi removido do molde. $O$ 
acabamento do modelo e sua base foram realizados com lixa d'água de granulação fina (1500 e 2000 - Norton - São Paulo), para que o modelo assentasse perfeitamente na plataforma da base do aparelho de aplicação de cargas. O acabamento foi feito com bastante cuidado a fim de evitar indução de tensões no modelo. Assim, o modelo fotoelástico com implantes tipo hexágono interno $3,75 \mathrm{~mm}$ de diâmetro x 10mm de comprimento (MD 10) foi obtido (Figura 4.40).

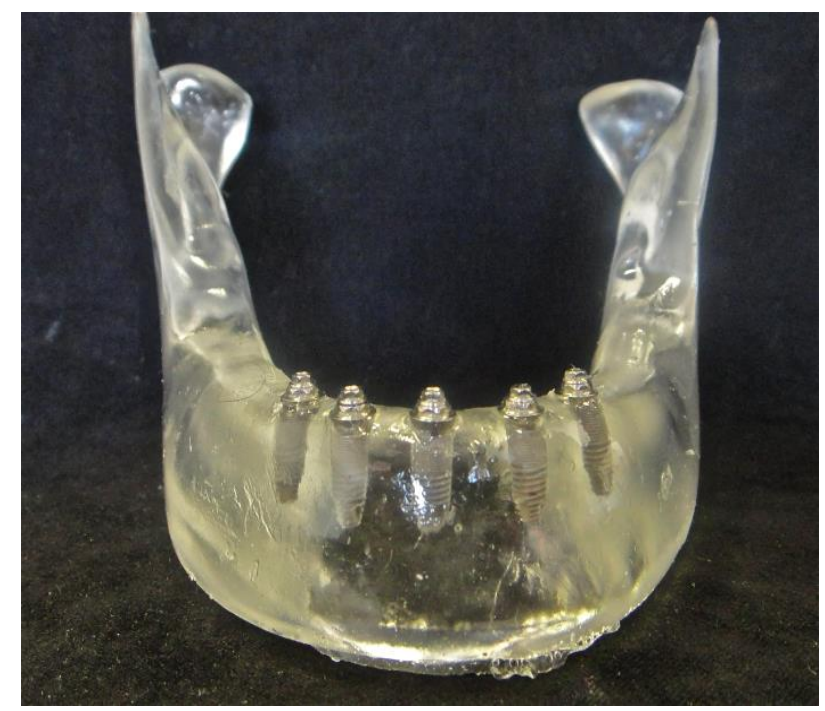

Figura 4.40 - Mandíbula fotoelástica com implantes de 10mm (MD 10)

O mesmo processo se repetiu rigorosamente igual com a fixação da prótese em micro units com cinta de $1 \mathrm{~mm}$ em implantes tipo hexágono interno de diâmetro $3,75 \times 13,0 \mathrm{~mm}$ de comprimento (MD 13) (Figura 4.41) e 15mm de comprimento (MD 15) (Figura 4.42), de tal forma que foram obtidos 3 modelos fotoelásticos, onde variou-se apenas o comprimento dos implantes. 


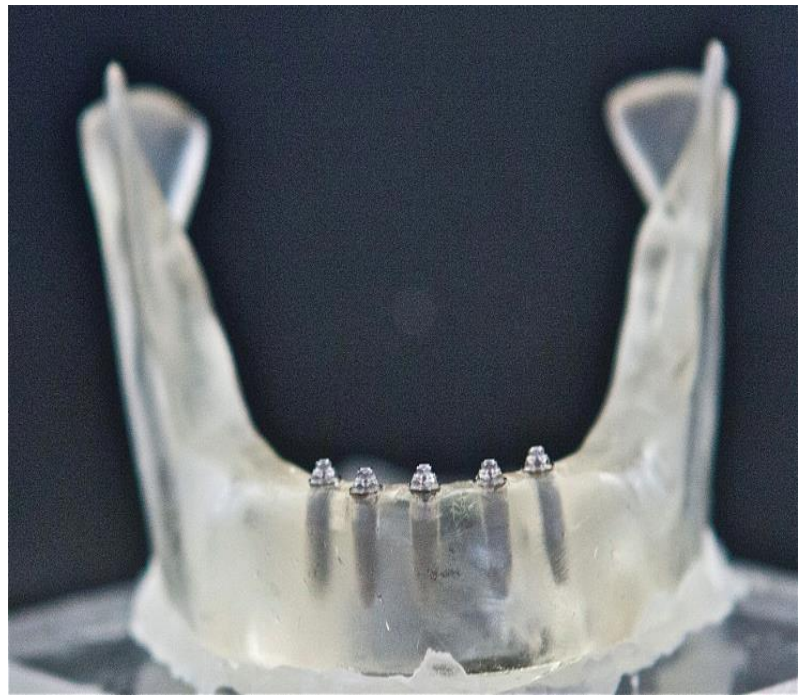

Figura 4.41 - Mandíbula fotoelástica com implantes de 13mm (MD 13)

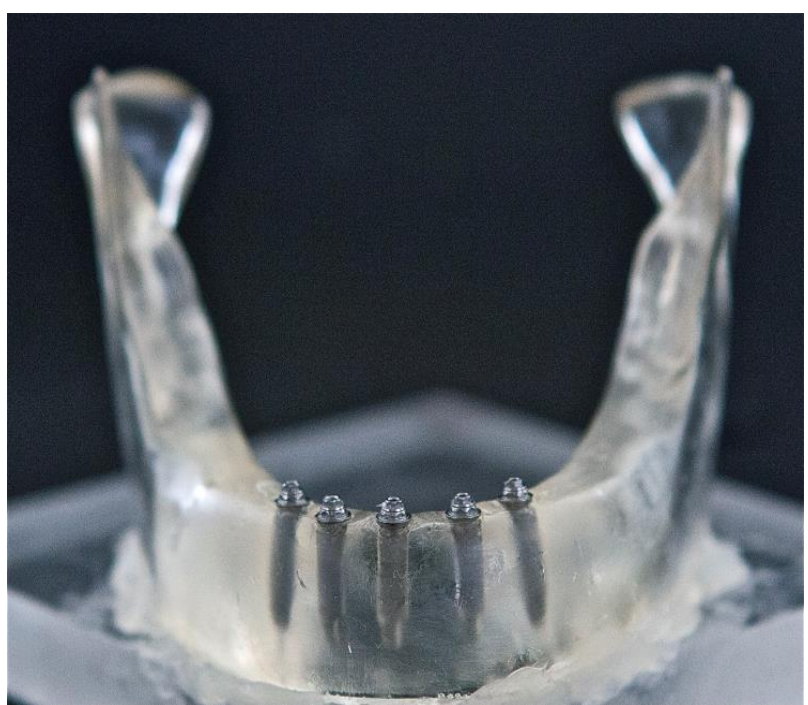

Figura 4.42 - Mandíbula fotoelástica com implantes de 15mm (MD 15)

Ajuste oclusal

A infraestrutura revestida foi acoplada nas 3 mandíbulas duplicadas em resina fotoelástica. Antes da aplicação de carga foi realizado novo ajuste oclusal com carbono tipo accufilm ${ }^{\circledR}$ (Parkell- NY-USA), brocas diamantadas de desgaste de 
resina da prótese parafusada na mandíbula articulada com a maxila do crânio fotoelástico, buscando-se o maior número de contatos simultâneos e bilaterais.

Metodologia para aplicação de cargas

O carregamento sobre os corpos de prova foi realizado pelo aparelho de aplicação de pressão, descrito anteriormente nesse mesmo capítulo. Foi transmitida a pressão de 1,0 e 3,0 bars.

Análise fotoelástica

Ajustada a oclusão, iniciou-se o procedimento da análise fotoelástica para se avaliar o comportamento das tensões, bem como registrá-las fotograficamente.

Foram realizadas tomadas fotográficas dos modelos fotoelásticos em vista frontal, para análise dos resultados, antes da aplicação de pressão, nos três modelos que compõem as variáveis em comprimento, independente da sobreposição de imagens que poderiam ocorrer nesse momento.

Para uma facilidade didática de interpretação, os implantes foram numerados da esquerda para a direita da fotografia, do número 1 ao 5 as áreas de maior concentração de franjas de tensão foram apontadas por setas.

O primeiro ensaio foi realizado com o corpo de prova denominado Modelo 10 , que compreende 5 implantes tipo hexágono interno, colocados na mandíbula, na região intraforaminal, com o comprimento de $10 \mathrm{~mm}$. 


\title{
5 RESULTADOS
}

Os resultados foram obtidos pela avaliação das tensões resultantes da aplicação de pressões sobre os corpos de prova, compostos pelos modelos fotoelásticos e próteses tipo protocolo metalo-plásticas, parafusadas em 5 implantes do tipo hexágono interno, de $3,75 \mathrm{~mm}$ de diâmetro, em máxima intercuspidação, nas condições de carregamento de 1,0 e 3,0 bars, levando-se em consideração as tensões presentes inicialmente nos modelos.

Os corpos de prova foram denominados:

\author{
Modelo 10: MD 10 \\ Modelo 13: MD 13 \\ Modelo 15: MD 15
}

As imagens apresentadas no corpo da mandíbula, sem aplicação de pressão, são áreas coloridas sugestivas de tensão, decorrente da manipulação e homogeneização dos componentes da resina fotoelástica, da confecção do corpo de prova, ajuste da prótese à maxila do crânio, bem como também da fixação à base de acrílico do aparelho de aplicação de pressão.

No modelo 10, diante da ausência de aplicação de pressão (Figura 5.1), os implantes 1 e 2 mostraram-se livres de tensão. $O$ implante 3 (central) apresentou colorações fotoelásticas no ápice, com um alo claro no ápice mais concentrado do lado esquerdo. Nos implantes 4 e 5 não foi notada também presença de tensão. 


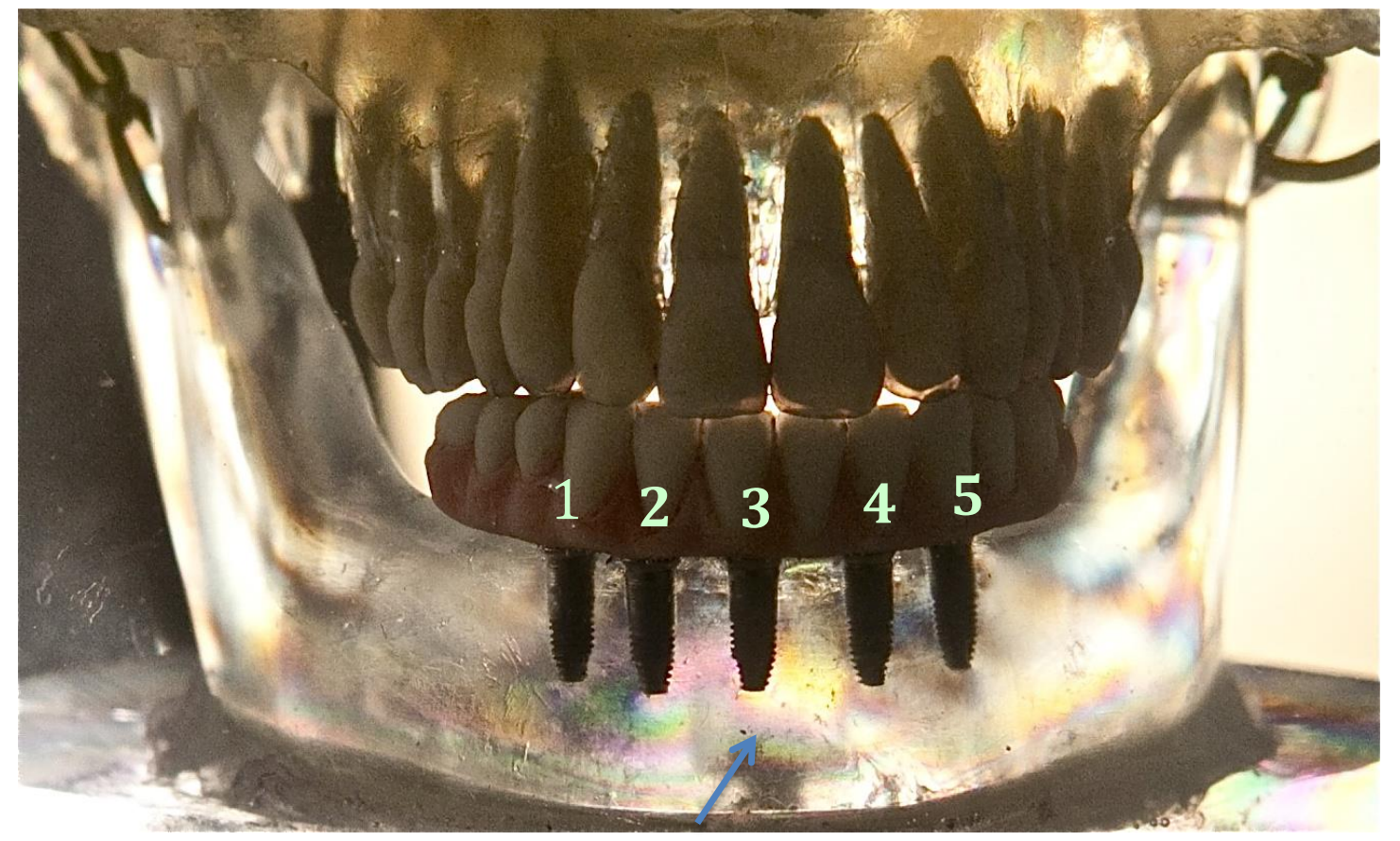

Figura 5.1 - Modelo 10 sem aplicação de pressão, apresentando colorações fotoelásticas em algumas regiões delimitadas

No modelo 10, com carregamento de 1,0 bar (Figura 5.2), o implante 1 sofreu uma alteração de coloração na distal, na mesial, na região do colo e na apical, mostrando assim uma diferença de comportamento. No implante 2, no ápice nota-se uma alteração de cor, indicativa de tensão e entre o implante 2 e 3 nota-se também maior tensão.

O implante 3 apresentou um aumento na intensidade das tensões na áreas analisadas anteriormente (lado direito), proporcionais à pressão aplicada, a coloração amarelada passou para um tom de rosa e não houve alteração na região. No implante 4 houve alteração de coloração ao seu redor, sua cor passou a ficar mais amarelada, com redução de cores rosas, apresentando a distal esverdeada.

No implante 5, na região do ápice, sua coloração ficou levemente mais clara, sugerindo alguma tensão. 


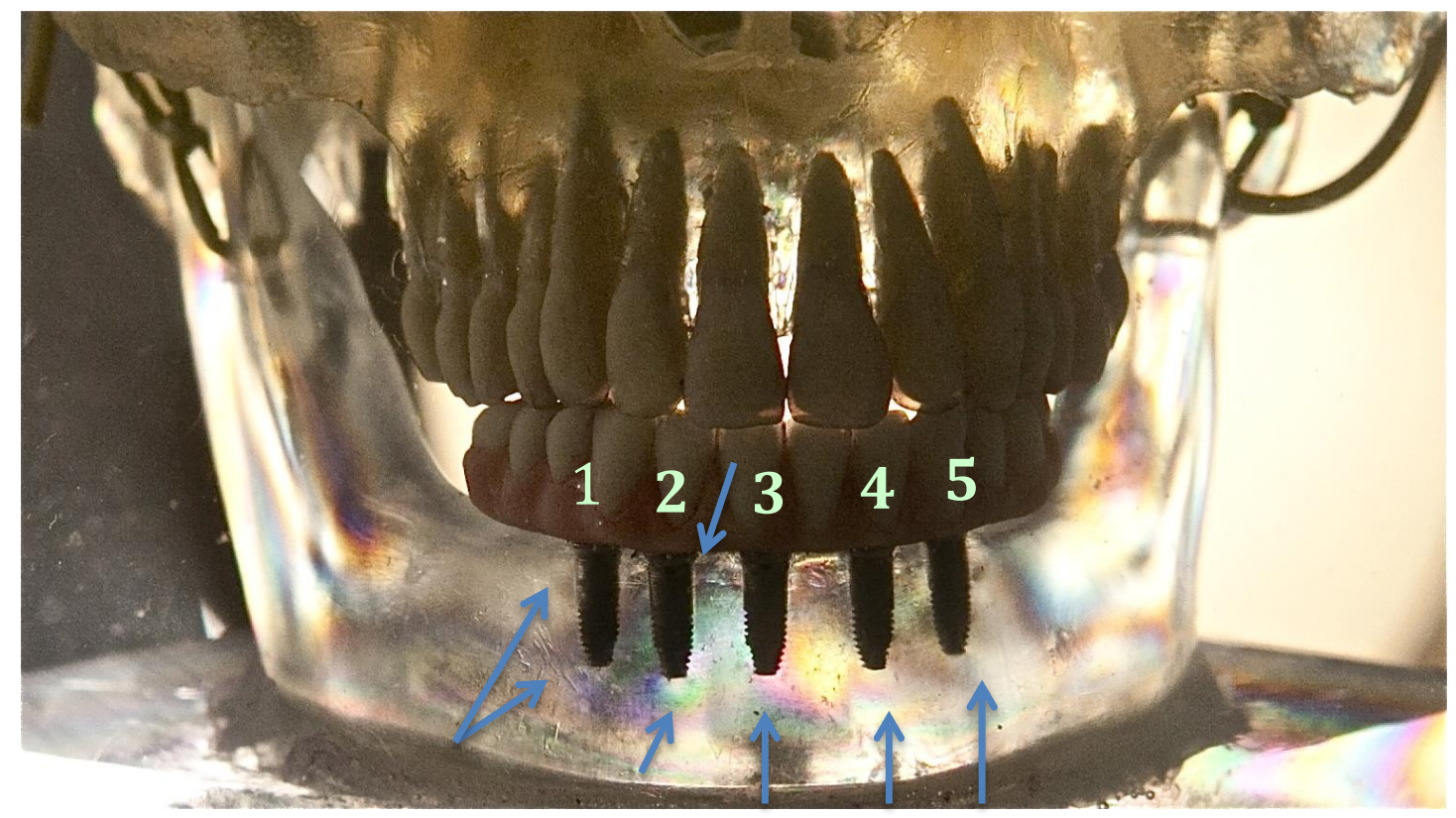

Figura 5.2 - Modelo 10 com aplicação de pressão de 1 bar

Em carregamento de 3,0 bars, o modelo 10 (Figura 5.3) mostrou que houve um aumento na intensidade das tensões, proporcional à pressão aplicada, e houve delimitação de franjas bem intensas ao redor do implante central e dos implantes distais bilaterais.

No implante 1, nota-se colorações fotoelásticas ao redor do ápice. Entre os implantes 2 e 3, 3 e 4, nota-se tensões na região cervical.

No implante 4, observamos maiores tensões no terço médio, região distal e na região apical. Essa diferença é bem marcante quando comparada com as imagens de pressão 0 e pressão 1 bar.

No implante 5, houve um maior aumento de franjas, mais acentuado no seu terço médio, até seu ápice, tanto na mesial, quanto na distal e ao redor de seu ápice.

A mandíbula mostra, muito bem, maior acúmulo de tensões no seu corpo, em direção ao ramo ascendente. 


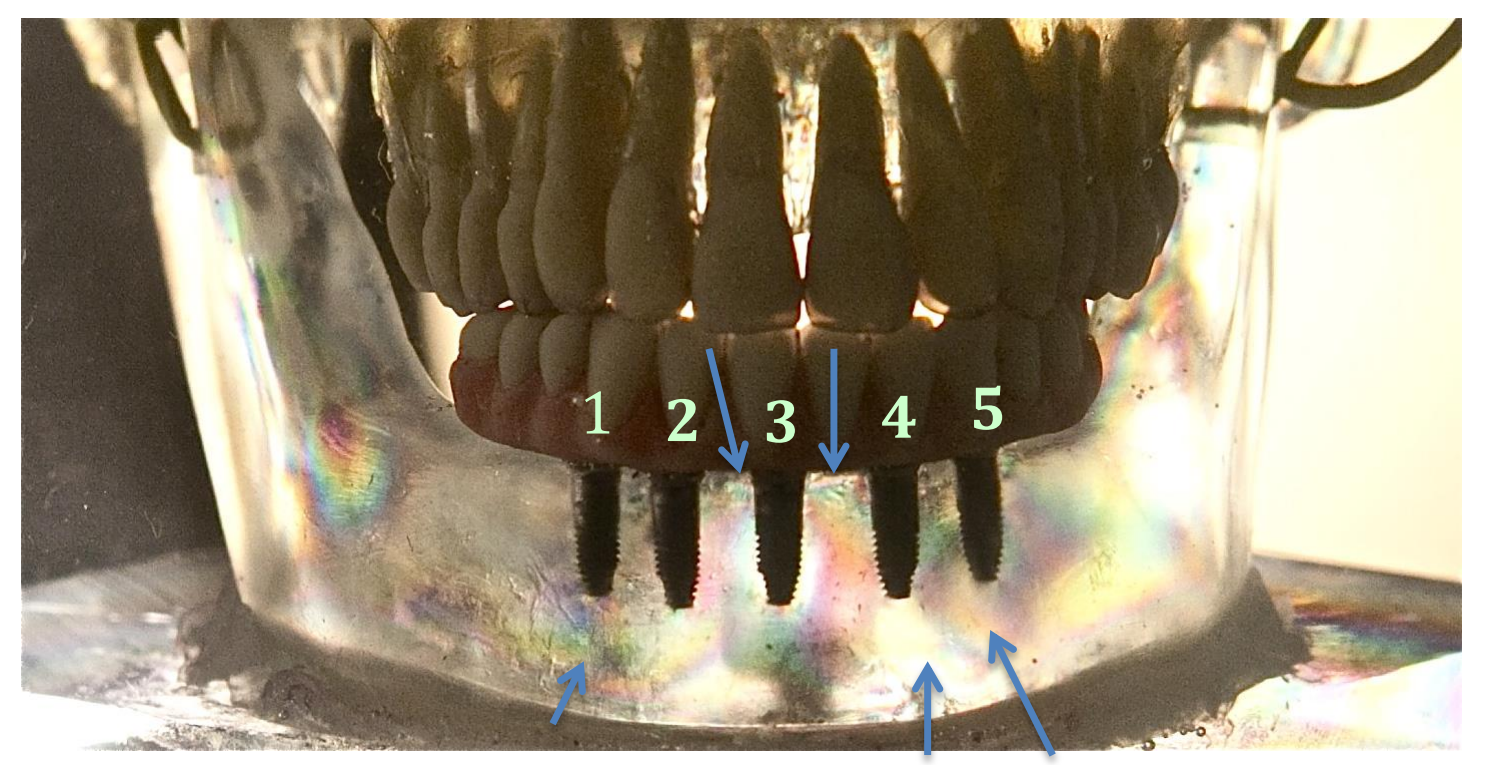

Figura 5.3 - Modelo 10 com aplicação de pressão de 3 bars

No carregamento com pressão de 3 bars foram realizadas tomadas fotográficas em vista lateral esquerda e direita. No lado esquerdo (Figura 5.4), podese observar grande concentração de tensões no implante mais distal, e no implante central.

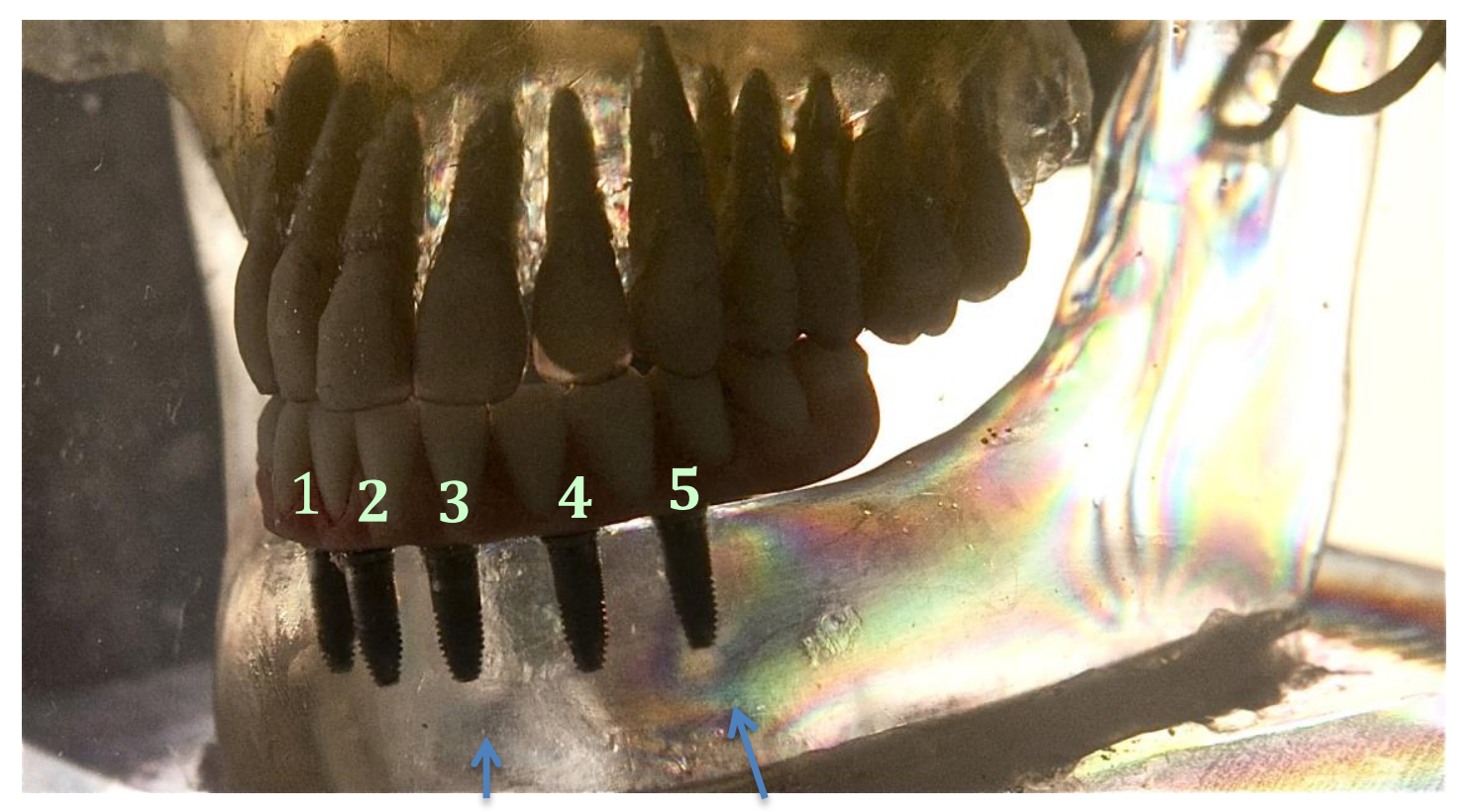

Figura 5.4 - Vista lateral esquerda do Modelo 10 com aplicação de pressão de 3 bars 
No lado direito (Figura 5.5), também observa-se concentração maior de tensões no implante mais distal e no implante central.

A mandíbula apresenta tensões relativas às linhas de força dos implantes.

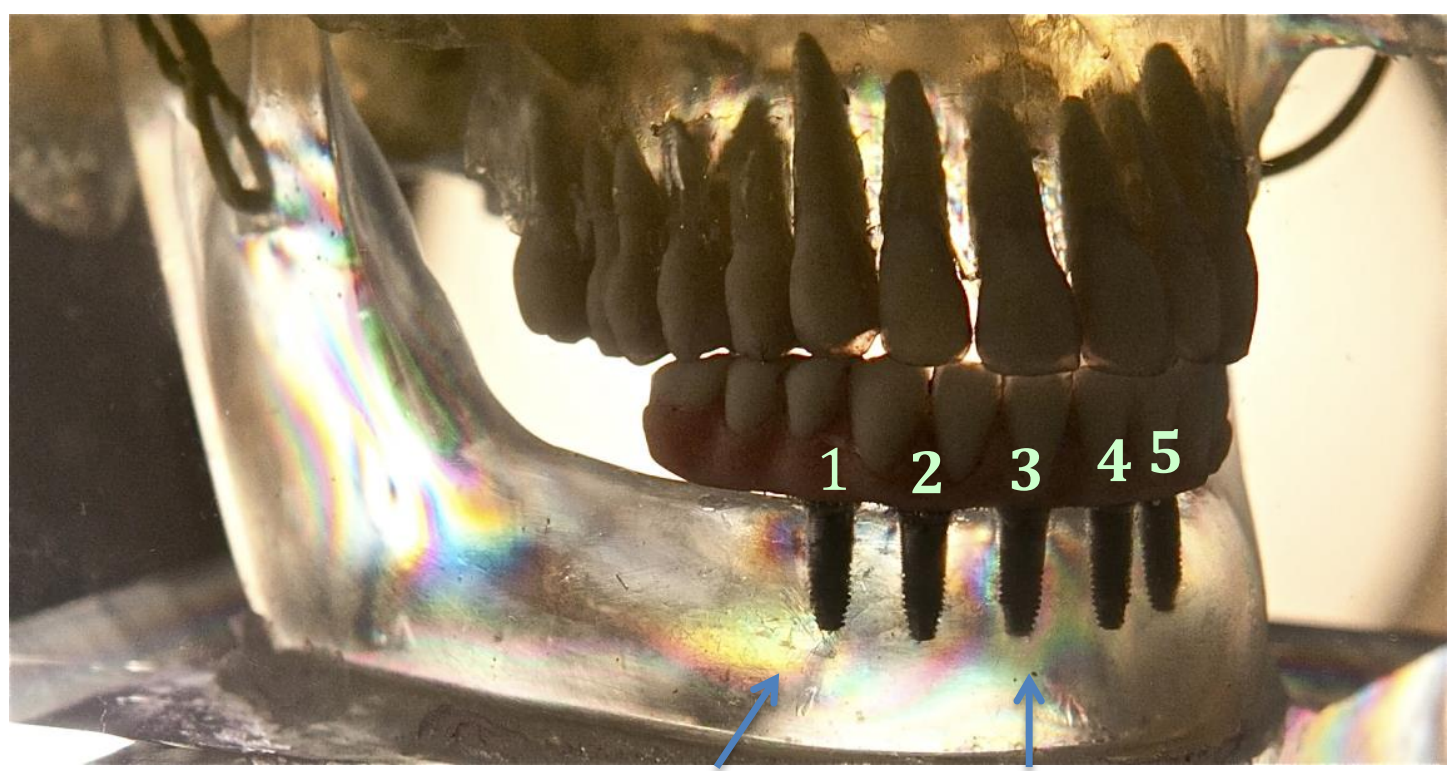

Figura 5.5 - Vista lateral direita do Modelo 10 com aplicação de pressão de 3 bars

O segundo ensaio foi realizado com o corpo de prova denominado Modelo 13, que compreende 5 implantes tipo hexágono interno, colocados na mandíbula, na região intraforaminal, com o comprimento de $13 \mathrm{~mm}$.

Em primeiro lugar foi feita análise do Modelo 13 diante da ausência de pressão (Figura 5.6). Notou-se pouca tensão nos implantes 1 e 2, tensão mais acentuada na região apical do implante central e do implante 4 . No implante 5 observou-se presença de tensões no terço médio e região apical. 


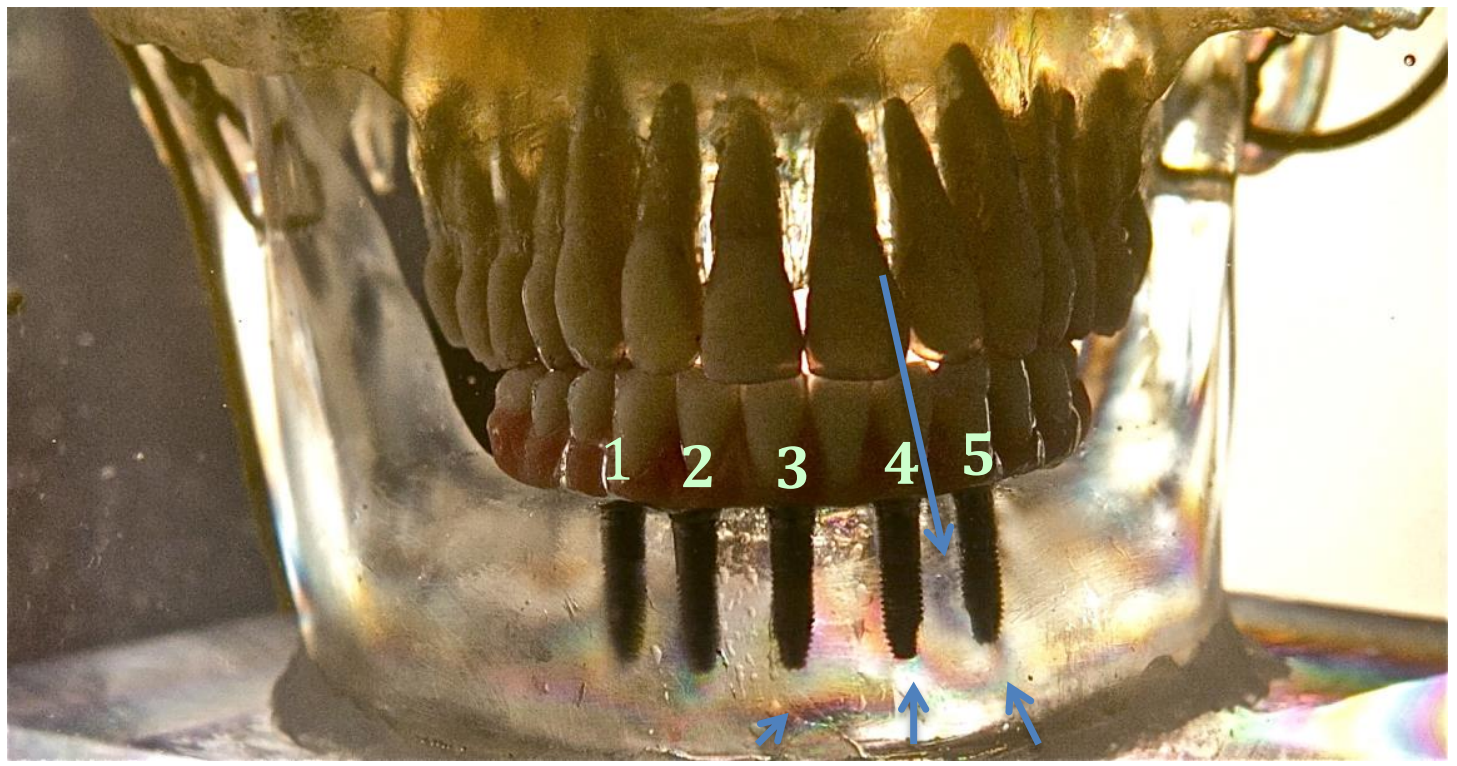

Figura 5.6 - Modelo 13 com ausência de pressão, mostrando tensões em algumas áreas

Em seguida foi realizado no Modelo 13 o carregamento com pressão de 1 bar (Figura 5.7), onde se observou pela imagem apresentada, que houve uma diversificação dessa imagem, quando comparada com o modelo de 0 pressão. Houve um aumento da intensidade das tensões, muito discretas nas áreas anteriormente descritas, proporcionais à pressão aplicada.

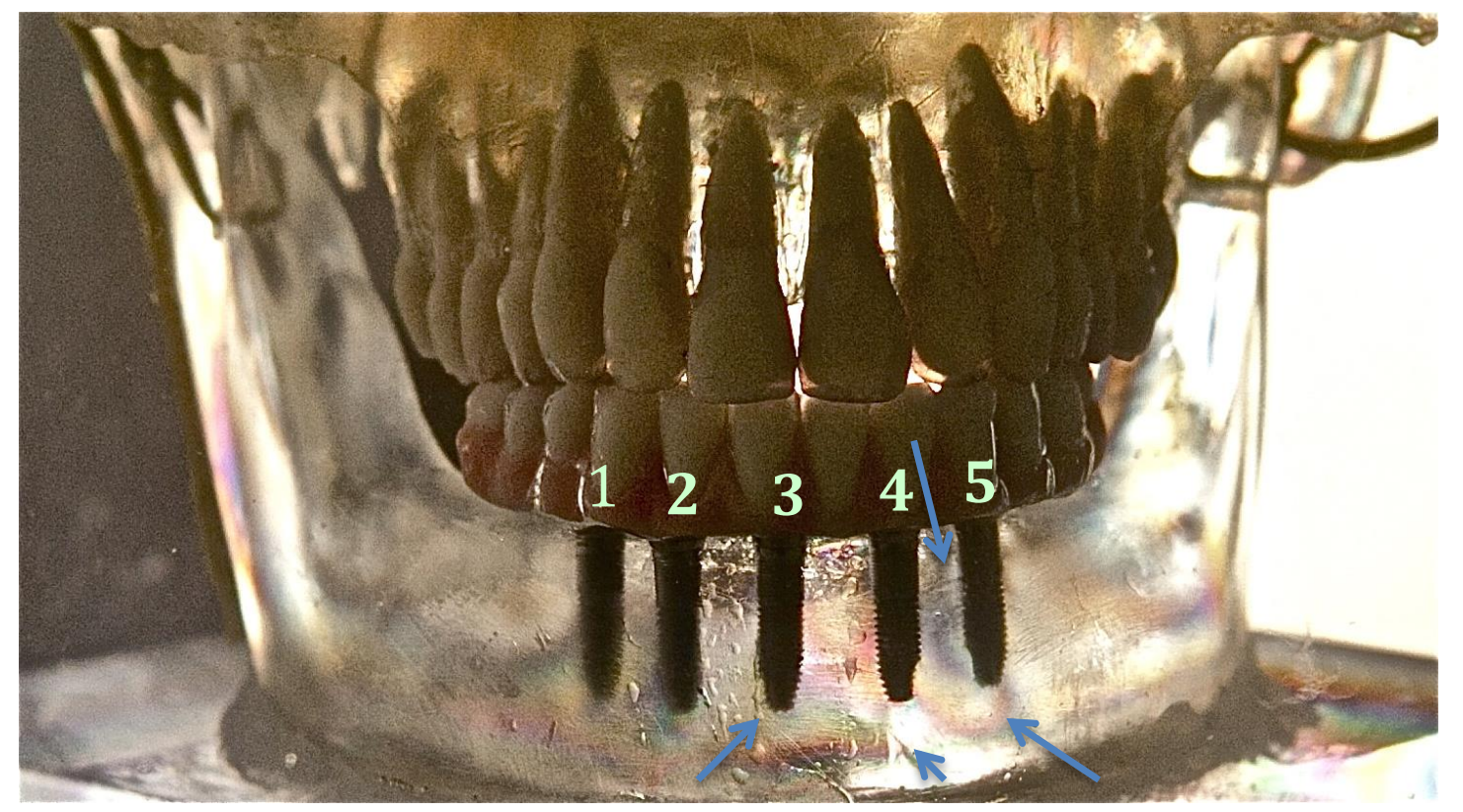

Figura 5.7 - Modelo 13 com aplicação de pressão de1 bar 
Em carregamento de 3 bars, no Modelo 13 (Figura 5.8), a diferença ao redor dos implantes 1 e 2 foi discreta e um pouco mais acentuada no implante 3 , principalmente na região do terço apical do lado direito.

No implante 4, as tensões se manifestaram de forma mais acentuada que os anteriores, estando presentes na região do terço apical ao seu redor. Houve, ainda, uma pequena alteração na distal e mesial do terço cervical até o terço apical.

O implante 5 também apresentou uma diferença de comportamento ao seu redor mais acentuada do terço médio até apical e ao redor dele.

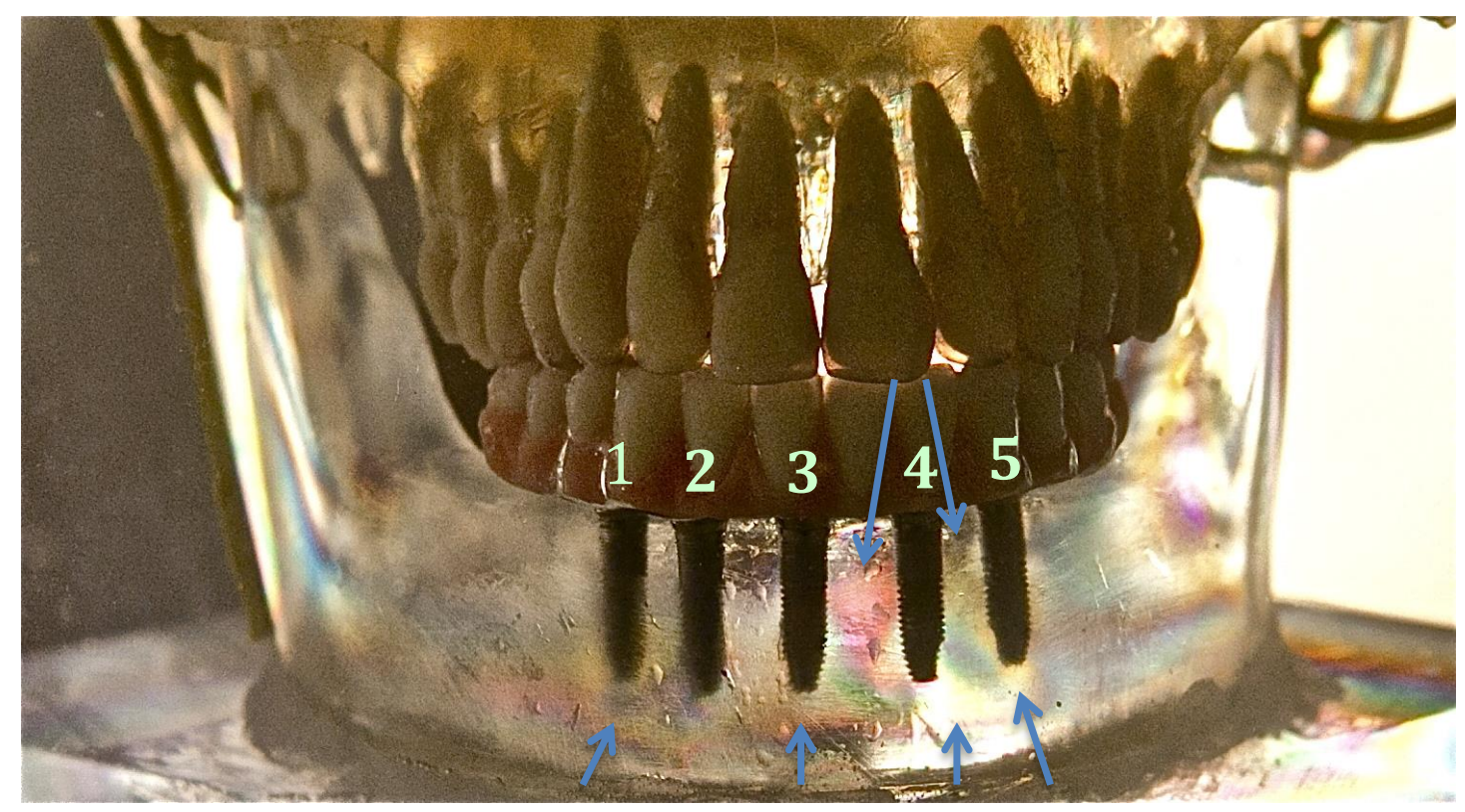

Figura 5.8 - Modelo 13 com aplicação de pressão de 3 bars

No carregamento com pressão de 3 bars foram realizadas tomadas fotográficas em vista lateral esquerda e direita. No lado direito (Figura 5.9), pode-se observar grande concentração de tensões ao redor dos implantes 1 e 2 , sendo que, no 1 , as tensões estão localizadas na região cérvico-mesial e em toda a extensão do terço médio para apical, tanto na mesial quanto na distal. No implante 2, as tensões estão presentes em toda sua extensão, de forma discreta, da cervical até metade do implante, e mais acentuada do terço médio até apical. 


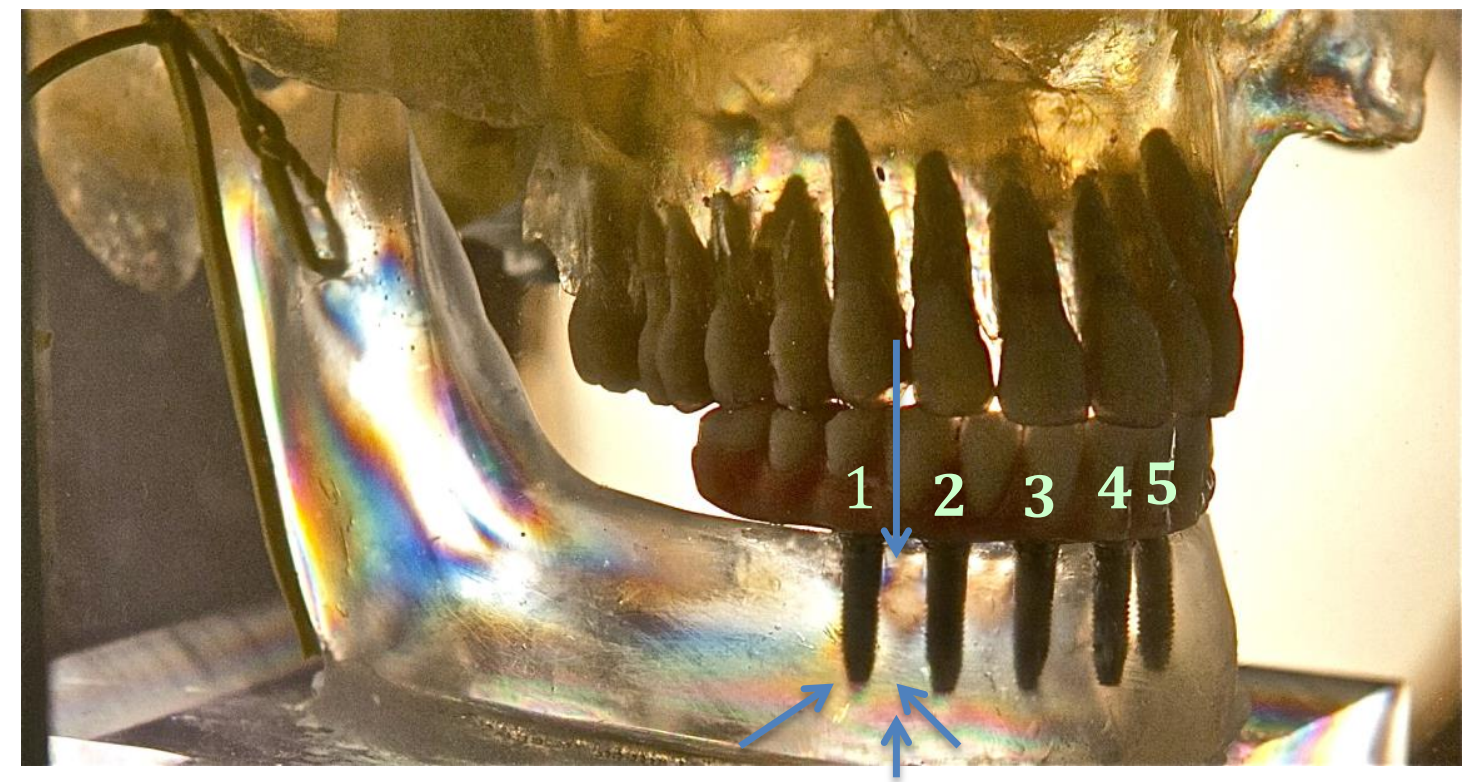

Figura 5.9 - Vista lateral direita do Modelo 13 com aplicação de pressão de 3 bars

Do lado esquerdo (Figura 5.10), quando analisadas as imagens, observam-se as tensões localizadas na mesma situação descrita anteriormente.

Observa-se na vista lateral, mais uma vez, o comportamento das tensões em relação à dissipação ao longo do ramo ascendente da mandíbula.

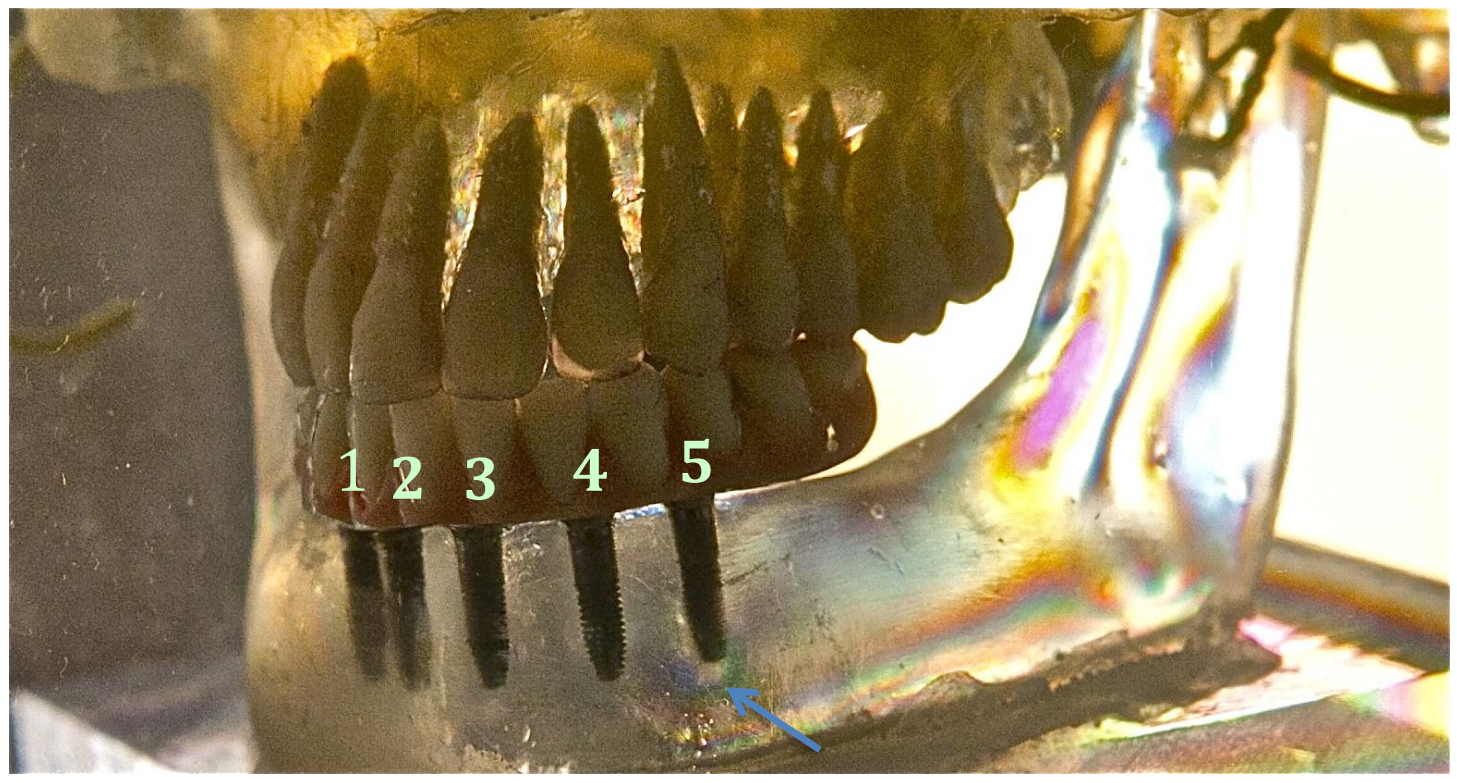

Figura 5.10 - Vista lateral esquerda do Modelo 13 com aplicação de pressão de 3 bars 
O terceiro ensaio foi realizado com o corpo de prova denominado Modelo 15, que compreende 5 implantes tipo hexágono interno, colocados na mandíbula, na região intraforaminal, com o comprimento de $15 \mathrm{~mm}$.

Foi feita tomada fotográfica com o Modelo 15, diante da ausência de pressão (Figura 5.11), e com carregamento de 1 bar (Figura 5.12), onde se percebe que no carregamento de 1 bar, em relação à pressão 0 , houve uma alteração muito discreta no conjunto das tensões.

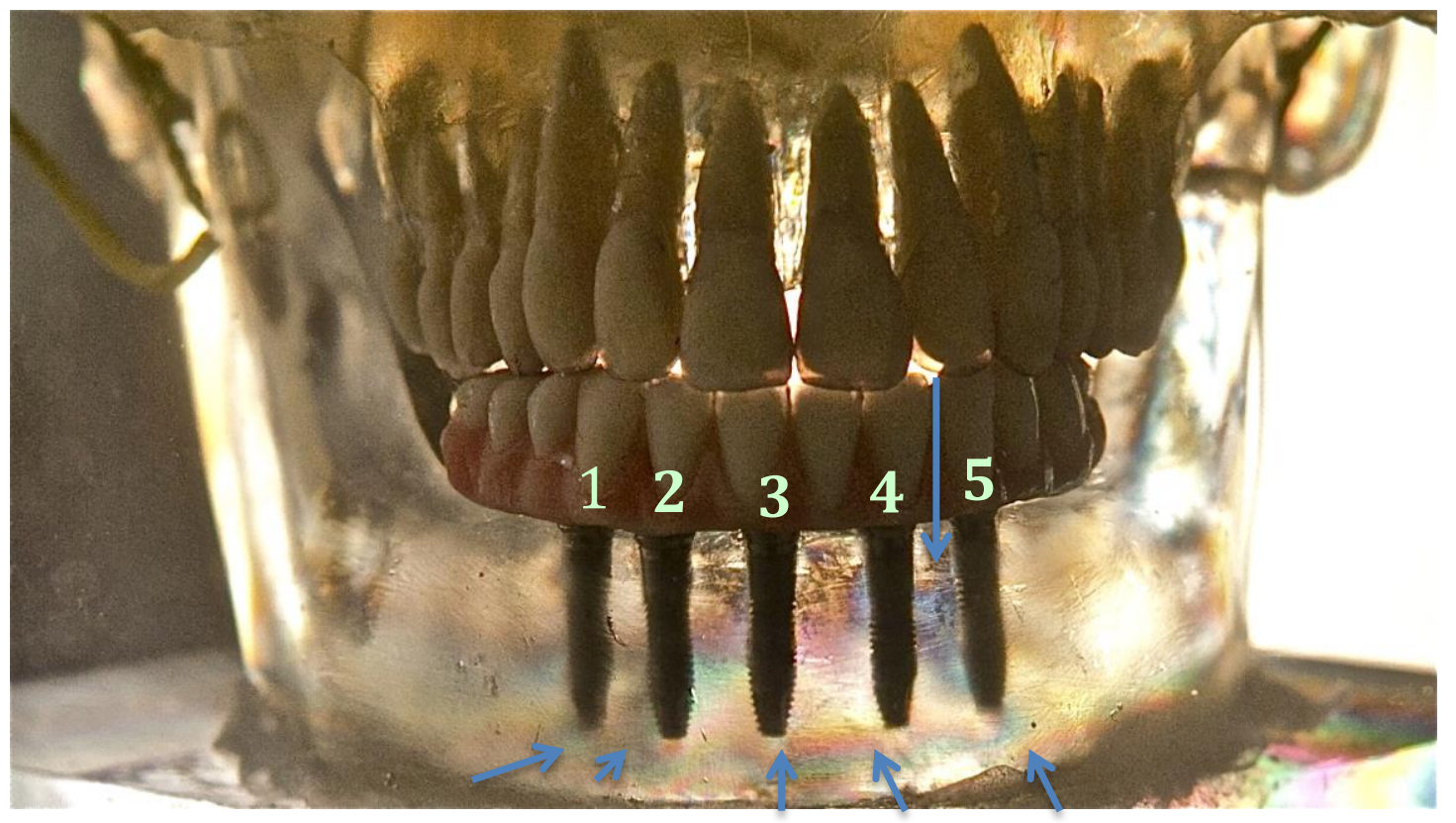

Figura 5.11 - Modelo 15 com ausência de pressão, mostrando tensões em algumas áreas 


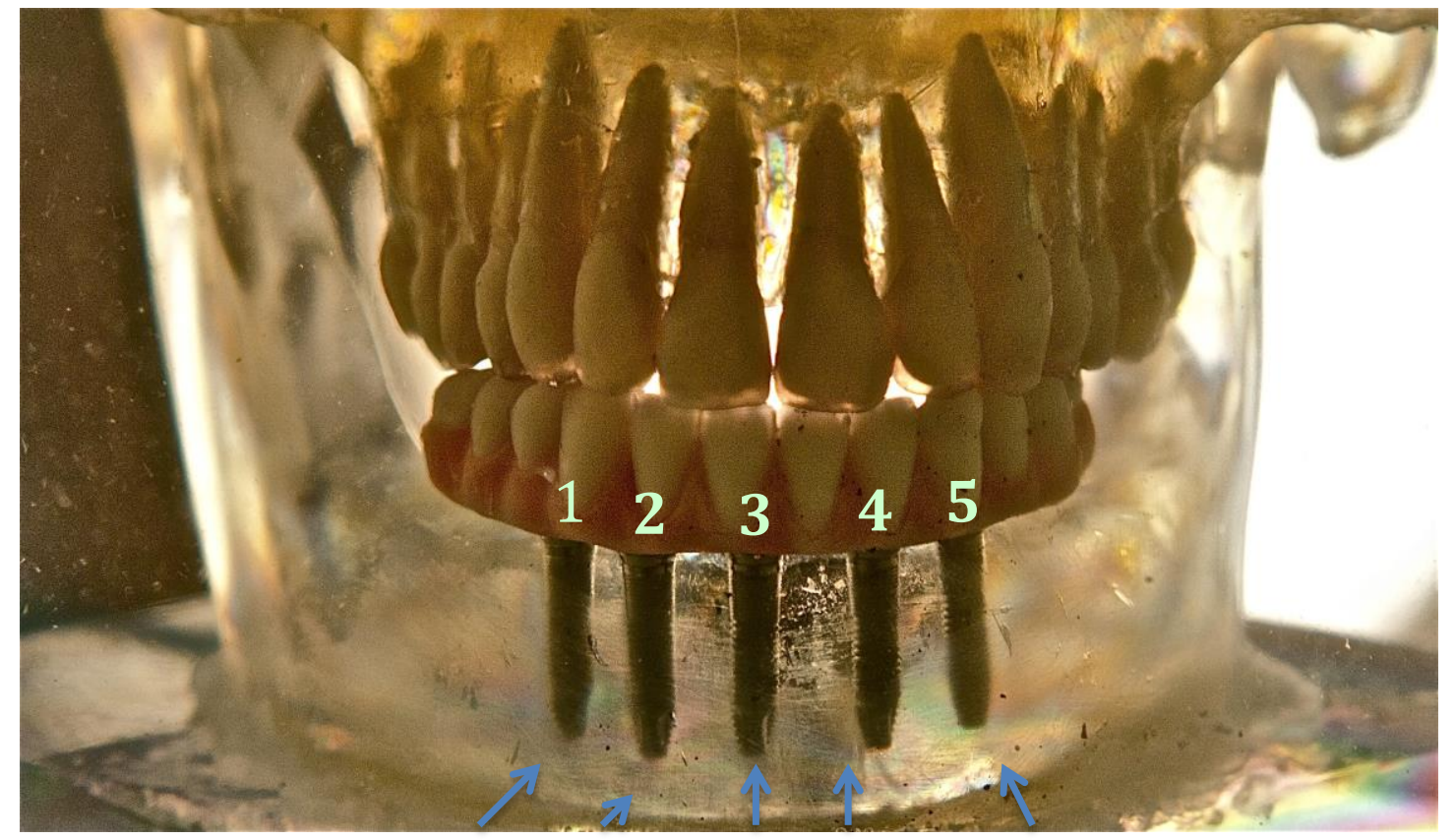

Figura 5.12 - Modelo 15 com aplicação de pressão de 1 bar

Em carregamento de 3 bars (Figura 5.13), no Modelo 15, houve uma alteração no padrão de distribuição de forças, e a vista vestibular mostra que para o implante 1 houve alterações das tensões ao redor de todo o corpo do implante, sendo menor a alteração sofrida na região cervical até o meio do implante, e mais acentuada da região média até apical, em todo seu contorno.

O implante 2 mostra alteração mais localizada da metade dele ao seu ápice, tendo maior ordem de franjas na ápico-distal e área mais clara na mesial.

O implante central mostra alterações ao seu redor de forma mais discreta que os anteriores, estando mais concentrada apicalmente.

O implante 4 sofreu mais alteração no terço médio apical, em todo seu contorno e mais acentuada na região do ápice.

O implante 5 sofreu mais alteração, desde a cervical, mais acentuada na mesial e ao redor de todo o implante, indo para distal. 


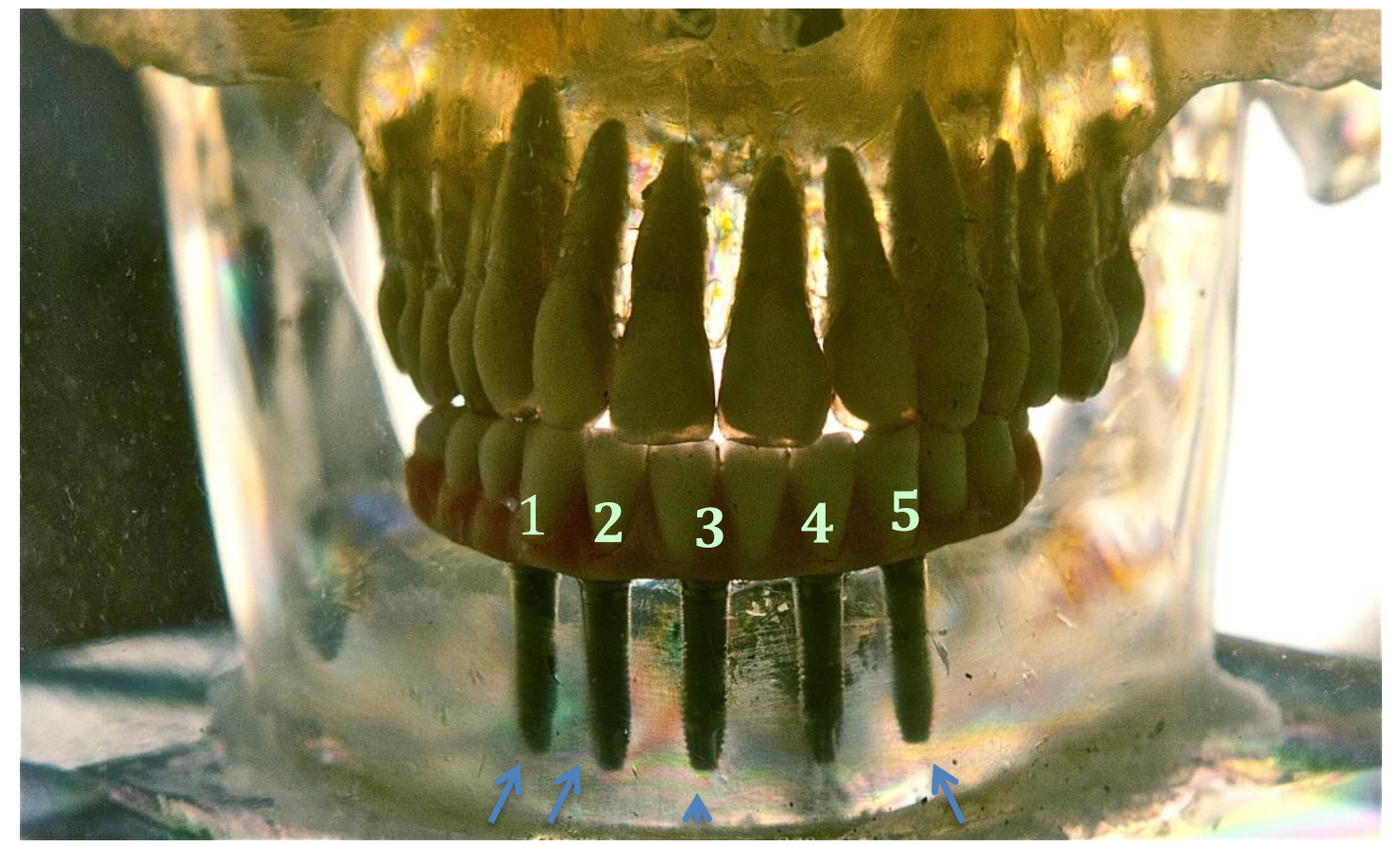

Figura 5.13 - Modelo 15 com aplicação de pressão de 3 bars

Em tomada fotográfica lateral, com carregamento de 3 bars, observou-se, do lado direito (Figura 5.14), a presença de tensões no implante 1 e 3.

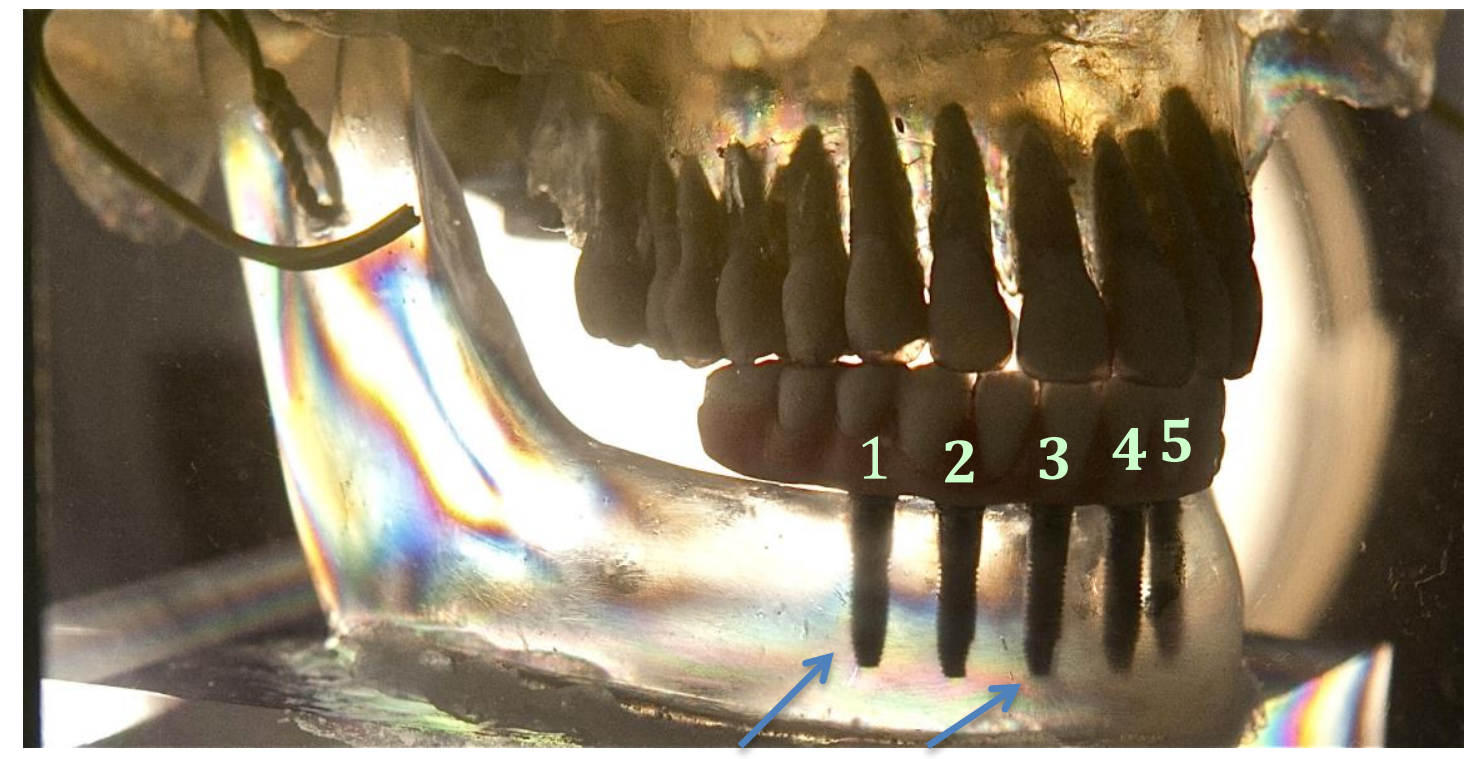

Figura 5.14 - Vista lateral direita do Modelo 15 com aplicação de pressão de 3 bars

No lado esquerdo do Modelo 15 (Figura 5.15), com carregamento de 3 bars, confirma-se a alteração do padrão de distribuição de forças no implante 5 e presença de tensões no implante 3. 


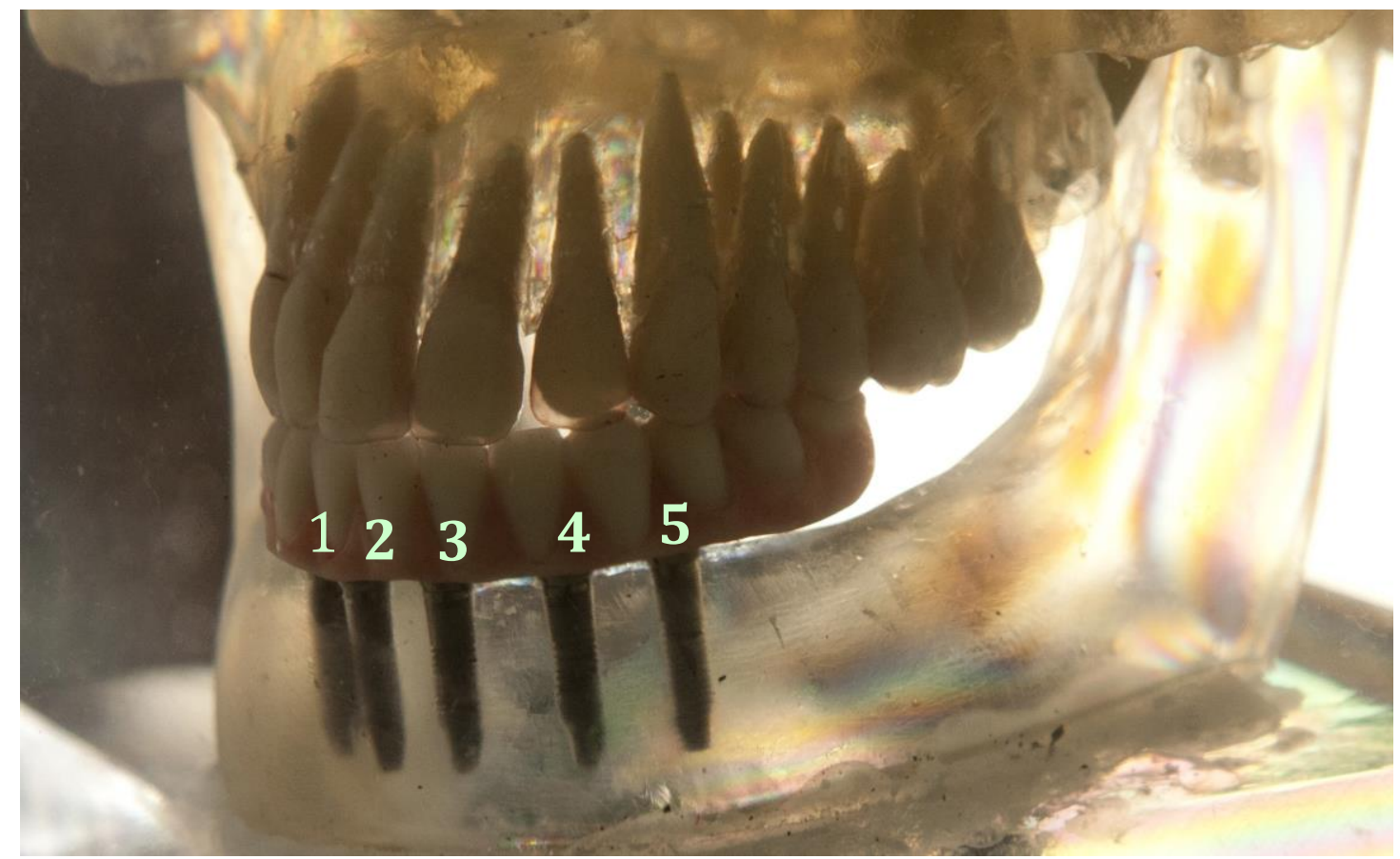

Figura 5.15 - Vista lateral esquerda do Modelo 15 com aplicação de pressão de 3 bars

Para melhor visualização dos resultados, as fotografias estão dispostas em vista frontal, com os seus diversos carregamentos, (Figura 5.16) e laterais (Figura 5.17). 


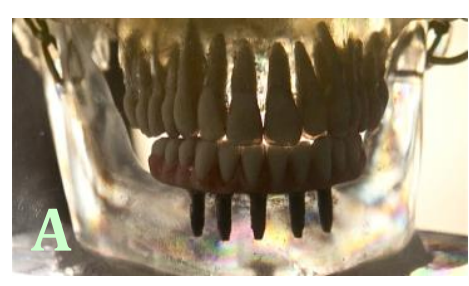

MD 10 - pressão 0

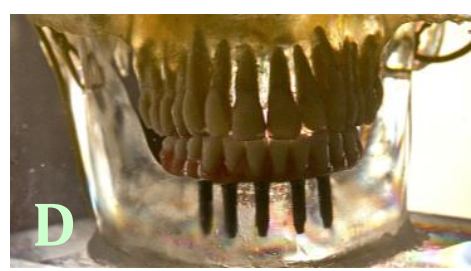

MD 13 - pressão 0

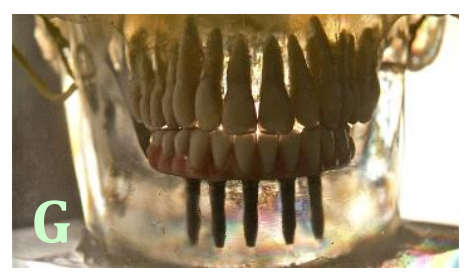

MD 15 - pressão 0

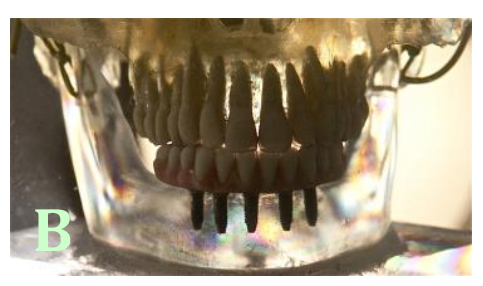

MD 10 - pressão 1

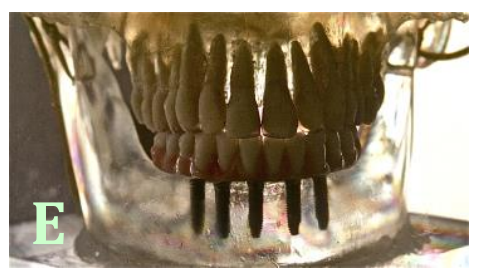

MD 13 - pressão 1

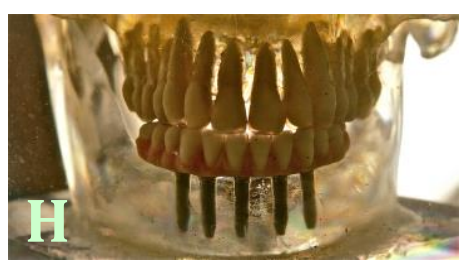

MD 15 - pressão 1

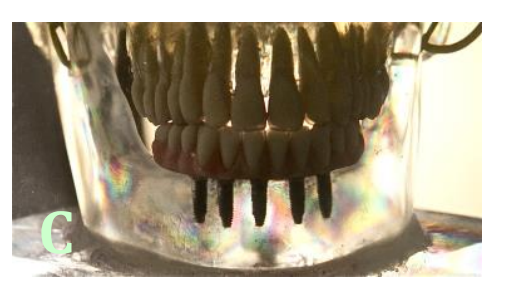

MD 10 - pressão 3

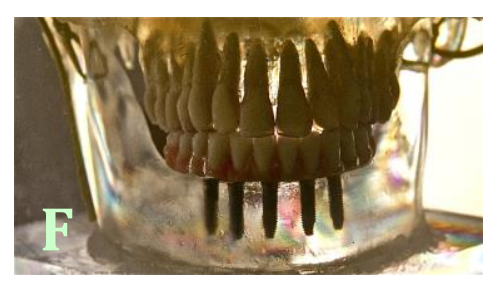

MD 13 - pressão 3

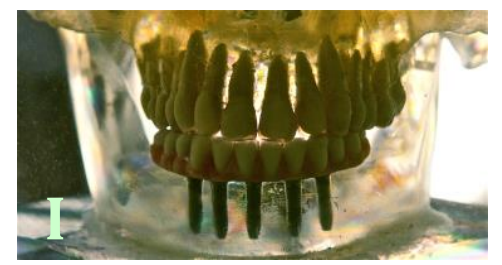

MD 15 - pressão 3

Figura 5.16 - Fotografia das vistas frontais de todos os comprimentos e todos os carregamentos a) MD 10 - pressão 0; b) MD 10 - pressão 1; c) MD 10 - pressão 3; d) MD 13 pressão 0 ; e) MD 13 - pressão 1 ; f) MD 13 - pressão 3 ; g) MD 15 - pressão 0 ; h) MD 15 - pressão 1; i) MD 15 - pressão 3 


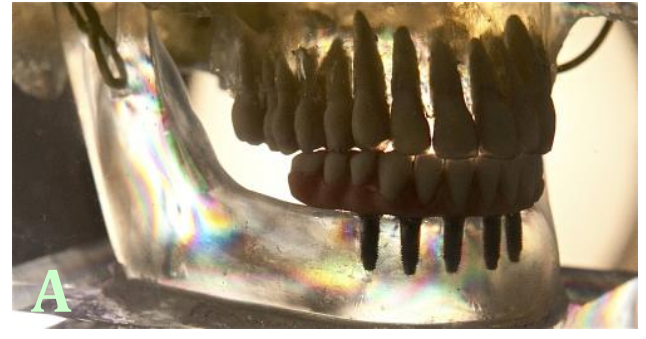

MD 10 - lado direito

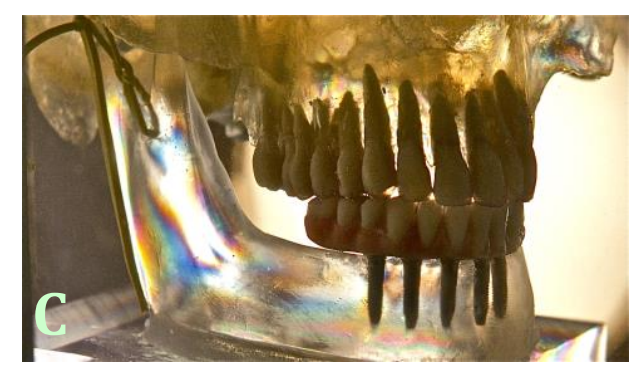

MD 13 - lado direito

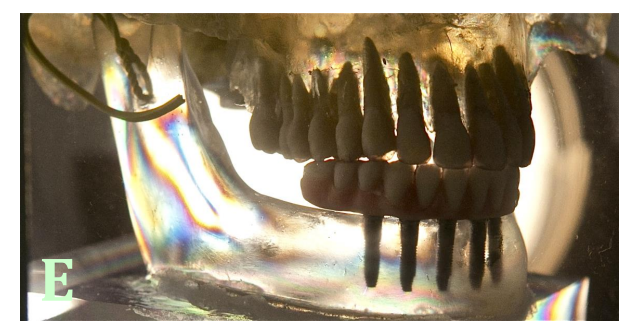

MD 15 - lado direito

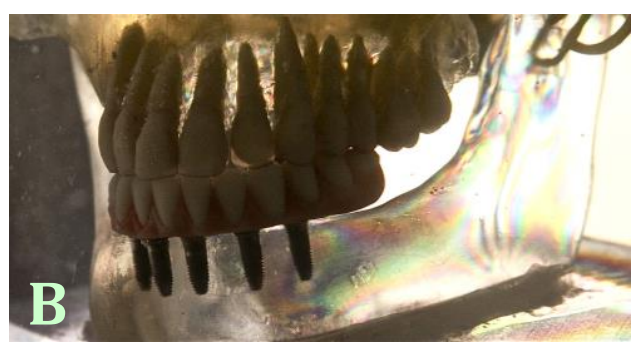

MD10 - lado esquerdo

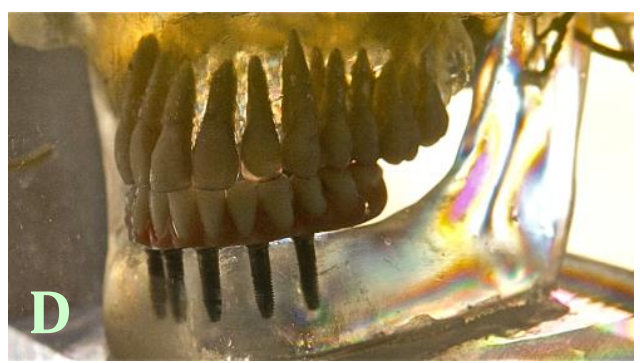

MD13 - lado esquerdo

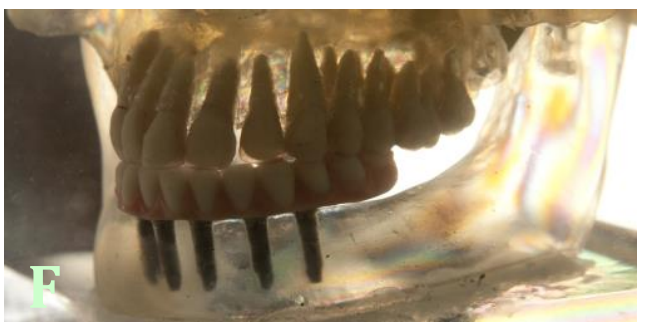

MD 15 - lado esquerdo

Figura 5.17 - Fotografias laterais de todos os comprimentos e todos carregamentos. a) MD 10 - lado direito; b) MD10 - lado esquerdo; c) MD 13 - lado direito; d) MD13 - lado esquerdo; e) MD 15 - lado direito; f) MD 15 - lado esquerdo 


\section{DISCUSSÃo}

Nesta pesquisa, foram avaliadas as tensões geradas nas estruturas de suporte em mandíbula, quando diferentes carregamentos foram aplicados sobre uma prótese tipo protocolo, com dentes de resina acrílica, do tipo parafusada, sobre cinco implantes, de $3,75 \mathrm{~mm}$ de diâmetro, hexágono interno, variando-se o comprimento dos implantes em $10 \mathrm{~mm}, 13 \mathrm{~mm}$ e $15 \mathrm{~mm}$. Foi confeccionada uma única prótese, conectada em 3 diferentes modelos fotoelásticos.

Um dos pontos mais críticos nas reabilitações de arcos dentários, realizadas com próteses que seguem o protocolo Brånemark, diz respeito ao comprimento dos cantilevers (Rangert et al., 1989; Rodriguez et al., 1993; Tashkandi et al., 1996; Eliasson et al., 2000; Wiebke et al., 2010). Dessa forma, a estrutura protética dos corpos de prova teve o cantilever dimensionado em $15 \mathrm{~mm}$ de comprimento, plataforma oclusal reduzida no sentido vestíbulo lingual e a oclusão aliviada com menor toque oclusal (Lundgren et al., 1989; Rangert et al., 1989; Rodriguez et al., 1993; Tashkandi et al., 1996; Eliasson et al., 2000).

Os resultados mostraram que o modelo fotoelástico com implantes de $15 \mathrm{~mm}$ (MD 15), apresentou menor quantidade de franjas ao seu redor, significando que ocorreram menores tensões, quando comparado aos modelos contendo implantes de comprimentos de $10 \mathrm{~mm}$ (MD 10) e 13mm (MD 13). As tensões mantiveram um padrão de distribuição que se manteve ao longo dos implantes, independente do seu comprimento, no decorrer dos ensaios. O que variou foi a magnitude das tensões, que foi diminuindo à medida que o comprimento do implante foi aumentando.

O método fotoelástico foi aplicado na Odontologia em inúmeros trabalhos de pesquisa (Campos et al., 1986; Caputo e Standlle, 1987; White et al., 1994; Waskewicz et al., 1994; Assif et al., 1996; Rubo; Souza, 2001; Bernardes et al., 2006) para análise do comportamento biomecânico dos implantes e a sua relação com os tecidos que os circunscrevem diante da submissão de cargas. $O$ modelo fotoelástico possui estrutura homogênea e isotrópica, diferindo das características estruturais dos tecidos biológicos, como as diferenças entre osso cortical e medular, densidade óssea e presença de ligamento periodontal (Caputo, 1993). Porém, ele nos auxilia na compreensão das possíveis causas que levam as próteses a 
apresentarem, com o decorrer do seu uso na cavidade bucal, afrouxamento dos parafusos, fratura das próteses e perda óssea ao redor dos implantes, perante a submissão de cargas.

Os modelos fotoelásticos foram construídos a partir de uma mandíbula natural, para serem mantidos a mesma geometria e padrão (Campos et al., 1986; Laganá, 1992), o mesmo ocorrendo com a prótese, construída da forma mais semelhante possível às realizadas clinicamente.

Um pré-requisito importante para o sucesso e manutenção da osseointegração é a obtenção de um assentamento, o mais passivo possível, da prótese sobre os implantes (Waskewics et al., 1994; Barbosa, 2006). Com o objetivo de tentar minimizar ao máximo a quantidade de distorções, desadaptações e tensões no modelo fotoelástico, como relatadas por Waskewics et al. (1994) e Barbosa (2006), a colocação dos implantes na mandíbula duplicada em resina foi feita após a construção da peça protética, para evitar essas ocorrências.

O modo como o modelo foi apoiado na plataforma que o segurava também foi outro fator de relevância, uma vez que esse apoio é que transmite a carga ao conjunto, mandíbula, implantes, pilares protéticos e próteses tipo protocolo. Esse apoio foi de grande importância a fim de que, além de garantir uma base bem fixada ao modelo, também estabilizasse o conjunto, para que fosse mantido 0 direcionamento das cargas obtidas durante o ajuste oclusal.

A estabilização do modelo à plataforma foi outro fator de relevância, para que o carregamento sobre o corpo de prova transmitisse a carga às estruturas mandibulares, implantes, pilares protéticos e prótese, da forma mais acurada possível, sem alteração do direcionamento das forças oclusais.

O ajuste oclusal foi realizado de acordo com Chapman (1989), de forma que os contatos oclusais transmitissem as cargas axialmente, de maneira simultânea e bilateral, obtendo-se estabilidade e equilíbrio.

Qualquer modificação na inclinação das cúspides poderia levar a diferente direcionamento das forças oclusais não axiais, como, por exemplo, forças transversais (Rangert et al., 1989), que poderiam alterar os resultados. A oclusão é um fator determinante para se estabelecer a direção de carga (Bidez; Misch, 1992) e também é fundamental para a longevidade das próteses sobre implante. Chapman (1989) verificou que, após 2,5 anos de uso, houve $97,7 \%$ de sucesso nos tratamentos realizados com essa modalidade protética. 
Contatos prematuros, desajuste oclusal, extensão de cantilever, número e localização dos contatos oclusais, poderão levar a uma situação de sobrecarga no conjunto e consequente periimplantite e perda óssea, sendo que uma possível sobrecarga influencia na interface osso/implante (Carter et al., 1981; Sahin et al., 2002; Kim et al., 2005; Rilo et al., 2008). Entretanto, Assenza et al. em 2003, relataram que a carga direcionada nos implantes não era importante, mas sim, a presença de microrganismos na interface. Sendo assim, um minucioso ajuste oclusal foi realizado, para que não se tornasse um fator de variação que pudesse interferir de maneira negativa nos resultados de distribuição das tensões ao redor dos implantes.

Na análise fotoelástica realizada após instalação da mandíbula em relação à maxila do crânio fotoelástico, com implantes de comprimento de $10 \mathrm{~mm}$, verificou-se uma situação em que, livre de pressão, somente o implante central apresentava mínima tensão, e os demais estavam praticamente isentos delas. Assim sendo, as avaliações do comportamento das tensões foram realizadas a partir dessa imagem inicial.

Esse resultado mostra um bom padrão de adaptação da peça protética em relação aos implantes e baixa transmissão de tensões ao conjunto, ou na interface resina/implante, o que não foi similar aos testes de tensão fotoelástica observada em outros estudos (Waskewics et al., 1994; Barbosa, 2006).

À medida que a aplicação de pressão, de 1 bar para 3 bars, foi sendo realizada, houve aumento de tensão nos implantes mais distais, na região cervical, tanto na mesial como na distal e, também, no terço médio e apical do implante distal direito. Esse resultado está em concordância com os obtidos por Lindquist et al. (1988), Lundgren et al. (1989), Rodriguez et al. (1993), Wang e Hobkirk (1996), Naconecy et al. (2010), Wiebke et al. (2010), que, nos ensaios realizados com próteses fixas sobre implantes com cantilever, também observaram tensões maiores no implante vizinho ao cantilever, embora Tashkandi et al. (1996), nas mesmas condições, as tenham encontrado na região cervical.

Deve-se ressaltar que, neste estudo, as tensões não se localizaram somente na região cervical dos implantes distais, mas, também, ao longo de seu corpo, pelo terço médio e apical como ocorreu com Bernardes et al. (2006) que, em análise fotoelástica das tensões junto à crista óssea, encontrou um menor valor de tensão 
cisalhante, em implantes com conexão tipo hexágono interno, o mesmo utilizado nesta pesquisa.

$\mathrm{Na}$ tentativa de minimizar as tensões nos implantes mais próximos do cantilever, a oclusão nessa região foi minimizada, com menor toque oclusal do que aquelas mais próximas do suporte implantar. As forças compressivas sobre o cantilever podem resultar em uma intensidade duas a três vezes maior que o valor da carga aplicada sobre esse segmento (Mcalarney; Stavropoulos, 2000). Posteriormente, em 2010, Naconecy et al. não só encontraram maiores tensões nos implantes distais, ou vizinhos ao cantilever, mas ainda maiores, quando estes estavam posicionados retos ou paralelos entre si, quando comparados com implantes distais colocados mais inclinados em relação aos demais.

O aumento de pressão também gerou tensões no implante central, principalmente na região apical. Esse resultado, que mostra aumento de tensões no implante central e nos implantes mais próximos ao cantilever, sugere a ocorrência de forças de compressão nos implantes mais próximos ao cantilever e forças de tração e compressão nos implantes mais distais (Duyck, 2000).

Neste estudo, quando comparamos as diferentes mandíbulas com diferentes comprimentos de implante, $10 \mathrm{~mm}, 13 \mathrm{~mm}$ e $15 \mathrm{~mm}$, observou-se que as tensões foram maiores no implante central e nos distais na mandíbula com implantes de $10 \mathrm{~mm}$. Estes ficaram mais sobrecarregados, nessas regiões, quando comparados com os de 13 e $15 \mathrm{~mm}$.

As tensões geradas pela carga oclusal, que se dissipam através da prótese, passando pelos implantes e ao redor da superfície dos implantes em contato com a resina, são transferidas com uma magnitude maior nos implantes mais curtos, podendo ocasionar maior tensão, deformação e levar, eventualmente, à perda óssea (Sahin et al., 2002).

Outros estudos (Lekholm, 1988; Ivanoff et al., 1999; Snauwaert et al., 2000; Sahin et al., 2002; Herrmann et al., 2005; Aparício et al., 2006; Degidi et al., 2007; Renouard; Nisand, 2006), avaliaram o índice de sucesso dos implantes e o comportamento do osso ao redor deles, quando relacionados ao comprimento e diâmetro de implantes dentários utilizados. Em relação ao comprimento dos implantes, a maioria dos autores observou uma correlação entre implantes curtos e uma baixa taxa de sobrevida, apesar de Iplikçioglu e Akça (2002), Wiebke et al. (2010), não correlacionarem o número e comprimento de implantes com a perda 
óssea marginal. Bidez e Misch (1992) correlacionaram uma melhor osseointegração, quando havia maior quantidade óssea e maior comprimento das fixações. Para Brånemark et al. (1995) e Herrmann et al. (2005), não só o comprimento do implante influencia para um bom prognóstico, mas também a região na qual o implante é instalado, destacando-se que a maxila seria uma região pior quando comparada com a mandíbula.

De acordo com Snauwaert et al. (2000), Renouard e Nisand (2006), os implantes de $13 \mathrm{~mm}$ apresentam maior índice de sucesso que os de $10 \mathrm{~mm}$, sendo que outros fatores poderão interferir na taxa de sucesso, tais como, hábitos parafuncionais, proporção cora/implante, inclinação, distribuição dos implantes e comprimento do cantilever. Glantz e Nilner (1988) mostraram que o aumento do comprimento das fixações poderia atenuar o momento fletor. Entretanto, deve-se ressaltar que, em pacientes com maior reabsorção óssea, menores serão os comprimentos dos implantes e, consequentemente, maiores serão as infraestruturas metálicas, com os seus recobrimentos estéticos, para compensar a alteração da dimensão vertical, gerando, assim, um momento fletor maior.

Esses estudos reforçam o resultado encontrado, onde se observou que os implantes de $15 \mathrm{~mm}$ de comprimento distribuíram melhor as forças por unidade de área. Entretanto, Iplikçioglue e Akça (2002), Himmlová et al. (2004), em estudos realizados em modelos computacionais em $3 \mathrm{D}$, relataram que a diminuição das tensões estão associadas ao aumento do diâmetro do implante e não ao comprimento.

Outros estudos também associaram a distribuição de tensões à variação do número de implantes, que irão suportar a prótese. Davis et al. (1988) recomendaram cinco implantes como sendo favoráveis a um melhor prognóstico. Duyck et al. (2001) observaram um momento fletor maior em próteses tipo protocolo em mandíbula, quando estas foram sustentadas por três implantes ao invés de cinco.

Os resultados encontrados neste estudo se limitaram à observação do comportamento mecânico de sistema de próteses similar ao realizado que segue o protocolo de Brånemark, com alteração do comprimento das fixações, em modelos experimentais com padronização de carregamento, comprimento de cantilever e posição, minimizando as intercorrências normalmente visíveis nos procedimentos clínicos, como citado por White et al. (1994). 
Os modelos fotoelásticos são utilizados em Odontologia para avaliação de tensões, porém representam um método que apresenta limitações ao diagnosticar qual seria a resposta do sistema biológico para um determinado carregamento, por ser um método que não quantifica os limiares de tensão nos diversos tipos ósseos. Sendo que é um método no qual utilizamos um modelo in vitro, que sugere uma interface perfeita entre implante e estrutura óssea, como se a osseointegração fosse da mesma forma em toda a superfície do implante (De Vree et al., 1993).

Ressaltamos, ainda, que os resultados desse estudo qualificam, mostram os locais de concentração e distribuição das tensões, dentro de uma simulação com cargas axiais e estáticas e que, ainda, a mandíbula está assentada numa base de acrílico, onde vai intercorrer uma somatória de tensões, como ação e reação em uma mandíbula fixada a uma base e ao crânio fotoelástico e não como realmente seria, uma mandíbula com mobilidade, limitada por feixes nervosos e musculares dentro de uma situação na qual se apresentariam cargas dinâmicas e, muitas vezes, transversas.

Assim, novas pesquisas empregando metodologias que possam induzir outras variáveis, com forças mastigatórias aplicadas sob vários ângulos e direções, forças de aplicação de cargas dinâmicas, alteração de inclinação dos implantes, alteração do revestimento da infraestrutura, empregando-se metodologias tanto clínicas como laboratoriais, são necessárias para novas avaliações das tensões em próteses que seguem o protocolo, instaladas em mandibular na região anterior. 


\section{CONCLUSÕES}

De acordo com a metodologia aplicada, pode-se concluir que:

1. Os implantes de maior comprimento distribuíram melhor as tensões ao longo do corpo do implante.

2. As tensões se localizaram mais apicalmente, tanto por mesial como distal, nos implantes de maior comprimento.

3. Os implantes que sofreram maiores tensões foram os mais próximos do cantilever e o implante central. 


\section{REFERÊNCIAS ${ }^{1}$}

Aparicio C, Lang NP, Rangert B. Validity and clinical significance of biomechanical testing of implant/bone interface. J Clin Oral Imp Res. 2006;17(2):2-7.

Assenza B, Scarano A, Petrone G, lezzi G, Thams U, Roman FS, Piatelli A. Osteoclast activity around loaded and unloaded implants: a Histological study in the beagle dog. J Oral Impl. 2003;29(1):1-7.

Assif D, Marshak B, Horowitz A. Analysis of load and stress distribution by an implant-supported fixed partial denture. J Prosth. Dent. 1996;75(3):285-91.

Barbosa GAS. Avaliação do ajuste pilar Ucla/implante e da tensão gerada ao redor dos implantes após procedimentos de fundição em monobloco e soldagem a laser de infra-estruturas confeccionadas em diferentes materiais [dissertação]. Ribeirão Preto: USP/FORP, 2006.

Becker W, Becker BE, Israelson H, Lucchini JP, Handelsman M, Ammons WI. OneStep surgical placement of Branemark Implants: A prospective multicenter clinical study. Int J Oral Maxillofac Implants. 1997;12:454-62.

Bernard JP, Belser UC, Martinet JP, Borgis SA. Osseointegration of Branemark fixtures using a single-step operating technique. A preliminary prospective one- year study in edentulous mandible. Clin Oral Implants Res. 1995;6:122-29.

Bernardes SR, Araújo Neto CA, Fernades Neto AJ, Neves FD. Análise fotoelástica da união de pilar a implantes de hexágonos externo e interno. Implant News. 2006;3(4):355-9.

Bidez WM, Misch CE. Force transfer in implant dentistry: basic concepts and principles. J Oral Implantol. 1992;18(3):264-73.

Binon PP. The effect of implant/abutment hexagonal misfit on screw joint stability. Int J Prosthodont. 1996;9(2):149-60.

${ }^{1}$ De acordo com Estilo Vancouver. 
Bozkaya D; Müflü S. Efficiency considerations for the purely tapered interference fit (TIF) abutments used in dental implants. J Biomech Eng. 2004;126:393-401.

Brånemark P-I, Svensson B, Van Stenberghe D. Ten years survival rates of fixed prostheses on four or six fixtures ad modum Brånemark in full edentulism. Clinic Oral Implants Res. 1995;6:227-31.

Brånemark P-I. Osseointegration and its experimental background. J Prosthet Dent. 1983;50(3):399-410.

Brånemark P-I, Hansson B, Adell R, Breine U, Lindstron J, Hallen O, Ohman A. Osseointegrated implants in the treatment of the edentulous jaw: experience from a 10-year period. Scand J Plast Reconst Surg. 1977;16:7-127.

Bruyn $\mathrm{H}$, Collaert B. Early loading of machined-surface Branemark implants in completely edentulous mandibles: healed bone versus fresh extraction sites. Clin Implant Dent Relat Res. 2002;4(2):136-42.

Campos Jr A, Passanezi E, Nahás D, Janson WA. A fotoelasticidade na pesquisa odontológica. Parte I - Campo de aplicação. Estomatol Cult. 1986;16(1):20-5.

Caputo AA, Standlle JP. Biomechanics in clinical dentistry. Chicago, Quintessence: 1987.

Caputo AA. Stress analysis. Apresentado no Seminário de Biomateriais, Science Section. Abstracts. Los Angeles: UCLA School of Dentistry; 1993.

Carter DR, Caler WE, Spengler DM, Frankel, VH. Fatigue behavior of adult cortical bone: the influence of mean strain and range. Acta Orthop Scand. 1981;52:481-90.

Cehreli M, Duyck J, De Cooman M, Puers R, Naert I. Implant design and interface force transfer. A photoelastic and strain - gauge analysis. J Clin Oral Implant. 2004;2:249-57.

Chapman RJ. Principles of occlusion for implants prostheses; guidelines for position, timing and force of oclusal contacts. Quintessence Int .1989;20(7):473-89. 
Cruz ANL. Análise fotoelástica das estruturas de suporte e craniofaciais de portadores prótese parcial removível superior, classe II de Kennedy, subclasse 1 [tese]. São Paulo: Faculdade de Odontologia da USP; 2004.

Davis DM, Zarb GA, Chao YL. Studies on frameworks for osseointegrated prostheses: Part 1. The effect of varying the number of supporting abutments. Int $\mathrm{J}$ Oral Maxillofac Implants. 1988;3(3):197-201.

De Kok IJ, Chang KH, Lu TS, Cooper LF. Comparison of three-implant-supported fixed dentures and two- implant-retained overdenture in the edentulous mandible: A Pilot study of treatment efficacy and patient satisfaction. Int J Oral Maxillofac Implants. 2011 March/April;26:415-26.

De Vree JHP, Peters MCRB, Plasschaert AJM. A comparison of photoelastic and finite elemento stress analysis in restored tooth structures. J Oral Rehabil. 1993;10:505-17.

Degidi M, Piattelli A, Lezzi G, Carinci F. Wide-Diameter implants: Analysis of clinical outcome of 304 fixtures. J Periodontal. 2007;78(1):52-8.

Duyck J. Magnitude and distribution of occlusal forces on oral implants supporting fixed prostheses: an in vivo study. J Clin Oral Implant Reserch. 2000;(5)11:465-76.

Duyck J, Ronold HJ, Osterwyck HV, Naert I, Sloten JV, Ellingsen JE. The influence of static and dynamic loading on marginal bone reactions around osseointegrated implants: an animal experiment study. Clin Oral Implants Res. 2001;12:207-18.

Dyn H. Atlas de cirurgia oral menor. Local:Santos; 2004. p.203.

Eliasson A, Palmqvist S, Svenson B, Sondell K. Five-year results with fixed complete- arch mandibular prostheses supported by 4 implants. Int J Oral Maxillofac Implants. 2000;15:505-10.

Engquist B, Astrand P, Dahlgren S, Engquist E, Feldmann H, Grondahl K. Marginal bone reaction to oral implants: a prospective comparative study of Astra Tech and Branemark System implants. Clin Oral Implants Res. 2002;13:30-7. 
Federick DR, Caputo AA. Effects of Overdentures retention designs and implant orientation on load transfer characteristics. J Prosthet Dent. 1996;76(6):624-31

Friedman N, Landesman HM. The influence of fear, anxiety, and depression on the pacient's adaptive responses to complete dentures. Part I. J Prosthet Dent. 1987;58:687-9.

Glantz PO, Nilner KN Biomechanical aspects of prosthetic implant-borne reconstructions. Periodontology 2000. 1988;17:119-24.

Glickman I, Roeber FW, Brion M, Pameijer JHN. Photoelastic analysis of internal stress in the periodotium created by occlusal forces. J Periodontal. 1970;41(1):30-5.

Hansson S. A conical implant-abutment interface at the level of the marginal bone improves the distribution of stresses in the supporting bone. An axisymmetric finite element analysis. Clin Oral Implants Res. 2003;(14):286-93.

Henry PJ, Bowert RC, Wall CD. Rehabilitation of the edentulous mandible with osseointegrated dental implants: 10 years follow-up. Aust Dent J. 1995;40(1):1-9.

Herrmann I, Holm S, Kult JEC. Evaluation of patient and implant characteristics as potential prognostic factors for oral implant failures. Int J Oral Maxillofac Implants. 2005;20(2):220-30.

Himmlová L, Dodtálová T, Kácovský A, Konvickova S. Influence of implant length and diameter on stress distribution: A finite element analysis. J Prosthet Dent. 2004;91:20-5.

Iplikçioglu H, Akça K. Comparative evaluation of the effect of diameter and number of implants supporting three-unit fixed partial prostheses on stress distribution in the bone. J Dent. 2002;30:41-46.

Ivanoff CJ, Gröndahl K, Sennerby L, Bergström C, Lekholm U. Influence of variations in implant diameters: a 3 to 5 years restrospctive clinical report. Int J Oral Maxillofac Implants. 1999;14:173-80. 
Jansen VK, Conrads G, Richter E-J. Microbial leakage and marginal fit of the implant/abutment interface. Int J Oral Maxillofac Implants. 1997;12(4):527-40.

Jemt T. Failures and complications in 391 cinsecutiveky inserted fixed prostheses supported by Branemark implants in edentulous jaws: a study of treatment from the time of prosthesis placement to the first anual checkup. Int $\mathrm{J}$ Oral Maxillofac Implants. 1991;6(3):270-6.

Kenny R, Richards MW. Photoelastic stress patterns produced by implant-retained overdentures. J Prosthet Dent. 1998;80(5):559-64.

Kim Y, Oh TJ, Misch CE, Wang HL. Occlusal considerations in implant therapy: clinical guidelines with biomechanical rationale. Clin Oral Impl Res. 2005;16:26-35.

Korioth TW, Chew CB, Chung DH. Effect of implant number on transverse bending moments during simuled unilateral loading of mandibular fixed-detachable prostheses. J Oral Implantol. 1998;24(2):93-6.

Laganá DC. Estudo comparativo do comportamento biomecânico das próteses removíveis de extremidade livre e das próteses parciais fixas em cantilever. Análise fotoelástica das reações das estruturas de suporte [tese]. São Paulo: Universidade de São Paulo, Faculdade de Odontologia; 1992.

Lekholm U. Surgical considerations and possible shortcomings of host sites. J Prothet Dent. 1988;79(1):43-8.

Lindquist LW, Rockler B, Carlsson GE. Bone reabsortion around fixtures in edentulous patients treated with mandibular fixed tissue integrated protheses. $\mathrm{J}$ Prosthet Dent. 1988;59(1):59-63.

Lundgren D, Falk H, Laurell L. Influence of number and distribution of occlusal cantilever contacts on closing and chewing forces in dentitions with implant supported fixed prostheses occluding with complete dentures. Int $\mathrm{J}$ of Oral Maxillofac Implants. 1989;4:277-83.

Mahler DB, Peyton FA. Photoelasticity as research technique for analyzing stresses in dental structures. J Dent Res.1955;34(6):831-8. 
McAlarney ME, Stavropoulos DM. Theoretical cantilever lenghts versus clinical variables in fifty-five clinical cases. J Prosthet Dent. 2000;83:332-43.

Meijer HJA, Starmans FJM, Steen WHA, Bosman F. A three-dimensional finite element study on two versus four implants in an edentulous mandible. Int $\mathrm{J}$ Prosthodontic. 1994;7(3):271-9.

Merz BR., Hunenbart S., Belser U.C. Mechanics of the implant-abutment connection: an 8-degree taper compared to a butt joint connection. Int J Oral Maxillofac Implants. 2000;15(4):519-26.

Minoretti R, Triaca A, Saulacic N. Unconventional implants for distal cantilever fixed full-arch prostheses: A long-term evaluation of four cases. Int J Periodontics Restorative Dent. 2012;32:e59-e67.

Moberg LE; Kondell PA, Saulin GB, Bolin A, Heimdahl A, Gynther GW, Branemark P. System and ITI Dental Implant System for treatment of mandibular edentulism. A comparative study: 3-year follow-up. J Clin Oral Implants Res. 2001;12:450-61.

Naconecy MM, Geremia T, Cervieri A, Teixeira ER, Shinkai RS. Effect of the number of abutments on biomechanics of Branemark prosthesis with straight and titled distal implants. J App Oral Sci. 2010 Apr;18(2):178-85.

Noonan MA. The use of photoelasticity in a study of cavity preparations. J Dent Child. 1949;16(4):24-8.

Porter AJ, Petropoulos VC, Brunski JB. Comparison of load distribution for implant overdenture attachment. Int J Oral Maxillofac Implants. 2002;17(5):651-62.

Rangert BO, Jemt T, Jorneus L. Force and moments on Branemark Implants. Int J. Oral Maxillofac Implants. 1989;4(3):241-7.

Renouard F, Nisand D. Impact of implant length and diameter on survival rates. Clin Oral Imp Res. 2006;17(suppl.2):35-51. 
Rilo B, Silva JL, Mora MJ, Santana U. Guidelines for occlusion strayegy in implantborne prostheses. A review. Int Dent J. 2008 Jun; 58(3):139-45.

Rodriguez AM, Aquilino SA, Lund PS, Ryther JS, Southard TE. Evaluation of strain at the terminal abutment site of fixed mandibular implant prosthesis during cantilever loading. Int J Prosthodontics. 1993;2(2):93-102.

Rubo JH, Souza EAC. Métodos computacionais aplicados à Bioengenharia: solução de problemas de carregamento em próteses sobre implantes. Rev FOB. 2001;9(3/4):97-103.

Sadowsky SJ, Caputo AA. Effect of anchorage system and extension base contact on load transfer with mandibular implant-retained Overdenture. J Prosthet Dent. 2000;84(3):327-35.

Sahin S, Cehreli MC, Yalçin E. The influence of functional force on biomechanics of implant-supported prostheses-a review. J Dent. 2002;30:271-82.

Schnitman PA, Wohrle PS, Rubenstein JE, da Silva J, Wang NH. Ten-year results for Branemark implants immediately load with fixed prostheses at implant placement. Int J Oral Maxillofac Implants. 1997;12(4):495-503.

Schwarz MS. Mechanical complications of dental implants. Clin Oral Impl Res. 2000;11(1):156-8.

Silva TB. Análise da adaptação marginal de próteses fixa implanto-suportadas: uma comparação entre pilares Ucla e Esteticone [tese]. Piracicaba: Universidade de Campinas/Faculdade de Odontologia; 2003.

Skalak R. Biomechanical considerations in osseointegrated prostheses. J Prosthet Dent. 1983;49(6):843-8.

Snauwaert K, Duyck D, Van Steenberghe D, Quirynen M, Naert I. Time dependent failure rate and marginal bone loss of implant supported prostheses: 15 year followup study. Clin Oral Invest. 2000;4:13-20. 
Tamaki T. Dentaduras completas. $4^{\text {a }}$ ed. São Paulo: Sarvier; 1983.

Tashkandi EA, Lang BR, Edge MJ. Analysis of strain at selected bone sites of cantilevered implant-supported prosthesis. J Prosthet Dent. 1996;76:158-64.

Van de Velde T, Collaert B, De Bruyn H. Immediate loading in completely edentulous mandible: technical procedure and clinical results up to 3 years of functional loading. Clin Oral Impl Res. 2007;18:295-303.

Wang S, Hobkirk JA. Load distribution on implants with a cantilevered superstructure: an in vitro pilot study. Implant Dent. 1996;5(1):36-42.

Waskewicz GA, Ostrowski JS, Parks VJ. Potoelastic analysis of stress distribution transmitted from fixed prostheses attached to osseointegrated implants. Int J Oral Maxillofac Implants. 1994;9(4):405-11.

White SN, Caputo AA, Anderkvist T. Effect of cantilever length on stress transfer by implant-supported prostheses. J Prosthet Dent. 1994;71:493-9.

Wiebke S, Susanne H, Katja N. Retrospective analysis of bar-retained dentures with cantilever extension: marginal bone level changes around dental implants over time. Int J Oral Maxillofac Implants. 2010 Mar/Apr;25:385-93. 